\title{
A CRPS triptych : studies on diagnosis, pathogenesis and treatment of the Complex Regional Pain Syndrome
}

Citation for published version (APA):

van de Vusse, A. C. (2004). A CRPS triptych : studies on diagnosis, pathogenesis and treatment of the Complex Regional Pain Syndrome. [Doctoral Thesis, Maastricht University]. Maastricht University. https://doi.org/10.26481/dis.20040930av

Document status and date:

Published: 01/01/2004

DOI:

10.26481/dis.20040930av

Document Version:

Publisher's PDF, also known as Version of record

Please check the document version of this publication:

- A submitted manuscript is the version of the article upon submission and before peer-review. There can be important differences between the submitted version and the official published version of record.

People interested in the research are advised to contact the author for the final version of the publication, or visit the DOI to the publisher's website.

- The final author version and the galley proof are versions of the publication after peer review.

- The final published version features the final layout of the paper including the volume, issue and page numbers.

Link to publication

\footnotetext{
General rights rights.

- You may freely distribute the URL identifying the publication in the public portal. please follow below link for the End User Agreement:

www.umlib.nl/taverne-license

Take down policy

If you believe that this document breaches copyright please contact us at:

repository@maastrichtuniversity.nl

providing details and we will investigate your claim.
}

Copyright and moral rights for the publications made accessible in the public portal are retained by the authors and/or other copyright owners and it is a condition of accessing publications that users recognise and abide by the legal requirements associated with these

- Users may download and print one copy of any publication from the public portal for the purpose of private study or research.

- You may not further distribute the material or use it for any profit-making activity or commercial gain

If the publication is distributed under the terms of Article $25 \mathrm{fa}$ of the Dutch Copyright Act, indicated by the "Taverne" license above, 


\section{A CRPS TRIPTYCH}

studies on diagnosis, pathogenesis and treatment of the Complex Regional Pain Syndrome 
A.C. van de Vusse

ISBN: $90-809018-2-2$

Opmaak en druk: SchrijenLippertzHuntjens, Voerendaal 


\title{
A CRPS TRIPTYCH
}

\author{
Studies on diagnosis, pathogenesis \\ and treatment of the \\ Complex Regional Pain Syndrome
}

\section{Proefschrift}

ter verkrijging van de graad van doctor

aan de Universiteit Maastricht

op gezag van de Rector Magnificus

Prof. mr. G..M.F. Mols

volgens het besluit van het College van Dekanen

in het openbaar te verdedigen

op donderdag 30 september 2004 om 14.00 uur

\section{Door}

Anton Cornelis van de Vusse

Geboren te Poortugaal op 20 augustus 1969 


\section{Promotor}

Prof. Dr. M. van Kleef

\section{Co-promotor}

Dr.W.E.J.Weber

\section{Beoordelingscommissie}

Prof. Dr. R.G.T. Geesink, hoogleraar Orthopaedie, UM (voorzitter)

Dr. S.K. Bulstra, afdeling Orthopaedie, UM

Dr.J.J. van Hilten, afdeling Neurologie, LUMC

Prof. Dr.J.G.M.Vles, hoogleraar Neurologie, UM

Prof. Dr.W.W.A. Zuurmond, hoogleraar Anestesiologie,VUme

The investigations described in this thesis were carried out at the Academic Pain Center, Dept. of Anesthesiology of the University Hospital Maastricht, the Netherlands.

The publication of this thesis is made possible by dept. of Anesthesiology of the University Hospital Maastricht.

Additional financial support for publication was provided by the pharmaceutical company Pfizer (Neurontin ${ }^{\oplus}$. 
"You are as healthy as you feel"

Robert de Niro, Taxi Driver

To my mothert and father 


\section{Inhoud}

pagina

1 Complex Regional Pain Syndrome: Diagnosis, Pathogenesis and Treatment

2 Interobserver Reliability of Diagnosis in Patients with Complex Regional Pain Syndrome

3 Interobserver Agreement on Differential Diagnosis of Complex Regional Pain Syndrome type 1

4 Discrepancy between Complaints and Objective signs in Complex Regional Pain Syndrome: a Multi-observer Study

$5 \quad$ HLA-DQ1 associated with Reflex Sympathetic Dystrophy

7 The Effect of Gabapentin Treatment on Pain and Sensory Deficit in Complex Regional Pain Syndrome type 1, a Placebo Controlled Study

Summery and conclusions 
Complex Regional Pain Syndrome, pathogenesis, diagnosis and treatment 


\title{
Complex Regional Pain Syndrome, Pathogenesis, Diagnosis and Treatment
}

\author{
Introduction
}

This thesis focuses on the Complex Regional Pain Syndrome (CRPS), a neuropathic pain syndrome. In recent years CRPS has gained considerable research interest: in the Netherlands, seven Ph.D. theses have been recently published on the subject by respectively Kurvers (1997), Geertzen(1999), van der Laan (1999), Oerlemans (1999), Kemler (2000), van de Beek (2001) en Ribbers (2001). Despite all research, CRPS or Reflex Sympathetic Dystrophy remains a controversial diagnosis.

This is also reflected in the great number of disciplines treating CRPS patients.

This introduction limits itself to describe the larger models and theories concerning the pathogenesis, diagnosis and treatment of CRPS. The following chapters are dedicated to studies in these three problem fields in CRPS. 
Complex Regional Pain Syndrome, pathogenesis, diagnosis and treatment

\section{DIAGNOSIS}

\section{The Diagnosis of Complex Regional Pain Syndrome.}

'CRPS Type 1 is a syndrome that usually develops after an initiating noxious event, is not limited to the distribution of a single peripheral nerve, and is apparently disproportionate to the inciting event. It is associated at some point with evidence of edema, changes in skin blood flow, abnormal sudomotor activity in the region of the pain, or allodynia or hyperalgesia.'- Definition of CRPS-I in IASP's 'Classification of Chronic Pain' by Merskey and Bogduk. ${ }^{\text {? }}$

Complex Regional Pain Syndrome is a consensus-based name for a complex of signs and symptoms, which should be present to an certain extent to meet this diagnosis. Its name and definition were established in 1993 by the leading pain organization the "International Association for the Study of Pain (IASP). 2,3 It was meant to replace other terms like Reflex Sympathetic Dystrophy (RSD) and causalgia,but this new terminology has not gained wide acceptance yet. ${ }^{4}$ RSD has no established neural damage in contrast to causalgia, but it is claimed that no essential differences can be found in its clinical presentation. ${ }^{5-7}$ The term causalgia was first described by Weir Mitchell in 1864, RSD by Evans in 1947. ${ }^{8}$ The term 'Sudecks' atrophy comes from a description of Sudeck in 1900 of acute post-traumatic atrophy of bone in the extremity. 9

In the IASP terminology, RSD was renamed as CRPS type 1 and causalgia as CRPS type 2. Although the older names are still being used clinically and in scientific literature, CRPS will be used in this thesis.

\section{Subtypes}

CRPS has two official subtypes; CRPS type 1 and CRPS type 2.

The difference between the two is that CRPS type 2 patients have proven nerve damage. Boas proposed the addition of a third type of CRPS, in which their was idiopathic pain with some sensory, motor and autonomic dysfunction, but not enough to meet the criteria for CRPS type 1. ${ }^{3}$

Others noticed the existence of patients with one single affected limb and those with CRPS spread to more than one extremity. It is found that these multiple CRPS patients were younger and more often female, more often reported a difference in skin temperature between the diseased and the healthy opposite limb at the onset of symptoms and had less often upper extremity CRPS. 10,11 .

Multiple CRPS is associated with its own HLA subtype, HLA subtype association in single CRPS is described in chapter $5 .{ }^{12}$

\section{Differential diagnosis}

The differential diagnosis of CRPS is not well established. Until recently, no study has been published to unravel CRPS' s differential diagnosis. Clinical observations have resulted in a list of more or less rare diagnoses that are normally easily distinguishable from CRPS.

Tendosynovitis, lymphedema, atrophy of disuse, senile or postmenopausal osteoporosis, tuberculous or pyogenic osteomyelitis, peripheral neuritis, radiculitis, peripheral vascular disease, hysteria, and rheumatoid arthritis were already mentioned by Hartley in $1955 .^{13}$ Boas added occupational overuse syndrome, tennis elbow, bursitis, nerve entrapment, myofascial pain syndrome and CRPS type III as potential differential diagnoses. ${ }^{3}$ Also neuropathies, root compression and polyneuropathies should be taken in 
consideration. ${ }^{14} \mathrm{~A}$ rather unknown, but important differential diagnosis is erythromelalgia. ${ }^{15}$

Absences of common features such as sensory disturbances, inciting events, therapy resistance to NSAID's and edema, discoloration or pain that does not increase in intensity during exercise, increase the chance on existence of other pathology. Also, CRPS can be distinguished from many of aforementioned diagnoses by normal blood values, its acute start, and asymmetry in body distribution. If one focuses on CRPS differential diagnosis, one should not limit the discussion to these syndromes. One should also clarify the vague boundaries of CRPS. There are patients with enigmatic chronic pain syndromes who do not meet sufficient severity, duration or distribution criteria to provide a sound CRPS diagnosis. ${ }^{3}$ The question how to diagnose CRPS should be followed by the question how to diagnose the remaining 'CRPS-like' pain patients. Chapter 3 discusses the role of idiopathic pain and somatoform pain syndromes in the differential diagnosis in CPRS

\section{Clinical tools in diagnosis}

The IASP definition of CRPS may work well as an informative description, but it is an insufficient tool for diagnosing patients. It is both a clinical and research problem how to diagnose patients, as there are no pathognomic clinical or laboratory abnormalities in CRPS. Since diagnosis is difficult and subjective, no clear estimates on incidence and prevalence of CRPS are yet possible. In general, one can only say that dysfunction of the neural system seems to be present in CRPS, which may result in different and fluctuating signs like pain, edema, motor disorders, hypesthesia, hyperesthesia, changed skin color, changed perspiration, changed temperature, and changed blood flow in skin, muscle and bone. Different tests have been developed to quantify these changes, but none has succeeded to gain enough support to reach golden standard in diagnosis. ${ }^{16-22}$. None of these changes are consistently present through the different phases of CRPS or through the entire patient population.

\section{Radiographic and bone scan tests}

Sometimes bone demineralization can be manifest in CRPS, but it might as well be absent in either early or late phases. Sudeck reported osteoporosis in 1900 after X-ray examination in CRPS patients. ${ }^{9}$ Meanwhile three-phase scanning is well established in CRPS diagnosis, although there are contradictory reports on its validity. ${ }^{23-25}$ Especially in the chronic phase of CRPS, bone metabolism might normalize or even decrease. 26,27 Different results are often found in children. 28 Interesting for future research can be Kozin et al's finding that a positive scintigraph might predict treatment outcomes. If this duality is also found in other clinical tools, possibly pain patients without positive scintigraphs resemble a different diagnostic group. ${ }^{29}$ But until now, these results have not been reproduced. ${ }^{30}$

\section{Skin temperature and cutaneous blood flow tests}

A subpopulation of CRPS patients does have abnormalities in temperature regulation. ${ }^{16,31,32}$ CRPS patients can be divided in primary warm and primary cold patients. Primary cold CRPS patients also appear to have a higher chance on refractory complaints or complications. ${ }^{10,33}$ Skin temperature measurement reveals problems of sensitivity and specificity, even if vasomotor tone was determined by measuring skin blood flow with laser Doppler flow meters and skin temperature by infrared thermometry. ${ }^{17}$ Disuse and inflammation can lead to temperature difference too. Healthy women in general have different vascular responses compared to men. ${ }^{34}$ Also in CRPS patients changes over time have been found. ${ }^{35,36}$ 
Complex Regional Pain Syndrome, pathogenesis, diagnosis and treatment

\author{
Sweat output tests \\ Sweat production is claimed to be important in diagnosing definite CRPS from controls. $17,18,37,38$ \\ Without doubt, 'sweat tests' can diagnose a subgroup in CRPS patients. But one can expect that there \\ are CRPS patients without sweat symptoms. Therefore it is not yet possible to determine the final \\ diagnostic value of sweat tests for the diagnosis of CRPS. ${ }^{39}$ \\ Therapy results of sympathetic blocks in CRPS patients did correlate with disturbed sweat output. ${ }^{40}$ \\ What this mean is yet unknown since sympathetic blocks are no longer considered effective in CRPS \\ therapy. 41
}

\title{
Histopathological findings
}

In several small studies disturbances were found pointing to perivascular inflammatory infiltration 42 , increased neuropeptides 43 and possible other signs of inflammation and oxidative stress 44,45 it has not resulted in diagnostic tests.

\section{Criteria systems}

In general, diagnostic criteria systems are developed to compensate the lack of unique symptoms in clinical syndromes. The vast amount of different possible combinations of signs and symptoms in CRPS and the change of signs during the different stages of the syndrome complicates the process of reaching consensus upon clinical criteria in the CRPS field. To achieve a more or less reliable diagnosis, criteria systems have been developed to weight the importance of the different CRPS signs and symptoms. The absence of consensus in scientific literature for these clinical criteria to diagnose CRPS, limits research in general and in specific the development of better diagnostic tests. ${ }^{39}$ In recent years different criteria systems have been developed for RSD or CRPS (appendix I). None of these were a result of scientific research, but all were based on clinical experience and consensus. Since no standard criteria exist in CRPS diagnosis, physicians and researchers can differ considerably in their judgment of possible CRPS patients. In the end, all differences in diagnosis can be summarized as 'how many signs and/or symptoms are needed to establish the diagnosis of CRPS?' Therefore, as long as there is no consensus, experienced based diagnosis in CRPS will not be valid (see chapter 2). Even if contemporary criteria systems are used in diagnosis, it appears that CRPS diagnosis is not a valid diagnosis. 7,46,47 (see also chapter 2). To construct a reliable diagnostic system in CRPS, reliability of patient reports of symptoms and validity of signs in CRPS needs to be studied. Also, strategies of CRPS physicians to establish CRPS diagnosis and their differential diagnosis need to be clarified to find better ways to standardize and validate the CRPS diagnosistic process.(see Chapter 2-4). 


\section{PATHOGENESIS}

\section{Sympathetic involvement}

There is enough proof of changed blood flow in CRPS in skin, subcutis, muscles and bone 21,31,36,48,49. This can explain the dystrophic aspect of many CRPS limbs. Increased sympathetic tone might change peripheral blood flow. This would explain why women are more prone to develop CRPS, since they have a different sympathetic tone compared to men. ${ }^{34}$

It was suggested in German scientific literature that people with vegetative vulnerability or 'sympathetic hyperreactors' were predisposed to CRPS 50-52, but this model has not received many followers.

Nevertheless, several authors have speculated about a central component in sympathetic dysfunction 49,53-56 and some even have found proof for central sympathetic dysfunction prior to the development of CRPS. ${ }^{57}$ More circumstantial evidence for a role of the central sympathetic system is that CRPS preceding events, such as post stroke hemiplegia, myocardial infarct and physical trauma might change sympathetic tone and therefore predispose to CRPS.A role for habitual smoking as a risk factor in CRPS could, although known for its sympathetic stimulating effect and decrease of cutaneous nutritious flow, has not been established. 58,59

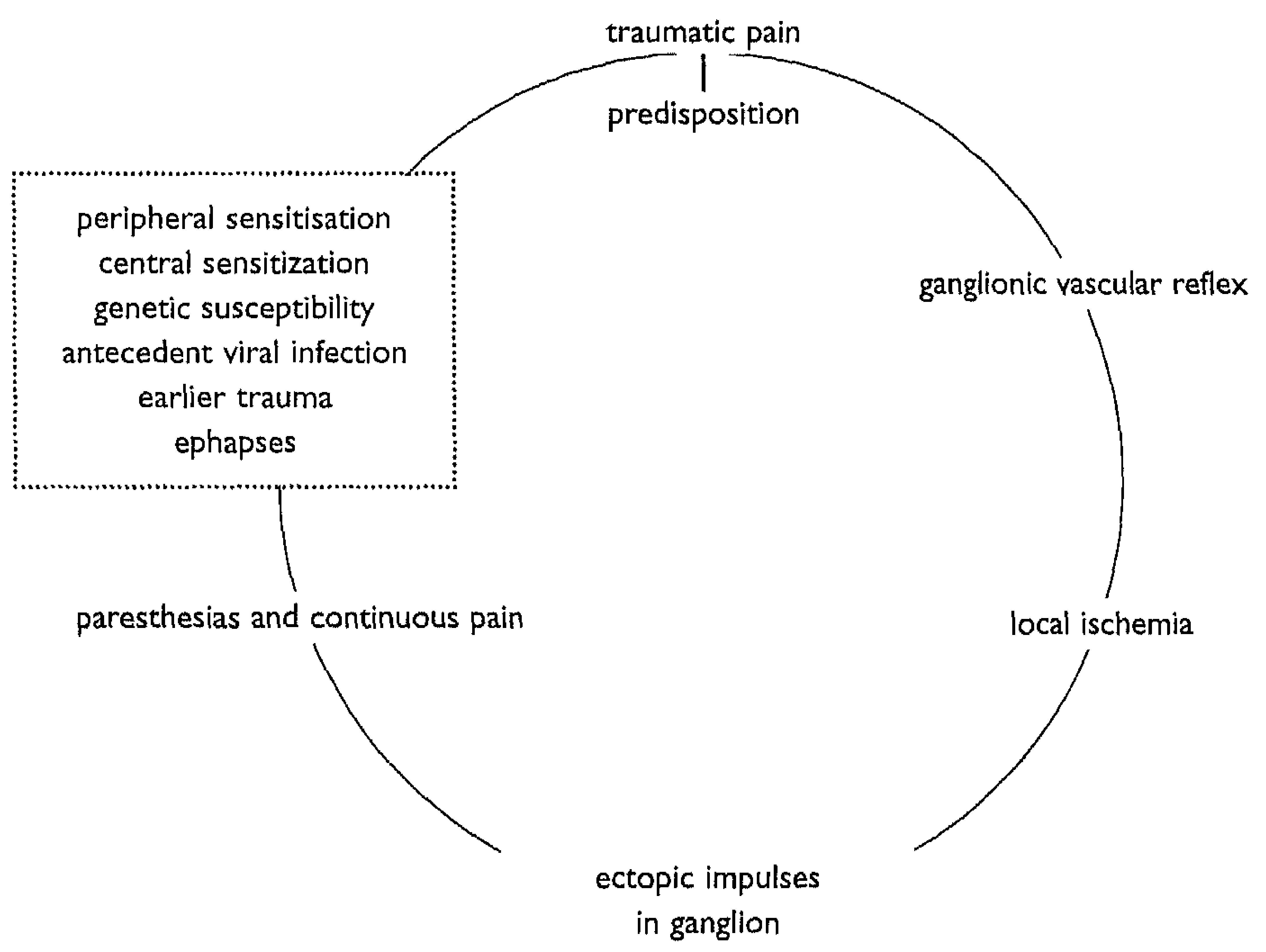

Figure 1.Possible pathogenetic process in CRPS 
Complex Regional Pain Syndrome, pathogenesis, diagnosis and treatment

Leriche was the first to claim that trauma elicited an increased sympathetic vasomotor reflex. 60 This would result in ischemic pain, which might enhance vasomotor reflexes and therefore would initiate a vicious circle of ischemia and pain. Although at several stages this theory can be of value, its validity is limited, since CRPS pain is often not sensitive to anti-sympathetic treatment (especially post-ganglionic treatment by local perfusion) and seldom to vasodilatory treatment. ${ }^{61-63}$ Relatively often though, CRPS pain is prone to increase by cold, dependency or emotional stress. This can be viewed as sympathetically dependent pain mechanisms. This sympathetic pain can physiologically be explained by trauma induced artificial synapses in the neural system between afferent sensory nerves and efferent sympathetic nerve fibers. These new synapses, also called ephapses, would increase nuncial interneuron activity. ${ }^{64}$ Another substrate for sympathetic pain could be the impulses of the sympathetic strain leading to local vasoconstriction in the dorsal root ganglion. The reduced blood flow would lead to ectopic ganglionic impulses. 65 These ectopic impulses are suggested to play a role in the maintenance of neuropathic pain, paresthesias ${ }^{66}$ and increase of the pain during cooling, dependency of the affected limb and increased emotions (figure 1). This would explain, that peripheral anti-sympathetic treatment with e.g., intravenous guanethedine has no proven effect and blocks of the paravertebrally located sympathetic ganglia clinically appear to have some, though yet insufficiently proven, pain reducing effect. With this last therapy though, transiently working local anesthetics are used, which aiso might have additional regional pain relieving effect. In line with this ganglionic theory of sympathetically maintained pain, Kurvers postulated that sympathetic impulses might be increased proximally, instead of distally, to the injury. ${ }^{67} \mathrm{~A}$ vicious circle might exist in CRPS where acute pain in predisposed patients, causes reflex ganglionic ischemia, enhanced ectopic ganglionic impulses and therefore chronic pain. Breaking this circle might explain how in some patients a sympathetic block with local anesthetics can give prolonged pain relief extending the time expected based on immediate pharmacological action. Vulnerability to re-enter this vicious circle would remain and therefore would predict recurrence of CRPS in 'cured' patients. Animal research suggests that nerve damage might change adrenergic sensibility by changed membrane properties of neurons in the dorsal root ganglion (DRG) and induced neuropathic pain can also be related to new connections formed between efferent sympathetic fibers and afferent sensory fibers. ${ }^{68-71}$ These structural changes might also explain why in 'cured' CRPS patients chronic pain can return after a renewed minor trauma of the affected limb. Other animal research suggests that evoked excitations (in the peripheral terminal regions) and adrenergic receptor changes in DRG 72 might explain why 'cured' patients can still have pain upon injection with noradrenalin in contrast to non CRPS patients. ${ }^{73}$

It appears that many cured CRPS patients still have different neurophysiological properties than nonCRPS patients. However, it is now clear there is no increased sympathetic activity, but hyposympathetic activity in the distal extremity. ${ }^{74} \mathrm{It}$ is possible that after a period of hyposympathetic activity peripheral adrenergic sensitization occurs. ${ }^{75-77}$ This would explain how many patients shift from warm CRPS (hyposympathetic response) in the acute phase to a cold CRPS (hyperreactive sympathetic response) in the chronic phase of their disease.

However, despite all these hypotheses, a definitive role for the sympathetic nervous system in the pathogenesis of CRPS, is not established. 


\section{Central pain mechanisms, spinal overload and sensitization}

CRPS pain cannot be explained by peripheral mechanisms alone. ${ }^{78-80}$ As mentioned above, different peripheral neurophysiological changes might occur in CRPS e.g. polymodal nociceptor neuron sensitization ${ }^{81}$ and ephapse formation, which are supposed to increase afferent sensory input to the spinal cord. This might cause secondary central (read: spinal) sensibilization. Hyperhidrosis is probably of central origin since it cannot be explained by sensitization of sweat glands or high circulating amount of catecholamins. $^{82}$

Livingston proposed in 1943 that sympathetic input might result in increasing activity of the internuncial pools in the spinal cord. ${ }^{83}$ This increased spinal activity results in increased sympathetic activity, which completes this vicious circle. Spinal overload might cause ipsilateral pain and dystonia, but also mirror phenomena of pain and motor manifestations in the contralateral limb. ${ }^{84-86}$

There are other theories concerning changed spinal activity. For example the gate-control theory, which describes that loss of central inhibition might facilitate pain. ${ }^{87}$ Although the gate-control theory was published in 1965, in 1955 Noordenbos already theorized that disproportional loss of thick fibers caused central facilitation and pain. ${ }^{88}$ Livingston's vicious circle hypothesis was continued by Bonica. ${ }^{89}$ Sunderland proposed a mechanism of retrograde changes in sympathetic ganglia resulting in spinal cord changes to explain the continuous pain. ${ }^{90}$ Important in the current opinion on CRPS was the article of Roberts on sensitization on central level 65,91 , and later by Dotson et al (1993) who postulated that the increased expression of peripheral 1-adrenergic receptors preceded activation of afferent somatic nerves and mechanoreceptors leading to tonic firing and therefore pain. ${ }^{72}$ The physical substrate for touch evoked pain or allodynia would be spinal 'wide dynamic range neurons' (WDR) activated by a persistent painful stimulus and sympathetic efferent actions. Sensitization of WDR neurons and nociceptive-specific neurons is possible and is referred to as plasticity of pain pathways. This is supposed to be partially NMDA (N-methyl-D-aspartate) dependent. ${ }^{92-96}$ Mechanical stimulation of A-fiber mechanoreceptors would not only lead to perception of touch, but through WDR sensitization also lead to pain. This is called mechanical allodynia. At spinal level long-lasting excitatory postsynaptic potentials are produced by central release of neuropeptides and excitatory amino acids. These summate and depolarize a population of dorsal horn interneurons. These decrease the Mg2+ block of NMDA ion channels of the central pain projecting neurons. This facilitates the central signal transmission. Contemporary NMDA antagonists reduce neuropathic pain, but have too many side effect to be clinically useful.

Pain, as with most chronic pain, is spread outside the original area of trauma in CRPS. This is explained because of wrong cortex interpretation, due to summation of impulses from increased activity in the internuncial pool. ${ }^{86}$ Another explanation is that activated peripheral ephapses cause referred pain to the entire area of distribution of that sensory nerve. ${ }^{97}$ The last explanation for spreading of pain and hypesthesia outside the original area of trauma is by the concept of referred pain. Numbness or mechanical hypesthesia is a frequently found complaint for approximately $75 \%$ of patients, which can improve in time spontaneously and after placebo treatment. ${ }^{98,99}$ For some authors, there is no neurological explanation for hypesthesia (in CRPS) when it is not limited to a single peripheral nerve and somatosensory evoked potentials are normally unaffected. 100 Others have described reversible mechanical hypesthesia in (experimental) muscle pain, without any nerve damage. ${ }^{101,102}$ One new finding is the improved cutaneous sensitivity in CRPS when gabapentin users are compared to placebo users (chapter 7) Reversal of sensory deficit during the use of gabapentin was already suggested by 3 case reports 
Complex Regional Pain Syndrome, pathogenesis, diagnosis and treatment

in other neuropathic pain syndromes. ${ }^{103}$ CRPS patients usually report hypersensitivity and pain to nonpainful stimuli, but CRPS pain also mimics experimental referred pain by intramuscular hypertonic saline infusion in most aspects. Both are diffuse, unpleasant and felt in structures at a mostly distal, but sometimes proximal, distance of the original site of either trauma or saline infusion. Besides referred pain, hypertonic saline induces deep tissue hyperalgesia. Similarly induced deep tissue hyperalgesia and referred pain are found upon i.m. injection of capsaicin, serotonin and bradykinin. ${ }^{104,105}$ Referred pain is a rather common phenomenon in neurology. It is possible that all the somatosensory findings and pain outside the original area of trauma in CRPS, which often has been adressed as non-neurological, can be attributed to referred pain mechanisms. Other research showed that referred pain is more extensively inducable in chronic pain patients with fibromyalgia or post whiplash syndrome. 106,107 It is possible that some fibromyalgia patients turn out to have a CRPS subtype ${ }^{108}$, nevertheless referred pain in CRPS patients has not been studied yet. Gabapentin has been reported to alleviate referred pain. 109 Since many CRPS patients have mechanical hypesthesia, we suggest that gabapentin by the same way it decreases pain, it might also decreases mechanical hypesthesia.

\section{Systemic pain mechanisms}

Meizack proposed that an increased stress reaction around the moment of trauma caused an increased catabolic reaction, through, e.g., cortisol. Therefore minor neural deficits would remain, which leads to prolongation and thereby centralization of pain. ${ }^{110}$. This mechanism possibly underlies several similar disorders like CRPS, irritable bowel disease, chronic fatigue syndrome and fibromyalgia in which a strong female predisposition is often coupled with common clinical features like fatigue, stiffness and sleeplessness ${ }^{3}$ of which sleeplessness appears to be related to increased cortisol levels. ${ }^{111} \mathrm{~A}$ common mechanism of sensitization to stimuli in these syndromes of 'subjective health complaint' is also hypothesized by several other authors. ${ }^{112,113}$ Others focus in these syndromes on the signs of dysregulation of the hypothalamic-pituitary-adrenal axis $112,114,115$. Whatever the relationship is between sustained stress reaction and these 'subjective health complaints', the relationship itself was already suggested in 1859 as Briquet described hysteria or asthenia as an overload of a weak ("asthenic") system. 116 The past 150 years has brought us new concepts as burnout and posttraumatic stress disorder and more detailed models to hypothesize on the pathogenesis of their symptoms. Clinically however, not much has changed as physicians still warn their patients not to overload their 'weak system' in e.g., CRPS, chronic fatigue syndrome, idiopathic low back pain and fibromyalgia.

\section{Disuse}

To maintain good limb function one should periodically use a limb. Some scientists has proposed that CRPS patients for unknown reasons do not use their affected limb enough, thereby creating secondary problems. Disuse in pain syndromes is proposed as a possible cause of osteoporosis and the nutritional disturbances in the $\operatorname{skin}^{13,117,118}$ It is a small step to suggest that disuse is a possible cause of CRPS. Some are suggesting disuse as an important factor by assessing and publishing the vaste amount of disuse of affected limbs in CRPS patients. ${ }^{119}$ An argument against this possible etiological factor is that CRPS (pain) often starts immediately after trauma, without several weeks of disuse before. The association between disuse and CRPS was wrongly suggested when, like in several other painful limb syndromes, false positive or at least indirect signs of disuse were found on X-ray films of CRPS patients. ${ }^{48,120 \text { - }}$ 
122 Firstly, it was not proven that these changes were disuse related, and secondly no cause-effect relationship had been established. There are no scientific arguments to claim that disuse in CRPS is not a result of pain and dystonia. The claim of disuse in pathogenesis of CRPS without further evidence should be avoided, since it unnecessarily stigmatizes patients by its association with inactivity and malingering.

Nevertheless, unnecessary disuse should be avoided in CRPS. An article on posttraumatic osteoporosis indicates that good fixation is necessary to improve weight bearing capacity and therefore related to the use of and osteogenesis in the affected limb. ${ }^{122}$ Maybe all movement-induced pain should be avoided through strict fixation to minimize avoidable disuse. This would improve osteogenesis and therefore might enhance recovering. Another reason to promote immobilization above painful movement is the suggestion that CRPS might be maintained by activity of deep somatic structures ${ }^{123}$ and that painful physiotherapy often appears to lead to aggravations of symptoms. ${ }^{124}$

\section{Genetic susceptibility}

Besides a discussion on direct preceding events leading to CRPS, one may wonder which persons are prone to development of CRPS. An indirect clue for the existence of a predisposition to CRPS might be that a subpopulation of patients with CRPS in one limb have a relative high chance to develop CRPS in another limb too. ${ }^{125} \mathrm{It}$ might be that changes in the immunological system whether or not caused by stress reactions, predispose to the development of chronic pain. Also, a genetically based theory could explain why only a small group is susceptible for developing chronic neuropathic pain. Perhaps changes in the central nervous system as for example in the descending inhibitory pathways, predispose to CRPS. ${ }^{126} \mathrm{~A}$ possible association of a human leukocyte antigen (HLA) subgroup DR 15(2) with CRPS not responding on treatment was described in $1994 .{ }^{127}$ In 2000, a prevalence of HLA DR13 was increased from $27 \%$ in controls to $46 \%$ in a group of refractory CRPS patients with tonic dystonia spreaded to two or more limbs. ${ }^{12}$ Recently, genetic susceptibility loci associated with auto-immune diseases have been described in a all female CRPS population with dystonia. ${ }^{128}$ More research is needed in a general CRPS population (see chapter 5).

\section{Chronic inflammation}

The concept of neurogenic inflammation is old. ${ }^{129}$ In neurogenic inflammation, neurons produce substances generating inflammatory (skin) responses. Goris published the idea that this inflammation is involved in CRPS, attributing a crucial role for free radicals. ${ }^{130}$ Free radicals play a role in macrophage and neutrophil mediated inflammatory processes. They cause tissue damage, a trigger for macrophage action and new radical formation. This free radical mediated processes result in edema, tissue damage by oxidative stress, but primarily antimicrobic activity. ${ }^{131}$ Circumstantial microscopic evidence of free radical induced changes, congruent to the chronic insufficient nutritious flow has been found. 132,133 Other circumstantial evidence for cellular hypoxia has been found by measuring phosphocreatin metabolism, arterial-venous oxygen saturation ratio, increased capillary permeability of macromolecules, lipufuscin deposition, lactate flux, clubbing of fingers and immediately increasing complaints upon exercise and adrenalin injection. $45,132,134-137$ It is not clear to which extent neuropeptides as substance $P$, and calcitonin gene-related peptide (CGRP) or cytokines are involved in pain and vasodilatation in acute CRPS, but the cytokines profile of chronic patients is not abnormal. ${ }^{138} \mathrm{~A}$ role for pain inducing vasoac- 
Complex Regional Pain Syndrome, pathogenesis, diagnosis and treatment

tive substances in CRPS was proposed in 1942.139 Both increased and decreased skin blood flow can be explained by $\mathrm{C}$-fiber stimuli through interaction of antidromic neurogenic inflammation and sympathetic vasomotor outflow. ${ }^{140,141}$ One study found increased levels of the neuropeptides bradykinin as well as CGRP in all their patients, suggestive for inflammation. ${ }^{43}$ Other results also suggest an increased releasability of cytokines and neuropeptides in CRPS. ${ }^{142-145}$ No evidence has been found for mobilization of neutrophils or macrophages, although there is one case-report on the existence of increased inflammation and CGRP associated, Langerhans cells. ${ }^{146,147}$ Nevertheless, the expected increase in antimicrobic activity has not been found. Instead, CRPS patients are extremely vulnerable for infections, which sometimes lead to amputation of the affected limb. Some physicians advocate the use of free radical scavengers in CRPS treatment. Mannitol has been given as a hydroxyl scavenger in CRPS, but in therapeutical doses its capacity to reduce free radical damage is doubted. ${ }^{148}$ The suggested action mechanism of mannitol would be an increased nutritional flow, which corrects the decreased oxygen extraction in CRPS. ${ }^{137,149}$ However, it's clinical effects have never been proven in a controlled trial. The mechanism behind chronic inflammation has not yet been elucidated. So for now, the most likely explanation for the laboratory findings is a decreased nutritious flow itself that causes oxidative stress and tissue damage. This mechanism is comparable to similar findings in diabetes mellitus. ${ }^{150-153}$ In CRPS this reduced nutritious flow could be caused by a chronic inflammation, but as well so by metabolic or neurogenic processes.

Inflammatory characteristics like bone atrophy, edema and redness are far less often explained in literature maybe because they are clinically seen as less relevant, but are sometimes explained as signs of tissue inflammation, either neurogenic or oxidative stress induced.9,129,146,154,155 The role for oxidative stress is further established after the publication of the preventive effect of antioxidants in a placebo controlled study, although CRPS incidence in the placebo control group of the study was extremely high. ${ }^{156}$ In rat models of neuropathic pain a role for free radicals has been established. ${ }^{157,158}$

\section{Post-infectious pain}

Several neuropathies like the Guillain-Barré syndrome and its variant, Miller-Fisher syndrome are probably post-infectious diseases. Support has been found for the molecular mimicry hypothesis as a mechanism for the induction of cross-reactive pathogenic antibodies in possible post infectious neuropathic syndromes as Bell's palsy 159,160, certain forms of Guillain-Barré syndrome 161-163 and even multiple sclerosis ${ }^{164-166}$ or Alzheimer's dementia ${ }^{167}$. Mimicry of body tissue and pathogens may lead to crossreactive autoimmunological processes leading to tissue damage, redness, swelling and pain. Neuropathic pain is viewed by some as a possibly autoimmunological disease, since immunoactive blood cells, increased glial activity and increased MHC class II can be found in a rat model of neuropathic pain. ${ }^{168}$ Theoretically, it is possible that the blood-nerve barrier prevents contact of several neural molecules. After minor trauma it might be that blood-nerve barrier is disturbed and that a cross reactivity starts between post viral antibodies and neural tissue. This has already been theorized for e.g., ParsonageTurner syndrome (neuralgic shoulder amyotrophy, plexus neuritis ). The Parsonage-Turner syndrome is comparable to the CRPS syndrome. ${ }^{159}$.The Parsonage- Turner etiology can sometimes be related to a minor trauma or recent infection, with e.g., Parvovirus B19.169 They differ so far that the former is always self-limiting, associated with motor dysfunction and EMG proven nerve damage. The role of Parvovirus B19 virus and other possible involved pathogens in CRPS is discussed in chapter 6. 
The psychological issue

Some clinicians are convinced of the existence of psychological features, which predispose to CRPS. ${ }^{170-176}$ Although it is described and generally accepted that pain in CRPS changes patient's behavior and mood, evidence for psychopathology preceding CRPS or continuing after resolving of the painful features has, despite many publications, not been established yet. 177.180

Recently, the "psychological discussion" was started again after a study suggested that CRPS patients

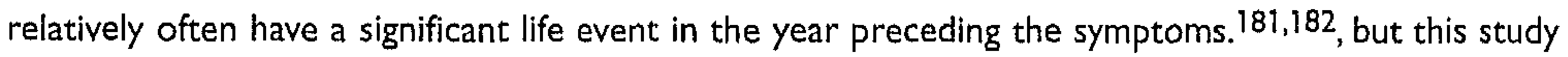
did not correct for events and physical traumas usually preceding CRPS e.g., strokes, operations, bone fractures and car accidents. The conclusion that psychological traumas or stress may lead to CRPS cannot be drawn. Whether psychological pathology may or may not lead to CRPS, physicians should always remember that somatoform patients are often wrongly diagnosed as CRPS patients. A group of people considering themselves as CRPS patients will also be falsely positive diagnosed somatoform patients. This was already predicted 118,183 , but more circumstantial evidence for this claim has been found in a small subpopulation of presumed CRPS patients with additional positive motor signs as spasms, jerks and tremors. ${ }^{100} \mathrm{~A}$ second bias in the conception of a role for the psyche in CRPS etiology is the diagnosis of psychogenic disturbances in these patients. This does not exclude the coexistence of CRPS. Many CRPS patients get involved in legal proceedings in which they are confronted with skepticism and disbelief. This might stimulate patients' exaggerations of clinical symptoms. 184

So conclusively, overdiagnosis and secondary psychological symptoms might bias the physicians view on the patient population, the presumed effect of therapies and the presumed psychological involvement of CRPS.

\section{TREATMENT}

The number of therapies available for a complaint is apparently correlated with therapy resistance in this complaint. For CRPS more than 50 treatments are described in literature. 185 In general, CRPS treatment can be divided in their presumed activity: mobilizing, desensibilisating, antisympathetic activity, blood vessel dilating, anti-inflammatory, free radical scavenging, edema decreasing, voltage channel stabilizing, bone tissue increasing, pain killing by NSAIDS or opiates, neuromodulating, neurosurgically (vital sensibility) and miscellaneous like ECT and non-medical therapies like acupuncture and color therapy. Several therapies are capable of multiple action properties.

Therapies should still be judged on its merits. Physical therapy, for example, is possibly the most advocated and practised therapy in CRPS. It is meant to be activating and desensitizating. Its effect is doubtful. In chronic CRPS patients it results in increased complaints in more than $50 \%{ }^{33,124}$ Also patients may benefit in short terms, it appears that this effect subsides and when evaluated after one year no pain relieving effect can be found in comparison to controls. ${ }^{186}$ The other main CRPS treatment was sympathetic block, since Leriche advocated its use in 1916. In the 1993 workshop the term Reflex Sympathetic Dystrophy was left, because it was doubted whether the sympathetic nervous system was important in CRPS patients. Nowadays, it is clear not to promote regional sympathetic blocks anymore for CRPS treatment. ${ }^{61,187}$ But it is also questionable whether CRPS patients without allodynia should still have paravertebral sympathetic blocks. ${ }^{63,188-190}$ Placebo controlled randomized controlled studies are available for calcitonin 191-194, corticosteroids 195,196, acupuncture 197-199, guanethidine 193,200-202, reserpine ${ }^{200}$, epidural clonidine 203 , DMSO 204 , biphosphonates ${ }^{205}$, phentolamine 206 epidural neuromo- 
Complex Regional Pain Syndrome, pathogenesis, diagnosis and treatment

dulation 207 and gabapentin (chapter 7). Acupuncture, phentolamine, reserpine and guanethidine and sympathetic blocks do not appear be benificial. Standardized meta-analysis of RCT's has been performed.

The most recent analyses showed only enough results in CRPS therapy of calcitonin 208,209 , but its clinical effect is small and many experience unpleasant,mostly gastroenterological, side-effects. ${ }^{210}$ One study did not show a pain relieving effect. 211 Its presumed action is stimulating bone activity, but more recently its claimed pain diminishing effect in phantom pain, Raynaud's phenomenon and diabetic neuropathy suggests other action mechanisms. ${ }^{212-215}$ In fact, calcitonin redistributes bloodflow in favor of cutaneous flow and probably enhances responsiveness to opoids. ${ }^{212,216} \mathrm{It}$ is also claimed to stabilize neuronal membranes and inhibite neuronal calcium influx. ${ }^{217}$ Also serotonergic and catecholaminergic mechanisms, protein phosphorylation, endorphin production cyclooxygenase inhibition and histamin interference has been proposed as antinociceptive mechanism. ${ }^{218}$

The presumed action of corticosteroids on CRPS has not been established. It is supposed that corticosteroids have an inhibitory effect on spontaneous neural discharge. ${ }^{219}$ Its use is limited, since the effect is only proven in the acute phase of CRPS.

Taken together, none of the used therapies for CRPS appears to be evidence-based.

\section{Aim of this thesis}

We sought to answer the following questions:

\section{Is CRPS type I a valid diagnosis?}

a What is the interobserver reliability of CRPS type I signs and symptoms?

b Do patient reports on symptoms in CRPS predict signs upon physical examination? cWhat are main differential diagnoses in CRPS type I?

2 Are neurotropic virusses/bacteria involved in CRPS type I pathogenesis?

3 Is there a HLA subtype association with CRPS type I?

4 Is gabapentin useful as a treatment in CRPS type I

Our studies on diagnosis are outlined in chapters 2-4 of this Ph.D. thesis. Our study focussed on reliability of patients' reports of symptoms, physical examination and diagnostic criteria systems in chronic CRPS patients; we assessed relevant differential diagnoses of CRPS. Our studies on pathogenesis of CRPS are described in chapter 5 6. We studied HLA associations and involvement of microbial pathogens in the development of CRPS. With a placebo controlled study of gabapentin in CRPS we evaluated a possible CRPS treatment, as described in chapter 7. 


\section{Appendix I}

Examples of criteria systems in CRPS

IASP Diagnostic criteria in Complex Regional Pain Syndrome type 12

as also published by Merskey and Bogduk (1994)':

1. The presence of an initiating noxious event, or a cause of immobilization.

2. Continuing pain, allodynia, or hyperalgesia with which the pain is disproportionate to any inciting event.

3. Evidence at some time of edema, changes in skin blood flow, or abnormal sudomotor activity in the region of the pain.

4. This diagnosis is excluded by the existence of conditions that would otherwise account for the degree of pain and dysfunction.

Note: Criteria 2-4 must be satisfied'

\section{Kozin (1981) ${ }^{220}$}

Proposed Clinical Diagnostic criteria for RSDS:

Definite RSDS

Pain and tenderness in the distal extremity

Signs and/or symptoms of vasomotor instability

Swelling in the extremity-often with periarticular

prominence

(Dystrophic skin changes usually present)

Probable RSDS

Pain and tenderness

AND

Vasomotor instability OR swelling

(Dystrophic changes often present)

Possible RSDS

Vasomotor instability OR/AND swelling

No pain, but mild-moderate tenderness may be present

(dystrophic skin changes occasionally present)

Doubtful RSDS

Unexplained pain and tenderness in a extremity
Consensus report of an Ad Hoc committee of the American Association for Hand Surgery on the Definition of Reflex Sympathetic Dystrophy Syndrome (1990) $)^{221}$ :

1. Diffuse pain

hyperalgesia, hyperpathia OR allodynia

2. Loss of hand/foot function

any activity or motion impairment associated with the pain

3. Sympathetic dysfunction

objective evidence of significant autonomic dysfunction, as reflected by skin, soft-tissue, or blood flow changes, such as temperature increase or decrease, sweating increase or decrease, hair growth increase or decrease, nail growth increase or decrease, atrophy of skin or subcutaneous tissue, edema, blood flow increase or decrease, Sudeck=s osteoporosis, or characteristic bone scan

\section{Bonica (1990) ${ }^{89}$ :}

History of recent or remote accidental or iatrogenic trauma or disease

Presence of a persistent pain that is

burning, aching and/or throbbing in character One or more of the following:

a) vasomotor and sudomotor disturbances

b) trophic changes, edema of the limb, sensitivity to cold, muscle weakness or atrophy, or trophic changes Relief of pain and modification of signs after regional sympathetic blockade 
Complex regional pain syndrome, Diagnosis, pathogenesis and treatment

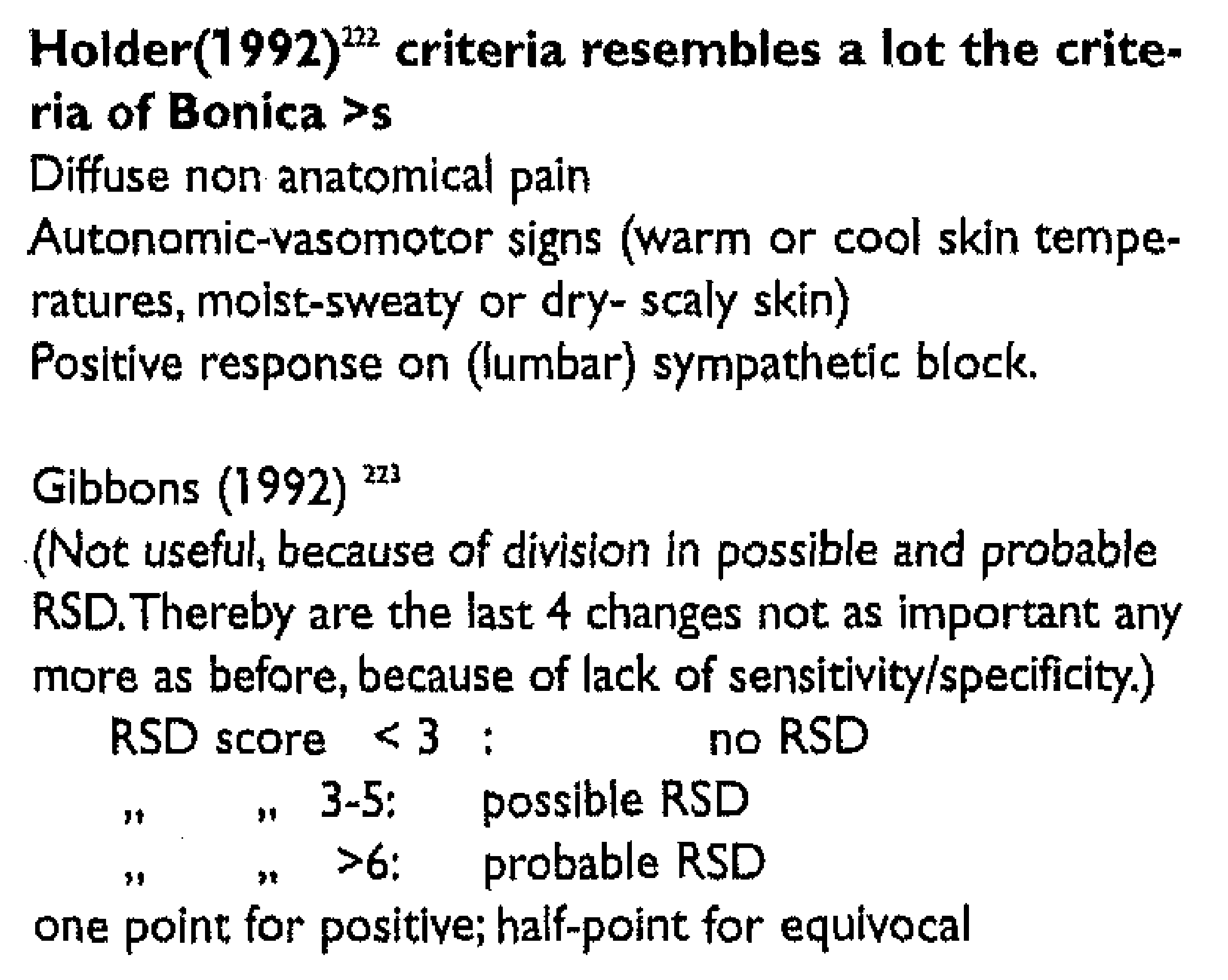

1. Allodynia or hyperpathia

2. Burning pain

3. Edema

4. Color or hair growth changes

5. Sweating changes

6. Temperature changes

7. Radiographic changes (demineralization)

8. Quantitative measurement of vasomotor/sudomotor disturbance

9. Bone scan consistent with RSD

10. Response to sympathetic block

Veldman $(1994)^{121,224,225}$; based on Goris ${ }^{33}$

*4 out of 5 :

Unexplained diffuse pain

Difference in skin color relative to other limb

Diffuse edema

Difference in skin temperature relative to other:

limb

Limited active range of motion

* Occurrence or increase or above signs and symptoms after use

*Above signs and symptoms present in an area larger than the area of primary injury or operation, including the area distal to the primary injury

\section{Wilson (1996) ${ }^{26}$}

- history of pain

- allodynia, hyperalgesia or hyperestesia

2 signs:

- edema

- vasomotor changes: color, temperature instability,

asymmetry

- sudomotor changes

- trophic changes in skin, joint, nail, hair

- impaired motor function (may include components of dystonia and tremor)

Bruehl (1999): proposed modified research diagnostic criteria for CRPS 7

(1) Continuing pain which is disproportionate to any inciting event

(2) At least one symptom in each of the following categories

Sensory: reports of hyperesthesia

Vasomotor: reports of temperature asymmetry and/or skin color changes and/or skin color asymmetry Sudomotor/edema: reports of decreased range of motion and/or motor dysfunction (weakness, tremor, dystonia) and/or trophic changes (hair, nail, skin)

(3) At least one sign in two or more of the following categories

Sensory: evidence of hyperalgesia (to pinprick) and/or allodynia (to light touch)

Vasomotor: evidence of temperature asymmetry and/or skin color changes and/or asymmetry

Sudomotor/edema :evidence of edema and/or sweating changes and/or sweating asymmetry

Motor/trophic: evidence of decreased range of motion and/or motor dysfunction (weakness, tremor, dystonia) and/or trophic changes (hair, nail, skin) 


\section{References}

1. Merskey $H$, Bogduk N. Classification of chronic pain. Descriptions of chronic pain syndromes and definitions of pain terms. 2 ed. Seattle: IASP Press, 1994.

2. Stanton Hicks M, Janig W, Hassenbusch S, Haddox JD, Boas R, Wilson P. Reflex sympathetic dystrophy: changing concepts and taxonomy. Pain 1995;63(1):127-33.

3. Boas R. Complex Regional Pain Syndromes: Symptoms, Signs and Differential Diagnosis. In: Jänig W, Stanton-Hicks M, eds. Reflex Sympathetic Dystrophy : a reappraisal. Seattle: IASP press, 1996: 79.92.

4. Alvarez-Lario B, Aretxabala-Alcibar I, Alegre-Lopez ], Alonso-Valdivielso JL. Acceptance of the different denominations for reflex sympathetic dystrophy. Ann Rheum Dis 2001;60(1):77-9.

5. Holden W. Sympathetic dystrophy. Arch Surg 1948;57:373.

6. Alexeyev W, Novikov AV, Yakhno NN. Are there differences in principle between type I and type II of Complex regional pain syndrome. Vienna: IASP Press, 1999.

7. Bruehl S, Harden RN, Galer BS, et al. External validation of IASP diagnostic criteria for complex regional pain syndrome and proposed research diagnostic criteria. Pain 1999;81 (1-2):147- 154.

8. Evans ]. Reflex sympathetic dystrophy. Surg Clin North Am 1946;26:780-790.

9. Sudeck P. Über die acute entzündliche Knochen-atrophie. Arch Klin Chir 1900;62:147- 156.

10. Veldman PHIM, Goris RJA. Multiple Reflex Sympathetic Dystrophy: Which Patients are at Risk for Developing a Recurrence of Reflex Sympathetic Dystrophy in the Same or Another Limb. Pain 1996;64:463-6.

11. Rowbotham M. Multiple Reflex Sympathetic Dystrophy: Which Patients Are at Risk for Developing a Recurrence of Reflex Sympathetic Dystrophy in the same or another limb-a commentary. The Pain Medicine Journal Club 1996;2(5):238240.

12. van Hilten J], van de Beek WJ, Roep BO. Multifocal or generalised tonic dystonia of Complex Regional Pain Syndrome: A distinct clinical entity associated with HLA-DR13. Ann Neurol 2000;48:113-116.

13. Hartley J. Reflex hyperemic deossification (Sudeck's atrophy). J Mt Sinaï Hosp 1955;22:268.

14. van de Beek WJT. Reflex Sympathetic Dystrophy. Clinical, pathophysiological and etiological aspects:
University of Leiden, 2001.

15. Christensen CR, Stubbs DH. Erythromelalgia-a case study. JVasc Nurs 1996;14(1):18-20.

16. Bruehl S, Lubenow TR, Nath $H$, Ivankovich $O$. Validation of thermography in the diagnosis of reflex sympathetic dystrophy. Clin-J-Pain 1996;12(4):316-25.

17. Low PA, Amadio PC, Wilson PR, McManis PG, Willner $C$.. Laboratory findings in reflex sympathetic dystrophy: a preliminary report. Clin J Pain 1994;10(3):235-9.

18. Chelimsky TC, Low PA, Naessens JM, Wilson PR, Amadio PC, PC OB. Value of autonomic testing in reflex sympathetic dystrophy. Mayo Clin Proc 1995;70(11):1029-40.

19. Schweitzer ME, Mandel S, Schwartzman RJ, Knobler RL, Tahmoush A]. Reflex sympathetic dystrophy revisited: MR imaging findings before and after infusion of contrast material. Rodiology 1995;195(1):211-4.

20. Graif M, Schweitzer ME, Marks B, Matteucci T, Mandel S. Synovial effusion in reflex sympathetic dystrophy: an additional sign for diagnosis and staging. Skeletal Radiology 1998;27(5):262-5.

21. Nazarian LN, Schweitzer ME, Mandel S, et al. Increased soft-tissue blood flow in patients with reflex sympathetic dystrophy of the lower extremity revealed by power Doppler sonography. AJR-Am-JRoentgenol 1998;171(5):1245-50.

22. Allen G, Galer BS, Schwartz L. Epidemiology of complex regional pain syndrome: a retrospective chart review of 134 patients. Poin 1999;80(3):539- 44.

23. Werner R, Davidoff $G$, Jackson MD, Cremer S, Ventocilla $C$, Wolf L. Factors affecting the sensitivity and specificity of the three-phase technetium bone scan in the diagnosis of reflex sympathetic dystrophy syndrome in the upper extremity. Journal of Hand Surgery. American Volume 1989;14(3):520-3.

24. Davidoff $G$, Werner R, Cremer S, Jackson MD, Ventocilla C, Wolf L. Predictive value of the threephase technetium bone scan in diagnosis of reflex sympathetic dystrophy syndrome. Archives of Physical Medicine And Rehabilitation 1989;70(2):135- 7.

25. Pollock FE, Jr., Smith TL, Koman LA. Microvascular response in the rabbit ear to total body cooling: a model for study of human digits. Microsurgery 1994;15(6):433-8.

26. Rico H, Merono E, Gomez-Castresana F, Torrubiano J, Espinos D, Diaz P. Scintigraphic evaluation of reflex sympathetic dystrophy; comparative study of the 
course of the disease under two therapeutic regimens. Clinical Rheumatology 1987;6(2):233-7.

27. Lee GW, Weeks PM. The role of bone scintigraphy in diagnosing reflex sympathetic dystrophy.J Hand Surg Am 1995;20(3):458- 63 .

28. Goldsmith DP, Vivino FB, Eichenfield AH, Athreya BH Heyman S. Nuclear imaging and clinical features of childhood reflex neurovascular dystrophy: comparison with adults. Arthritis And Rheumatism 1989;32(4):480-5.

29. Kozin F, Soin JS, Ryan LM, Carrera GF, Wortmann RL Bone scintigraphy in the reflex sympathetic dystrophy syndrome. Radiology 1981;138(2):437-43.

30. Zyluk A.The reasons for poor response to treatment of posttraumatic reflex sympathetic dystrophy. Acta-Orthop-Belg 1998;64(3):309-13.

31. Cooke ED, Steinberg MD, Pearson RM, Fleming CE, Toms SL, Elusade JA. Reflex sympathetic dystrophy and repetitive strain injury: temperature and micro. circulatory changes following mild cold stress. J $R$ Soc Med 1993;86(12):690-3.

32. Gulevich SJ, Conwell TD, Lane J, et al. Stress infrared telethermography is useful in the diagnosis of complex regional pain syndrome, type I (formerly reflex sympathetic dystrophy). Clin J Pain 1997;13(1):50-9.

33. Goris RJ, Reynen JA, Veldman P. [The clinical symptoms in post-traumatic dystrophy]. Ned Tijdschr Geneesk 1990;134:2138-2141.

34. Pollock FEJ, Koman LA, Smith BP, Holden M, Russell GB, Poehling GG. Measurement of hand microvascular blood flow with isolated cold stress testing and laser Doppler fluxmetry. Journal Of Hand Surgery. American Volume 1993;18(1):143-50.

35. Sherman RA, Karstetter KW, Damiano $M$, Evans CB. Stability of temperature asymmetries in reflex sympathetic dystrophy over time and changes in pain. Clin J Pain 1994;10(1):71-7.

36. Kurvers HA, Jacobs MJ, Beuk RJ, et al. Reflex sympathetic dystrophy: evolution of microcirculatory disturbances in time. Pain 1995;60(3):333-40.

37. Blumberg H.A new clinical approach for diagnosing reflex sympathetic dystrophy. In: Bond MR, Charlton JE, Woolf CJ, eds. Pain research and clinical management. Amsterdam: Elsevier Science, 1991: 399-403.

38. Sandroni P, Low PA, Ferrer T, Opfer Gehrking TL, Willner CL, Wilson PR. Complex regional pain syndrome I (CRPS I): prospective study and laboratory evaluation. Clin-f-Pain 1998;14(4):282-9.

39. Rommel O, Tegenthoff M, Pern U, Strumpf M, Zenz
M, Malin JP. Sympathetic skin response in patients with reflex sympathetic dystrophy. Clin Auton Res 1995;5(4):205-10.

40. Chelimsky TC, Low PA, Naessens JM, Wilson PR, Amadio PC, O'Brien PC.Value of autonomic testing in reflex sympathetic dystrophy [see comments]. Mayo Clinic Proceedings 1995;70(11):1029-40.

41. Schott GD. Interrupting the sympathetic outflow in causalgia and reflex sympathetic dystrophy. BMJ 1998;31 6(7134):792-3.

42. Kozin F, McCarthy D, Sims ], Genant H. The Reflex Sympathetic Dystrophy Syndrome 1. Clinical and Histologic Studies: Evidence for Bilaterality, Response to Corticosteroids and Articular Involvement. The American Journal of Medicine 1976;60:321-331.

43. Blair SJ, Chinthagada M, Hoppenstehdt D, Kijowski R, Fareed $\mathrm{J}$. Role of neuropeptides in pathogenesis of reflex sympathetic dystrophy. Acta- Orthop-Belg 1998;64(4):448-51.

44. van der Laan L, ter Laak HJ, Gabreels Festen A, Gabreels F, Goris RJ. Complex regional pain syndrome type I (RSD): pathology of skeletal muscle and peripheral nerve. Neurology 1998;51(1):20-5.

45. Heerschap A, den Hollander J, Reynen H, Goris R. Metabolic changes in reflex sympathetic dystrophy: a 31P NMR spectroscopy study. Muscle Nerve 1993;16:367-373.

46. Harden RN, Bruehl S, Galer BS, et al. Complex regional pain syndrome: are the IASP diagnostic criteria valid and sufficiently comprehensive? Poin 1999;83:211-219.

47. Galer B, Bruehl S, Harden N. IASP Diagnostic Criteria for Complex Regional Pain Syndrome:A Preliminary Empirical Validation Study. Clin J Pain 1998;14:48- 54.

48. Greyson ND, Tepperman PS. Three-phase bone studies in hemiplegia with reflex sympathetic dystrophy and the effect of disuse. Journal Of Nuclear Medicine 1984;25(4):423-9.

49. Wasner G, Heckmann K, Maier C, Baron R. Vascular abnormalities in acute reflex sympathetic dystrophy (CRPS I): complete inhibition of sympathetic nerve activity with recovery. Arch- Neurol 1999;56(5):61320.

50. Marti T.Wesen and Behandlung des Sudeckschen Syndroms. Proxis 1954;43:742.

51. Exner G. Zur Pathogenese und Therapie des Sudekschen Syndroms. München. med.Wchnschr 1956;98:257. 
52. Silber T.Anorexia nervosa and reflex sympathetic dystrophy, Psychosomatics 1989;30(1):108-111.

53. Blumberg $H$. [Development and treatment of the pain syndrome of reflex sympathetic dystrophy: Clinical picture, experimental investigations and new pathological considerations.]. Der Schmerz 1988;2:125-143.

54. Baron R, Blumberg $H$, Jänig W. Clinical Characteristics of Patients with Complex Regional Pain syndrome in Germany with Special Emphasis on Vasomotor Function, In: Jänig W, Stanton- Hicks M, eds. Reflex Sympathetic Dystrophy. A Reappraisal. Seattle: IASP Press, 1996: 25.

55. Birklein F, Riedl B, Neundörfer B, Handwerker $H$. Sympathetic vasoconstrictor reflex pattern in patients with complex regional pain syndrome. Pain 1998;75:93-100

56. Kurvers $H A$, jacobs $M$ J, Beuk RJ, et al. The spinal component to skin blood flow abnormalities in reflex sympathetic dystrophy. Arch Neurol 1996;53(1):58-65.

57. Schurmann M, Gradl G, Zaspel ], Kayser M, Lohr P, Andress HJ. Peripheral sympathetic function as a predictor of complex regional pain syndrome type I (CRPS I) in patients with radial fracture. Auton Neurosci 2000;86(1-2):127-34.

58. An HS, Hawthorne KB, Jackson WT. Reflex sympathetic dystrophy and cigarette smoking [see comments]. J Hand Surg Am 1988;13(3):458-60.

59. Pawelka S, Fialka V, Ernst E. Reflex sympathetic dystrophy and cigarette smoking. J Hand Surg Am 1993;18(1):168-9.

60. Leriche R. De la causalgie envisage comme une névrite du sympathique et de son traitement par la dénutation et l'excision des plexus nerveux périartériels. Presse Médicine 1916;24:178- 180.

61. Ramamurthy S, Hoffman J. Intravenous regional guanethidine in the treatment of reflex sympathetic dystrophy/causalgia: a randomized, double-blind study. Guanethidine Study Group. Anesth Analg 1995;81(4):718- 23.

62. Kingery W.A critical review of controlled clinical trials for periphera! neuropathic pain and complex regional pain syndromes. Pain 1997;73(2):123-139.

63. Forouzanfar T, van Kleef M, Weber WE. Radiofrequency lesions of the stellate ganglion in chronic pain syndromes: retrospective analysis of clinical efficacy in 86 patients. Clin I Pain 2000;16(2):164-8.
64. Doupe J, Cullen C, Chance G. Post- traumatic pain and the causalgic syndrome. J Neurol Neurosurg Psychiatry 1944;7:33-48.

65. Wirth FPJ, Rutherford RB.A civilian experience with causalgia. Archives Of Surgery 1970;100(6):633-8.

66. Amir R, Michaelis M, Devor M. Membrane potential oscillations in dorsal root ganglion neurons: role in normal electrogenesis and neuropathic pain. Journal Of Neuroscience 1999;1 9(19):8589-96.

67. Kurvers HA, Hofstra L, Jacobs MJ, et al. Reflex sympathetic dystrophy: does sympathetic dysfunction originate from peripheral neuropathy? Surgery 1996;119(3):288-96.

68. Petersen M, Zhang J, Zhang JM, LaMotte RH. Abnormal spontaneous activity and responses to norepinephrine in dissociated dorsal root ganglion cells after chronic nerve constriction. Pain 1996;67(2- 3):391-7.

69. Chung K, Yoon YW, Chung JM. Sprouting sympathetic fibers form synaptic varicosities in the dorsal root ganglion of the rat with neuropathic injury. BrainRes 1997;751 (2):275-80 issn: 0006-8993.

70. Zhang JM, Song XJ, LaMotte RH. An in vitro study of ectopic discharge generation and adrenergic sensitivity in the intact, nerve-injured rat dorsal root ganglion. Pain 1997;72(1 - 2):51-7.

71. Ramer MS, Thompson WN, McMahon SB. Causes and consequences of sympathetic basket formation in dorsal root ganglia. Poin 1999;suppl. 6:S111-S120.

72. Perl E. Causalgia and Reflex Sympathetic Dystrophy Revisited. In: Boivie J, Hansson P, Lindblom U, eds. Touch, Temperature, and Pain in Health and Disease: Mechanisms and Assessments, 1994.

73. Wallin G, Torebjork E, Halin R. Preliminary observations on the pathophysiology of hyperalgesia in the causalgic pain syndrome. In: Zotterman Y, ed. Sensory functions of the skin with special reference to man. Oxford: Pergamon Press, 1976: 489-499.

74. Wasner G, Schattschneider J, Heckmann K, Maier C, Baron R.Vascular abnormalities in reflex sympathetic dystrophy (CRPS 1): mechanisms and diagnostic value. Broin 2001;124(Pt 3):587-99.

75. Marchettini $P$, Lacerenza $M$, leracitano $D$, Canal $N$. Sensitized nociceptors in reflex sympathetic dystrophies. Funct Neurol 1989;4(2):135-40.

76. Ochoa JL, Yarnitsky D. The triple cold syndrome. Cold hyperalgesia, cold hypoaesthesia and cold skin in peripheral nerve disease. Brain 1994;117(Pt 1):185-97. 
Complex regional pain syndrome, Diagnosis, pathogenesis and treatment

77. Chemali KR, Gorodeski R, Chelimsky TC. Alphaadrenergic supersensitivity of the sudomotor nerve in complex regional pain syndrome. Ann Neurol $2001 ; 49(4): 453-9$.

78. Schott GD. Induction of involuntary movements by peripheral trauma: an analogy with causalgia. Loncet 1986;2(8509):712-6.

79. Schwartzman RJ. Reflex sympathetic dystrophy. Curr Opin Neurol Neurosurg 1993;6(4):531-6.

80. Sieweke N, Birklein F, Riedl B, Neundorfer B, Handwerker $\mathrm{HO}$. Patterns of hyperalgesia in complex regional pain syndrome. Pain 1999;80(1-2):1717.

81. Schott G. Clinical features of algodystrophy: is the sympathetic nervous system involved? Functional Neurology 1989;4(2):131-4.

82. Birklein F, Sittl R, Spitzer A, Claus D, Neundorfer B, Handwerker HO. Sudomotor function in sympathetic reflex dystrophy. Pain 1997;69(1-2):49-54.

83. Livingston W. Pain Mechanisms. New York: Macmillan, 1943.

84. Schwartzman R, Kerrigan J. The movement disorder of reflex sympathetic dystrophy. Neurology 1990;40:57-61.

85. Shir Y, Seltzer Z. Effects of sympathectomy in a model of causalgiform pain produced by partial sciatic nerve injury in rats. Pain 1991;45(3):309-20.

86. Aloisi AM, Porro CA, Cavazzuti M, Baraldi P, Carli G. 'Mirror pain' in the formalin test: behavioral and 2deoxyglucose studies. Pain 1993;55(2):267-73.

87. Melzack R, Wall P. Pain mechanisms: a new theory. A gate control system modulates sensory input from the skin before it evokes pain perception and response. Science 1965;150:971-978.

88. Noordenbos W. Pain: problems pertaining to the transmission of nervous impulses which give rise to pain;preliminary statements. Amsterdam: Elsevier, 1955

89. Bonica J. Causalgia and other reflex sympathetic dystrophyies. In: Bonica J, ed. The management of pain. Philadelphia: Lea \& Febiger, 1990: 220-243.

90. Sunderland S. Pain mechanisma in causalgia. J Neurol Neurosurg Psychiatry;39:169-177.

91. Roberts WJ. A hypothesis on the physiological basis for causalgia and related pains. Pain 1986;24(3):297311.

92. Woolf CJ, Thompson SW. The induction and maintenance of central sensitization is dependent on $\mathrm{N}$.
methyl-D-aspartic acid receptor activation; implications for the treatment of post-injury pain hypersensitivity states. Pain 1991;44(3):293-9.

93. Ren K. Hylden JL, Williams GM, Ruda MA, Dubner R. The effects of a non-competitive NMDA receptor antagonist, MK-801, on behavioral hyperalgesia and dorsal horn neuronal activity in rats with unilateral inflammation. Pain 1992;50(3):331-44.

94. Leem JW, Choi EJ, Park ES, Paik KS. N-methyl-Daspartate (NMDA) and non-NMDA glutamate receptor antagonists differentially suppress dorsal horn neuron responses to mechanical stimuli in rats with peripheral nerve injury. Neuroscience Letters 1996;211(1):37 40 .

95. Zhang KM, Wang XM, Peterson AM, Chen WY, Mokha SS. alpha2-adrenoceptors modulate NMDAevoked responses of neurons in superficial and deeper dorsal horn of the medulla. Journal of Neurophysiology 1998;80(4):2210-4.

96. Svendsen F, Tjølsen A, Rygh LJ, Hole K. Expression of long-term potentiation in single wide dynamic range neurons in the rat is sensitive to blockade of glutamate receptors. Neuroscience Letters $1999 ; 259(1): 25-8$.

97. Nathan PW. The pathogenesis of causalgia in peripheral nerve injuries. Brain 1947;70:145.

98. Kemler MA, Schouten HJ, Gracely RH. Diagnosing sensory abnormalities with either normal values or values from contralateral skin: comparison of two approaches in complex regional pain syndrome $\mathrm{I}$. Anesthesiology 2000;93(3):718- 27.

99. Verdugo RJ, Ochoa JL. Reversal of hypoaesthesia by nerve block, or placebo: a psychologically mediated sign in chronic pseudoneuropathic pain patients. Neurol Neurosurg Psychiatry 1998;65(2):196-203.

100. Verdugo RJ, Ochoa JL. Abnormal movements in complex regional pain syndrome: assessment of their nature. Muscle Nerve 2000;23(2):198-205.

101. Graven-Nielsen T, Babenko V, Svensson P, ArendtNielsen L. Experimentally induced muscle pain induces hypoalgesia in heterotopic deep tissues, but not in homotopic deep tissues. Brain Res 1998;787(2):203-10

102. Leffler AS, Kosek E, Hansson P. Injection of hypertonic saline into musculus infraspinatus resulted in referred pain and sensory disturbances in the ipsilateral upper arm. Eur J Pain 2000;4(1):73-82.

103. Chong MS, Smith TE, Hanna M. Case reports reversal of sensory deficit associated with pain 
relief after treatment with gabapentin. Pain 2002;96(3):329-33.

104. Babenko VV, Graven-Nielsen T, Svensson P, Drewes AM, Jensen TS, Arendt-Nielsen L. Experimental human muscle pain induced by intramuscular injections of bradykinin, serotonin, and substance P. Eur J Pain 1999;3(2):93-102.

105. Witting N, Svensson P, Gottrup H, Arendt-Nielsen $L$, Jensen TS. Intramuscular and intradermal injection of capsaicin: a comparison of local and referred pain. Pain 2000;84(2-3):407-12.

106. Sorensen J, Graven-Nielsen T, Henriksson KG, Bengtsson M, Arendt-Nielsen L. Hyperexcitability in fibromyalgia.J Rheumatol 1998;25(1):152-5.

107. Koelbaek Johansen M, Graven-Nielsen T, Schou Olesen A, Arendt-Nielsen L. Generalised muscular hyperalgesia in chronic whiplash syndrome. Pain 1999;83(2):229-34.

108. Martinez-Lavin M. Is fibromyalgia a generalized reflex sympathetic dystrophy? Clin Exp Rheumatol 2001;19(1):1-3.

109. Filadora VA, 2nd, Sist TC, Lema MJ.Acute herpetic neuralgia and postherpetic neuralgia in the head and neck: response to gabapentin in five cases. Reg Anesth Pain Med 1999;24(2):170-4.

110. Melzack R. From the gate to the neuromatrix. Pain 1999;suppl. 6:5121-5126.

111. Spiegel K, Leproult R, Van-Cauter E. Impact of sleep debt on metabolic and endocrine function. Lancet 1999;354:1435-9.

112. Clauw DJ, Chrousos GP. Chronic pain and fatigue syndromes; overlapping clinical and neuroendocrine features and potential pathogenic mechanisms. Neuroimmunomodulation 1997;4:134-153.

113. Buskila D, Press J. Neuroendocrine mechanisms in fibromyalgia-chronic fatigue. Best Pract Res Clin Rheumatology 2001;15(5):747-58.

114. Griep EN, Boersma JW, Lentjes EG, al. e. Function of the hypothalamic-pituitary-adrenal axis in patients with fibromalgia and low back pain. Rheumatol 1998;25:1374-1381.

115. Demitrack MA, Crofford LJ. Evidence for and pathofphysiological implications of hypothalamic-pituitary-adrenal axis dysregulation in fibromyalgia and chronic fatigue syndrome. Ann NY Acad Sci 1998;840:684-697.

116. Guze SB. The validity and significance of the clinical diagnosis of hysteria (Briquet's syndrome). Am J Psychiatry 1975;132:138-141.
117. Watson-jones R. Fractures and other bone and joint injuries. Baltimore:Williams \& Wilkins Co., 1940.

118. Ochoa J. Reflex sympathetic dystrophy: fact and fiction. Am-Fam-Physician 1997;56(9):2182, 2185.

119. Galer BS, Henderson J, Perander J, Jensen MP. Course of symptoms and quality of life measurement in Complex Regional Pain Syndrome: a pilot survey. J Pain Symptom Manage 2000;20(4):286-92.

120. Lagier R, Van Linthoudt D. Articular changes due to disuse in Sudeck's atrophy. International Orthopaedics 1979;3(1):1-8.

121. Bickerstaff DR, O'Doherty DP, Kanis JA. Radiographic changes in algodystrophy of the hand. Journal Of Hand Surgery. British Volume $1991 ; 16(1): 47-52$.

122. Tandon SC, Gregson PA, Thomas PB, Saklatvala J, Singanayagam J, Jones PW. Reduction of post-traumatic osteoporosis after external fixation of tibial fractures. Injury 1995;26(7):459-62.

123. Jänig W. The Puzzle of "Reflex Sympathetic Dystrophy": Mechanisms, Hypotheses, Open Questions. In: Jänig W, Stanton-Hicks M, eds. Reflex Sympathetic Dystrophy. A Reappraisal. Seattle: IASP Press, 1996: 1-24.

124. Veldman PH, Reynen HM, Arntz IE, Goris RJ. Signs and symptoms of reflex sympathetic dystrophy: prospective study of 829 patients. Lancet 1993;342(8878):1012-6.

125. van de Beek WJT, van Nes SI, van Hilten JJ. The clinical spectrum and course of Complex Regional Pain syndrome: new insights in a poorly understood disorder. Reflex Sympathetic Dystrophy. Clinical, pathophysiological and etiological aspects. Leiden: University of Leiden, 2001: 45-57.

126. Toda K, Muneshige $H$, lkuta Y.Antinociceptive effects of neurotropin in a rat model of painful peripheral mononeuropathy. Life Sci 1998;62(10):913-21.

127. Mailis $A$, Wade J. Profile of Caucasian women with possible genetic predisposition to reflex sympathetic dystrophy: a pilot study. Clin J Pain 1994;10(3):210-7.

128. van de Beek WJT, Roep BO, van der Slik MJ, Giphart MJ, van Hilten JJ. Susceptibility loci for Complex Regional Pain Syndrome. submitted.

129. Lewis T. Experiments relating to cutaneous hyperalgesia and its spread through somatic nerves. Clin SC 1936;2:373. 
130. Goris R. Treatment of Reflex Sympathetic Dystrophy with Hydroxyl Radical Scavengers. Unfallchirurg 1985;88:330-332.

131. Fantone JC, Ward PA. Role of oxygen-derived free radicals and metabolites in leukocyte-dependent inflammatory reactions. Am J Pathol 1982;107(3):395-418.

132. Tilman P, Stadhouders A, Jap P, Goris R. Histopathologic findings in skeletal muscle tissue of patients suffering from reflex sympathetic dystrophy. Micron and Microscopica Acta 1990;21:271-272.

133. van der Laan L, ter Laak HJ, Gabreäls-Festen $A$, Gabreëls F, Goris RJ. Complex regional pain syndrome type I (RSD): pathology of skeletal muscle and peripheral nerve. Neurology 1998;51 (1):20-5.

134. Goris R, Kolkman W, Leenen $L$, van Bebber I, Corstens F, Heerschap A. Symptomatologie van posttraumatische dystrofie. In: van Es J, Joossens J, Mandema E, Olthuis G, eds. Het medisch jaar 1988. Utrecht: Bohm, Scheltema and Holkema, 1988: 165177.

135. Drummond PD, Finch PM, Smythe GA. Reflex sympathetic dystrophy: the significance of differing plasma catecholamine concentrations in affected and unaffected limbs. Brain 1991;1 14(Pt 5):2025-36.

136. Oyen W, Arntz I, Claessens R, Van der Meer J, Corstens F, Goris R. Reflex sympathetic dystrophy of the hand: an excessive inflammatory response? Pain 1993;55:151-157.

137. Goris RJ. Reflex sympathetic dystrophy: model of a severe regional inflammatory response syndrome. World-J-Surg 1998;22(2):197-202.

138. van de Beek WJT, Remarque E], Westendorp RGJ, van Hilten JJ. Innate cytokine profile in patients with Complex Regional Pain Syndorme is normal. Pain 2001;91: 259-261.

139. Miller DS, DeTakat G. Post-traumatic dystrophy of the extremities (Sudeck's atrophy). Surg Gynec \& Obst 1942;75:558.

140. Schott GD. An unsympathetic view of pain. Lancet 1995;345(8950):634-6.

141. Ochoa JL, Yarnitsky D, Marchettini P, Dotson R, Cline M. Interactions between sympathetic vasoconstrictor outflow and $C$ nociceptor-induced antidromic vasodilatation. Pain 1993;54(2):191-6.

142. Weber M, Birklein F, Neundorfer B, Schmelz M. Facilitated neurogenic inflammation in complex regional pain syndrome. Pain 2001;91 (3):251-7.

143. Huygen F, De Bruijn A, De Bruin M, Groeneweg J,
Klein J, Zijlstra F. Evidence for local inflammation in complex regional pain syndrome type 1 . Mediators Inflamm 2002;11(1):47-51.

144. Hartrick C. Increased production of nitric oxide stimulated by interferon-gamma from peripheral blood monocytes in patients with complex regional pain syndrome. Neurosci Lett 2002;323(1):75-7.

145. Birklein F, Schmelz M, Schifter S, Weber M. The important role of neuropeptides in complex regional pain syndrome. Neurology 2001;57(12):2179- 84.

146. Calder JS, Holten I, McAllister RM. Evidence for immune system involvement in reflex sympathetic dystrophy. J-Hand-Surg-Br 1998;23(2):147-50.

147. Torii H, Tamaki K, Granstein RD. The effect of neuropeptides/hormones on Langerhans cells. Journal Of Dermatological Science 1998;20(1):21-8.

148. Gillbe CE, Sage F], Gutteridge JMC. Mannitol: Molecule Magnifique or a Case of Radical Misinterpretation? Free Rad Res 1996;24(1):1-7.

149. Goris R. Conditions associated with impaired oxygen extraction. In: Gutierrez G,Vincent J, eds. Tissue oxygen utilization. Berlin: Springer Verlag, 1991: 350369.

150. Boulton AJ, Scarpello JH, Ward JD. Venous oxygenation in the diabetic neuropathic foot: evidence of arteriovenous shunting? Diabetologia 1982;22(1):6-8.

151. Young MJ, Veves A, Walker MG, Boulton AJ. Correlations between nerve function and tissue oxygenation in diabetic patients: further clues to the aetiology of diabetic neuropathy? Diabetologia 1992;35(12):1146- 50

152. Cameron NE, Cotter MA. Neurovascular dysfunction in diabetic rats. Potential contribution of autoxidation and free radicals examined using transition metal chelating agents. J Clin Invest 1995;96(2):115963.

153. Nagamatsu M, Nickander KK, Schmelzer JD, et al. Lipoic acid improves nerve blood flow, reduces oxidative stress, and improves distal nerve conduction in experimental diabetic neuropathy. Diabetes-Core 1995;18(8):1160-7.

154. Chahl L. Antidromic vasodilatation and neurogenic inflammation. Pharmac. Ther. 1988;37:275- 300.

155. Goris R, Dongen L, Winters H.Are toxic oxygen radicals involved in the pathogenesis of reflex sympathetic dystrophy? Free Radic Res Commun 1987;3:13-18.

156. Zollinger PE, Tuinebreijer WE, Kreis RW, Breederveld RS. Effect of vitamin $C$ on frequency of 
reflex sympathetic dystrophy in wrist fractures: a randomised trial. Lancet 1999;354:2025-28.

157. Liu T, Tracey DJ. Free radicals contribute to the initiation and maintenance of thermal neuropathic hyperalgia in the rat. 9th world congress on pain 1999, Vienna.

158. van de Vusse AC, Mondria T, Weber W. Free radical scavengers and hyperalgesia in a rat model of neuropathic pain. Abstracts. 9th World Congress on Pain.Vienna: IASP Press, 1999: 275.

159. Imarhiagbe D, Prodinger WM, Schmutzhard E. [Infective pathogens as a possible etiology of idiopathic peripheral facial paralysis]. Wien Klin Wochenschr 1993;105(21):611 - 3

160. Gianoli GJ, Kartush JM. Delayed facial palsy after acoustic neuroma resection: the role of viral reactivation. Am J Otol 1996;17(4):625-9.

161. Mishu B, Blaser MJ. Role of infection due to Campylobacter jejuni in the initiation of GuillainBarre syndrome. Clin-Infect-Dis 1993;1 7(1):104-8.

162. Jacobs B, Rothbarth P,Van der Meché F, et al. The spectrum of antecedent infections in Guillain-Barré syndrome: a case-control study. Neurology 1998:51:1110-1115.

163. Hayase Y,Tobita K. Influenza virus and neurological diseases. Psychiatry-Clin-Neurosci 1997;51 (4):181-4.

164. Dekaban GA, Hudson AJ, Rice GP.Absence of HTLV-I and HTLV-II proviral genome in the brains of patients with multiple sclerosis and amyotrophic lateral sclerosis. Can-J-Neurol-Sci 1992;19(4):458-61.

165. Andersen $O$, Lygner PE, Bergstrom T, Andersson $M$, Vahlne A.Viral infections trigger multiple sclerosis relapses: a prospective seroepidemiological study. JNeurol 1993;240(7):417-22

166. Berti R, Soldan S, Sechiero P, et al. Association of HHV-6 and multiple sclerosis. 2nd symposium on the neurovirology and neuroimunnology of schizophrenia and bipolar disorder 1996, Bethesda, Maryland.

167. Ball MJ, Kaye JA, Steiner I. Neocortical temporal lobe sclerosis masquerading as Alzheimer dementia: does herpes virus encephalopathy protect against Alzheimer's disease? Clin Neuropothol 1997;1 6(1):1 12.

168. Colburn RW, Rickman AJ, DeLeo JA. The effect of site and type of nerve injury on spinal glial activation and neuropathic pain behavior. Experimental Neurology 1999;157(2):289- 304.

169. Walsh K, Armstrong R, Turner A. Brachial plexus neuropathy associated with human parvovirus infection. Br Med J 1988;296:896.

170. Leriche R. The surgery of pain. London: Baillière, tindall and Cox, 1939: 119-201.

171. Reichle R. Das Sudeckche Syndrom. Arch klin Chir 1956;284:18-

172. Egle UT, Hoffmann SO. [Psychosomatic correlations of sympathetic reflex dystrophy (Sudeck's disease). Review of the literature and initial clinical results]. Psychotherapie, Psychosomatik, Medizinische Psychologie 1990;40(3-4):123- 35.

173. Van Houdenhove $B$, Vasquez $G$. Is there a relationship between reflex sympathetic dystrophy and helplessness? Case reports and a hypothesis. Gen Hosp Psychiatry 1993;15(5):325-9.

174. Ochoa JL,Verdugo RJ. Reflex sympathetic dystrophy. A common clinical avenue for somatoform expression. Neurol Clin 1995;13(2):351-63.

175. Bruehl S, Husfeldt B, Lubenow TR, Nath $H$, Ivankovich AD. Psychological differences between reflex sympathetic dystrophy and non-RSD chronic pain patients. Pain 1996;67(1):107-14.

176. Rauiis AL. Psychological aspects. A series of 104 posttraumatic cases of reflex sympathetic dystrophy. Acta Orthopaedica Belgica 1999;65(1):86-90.

177. Lynch ME. Psychological aspects of reflex sympathetic dystrophy: a review of the adult and paediatric literature. Pain 1992;49(3):337-47.

178. BruehI S, Carlson CR. Predisposing psychological factors in the development of reflex sympathetic dystrophy. A review of the empirical evidence. Clinical Journal Of Pain 1992;8(4):287-99.

179. Field J, Gardner FV. Psychological distress associated with algodystrophy. / Hand Surg Br 1997;22(1):100-1.

180. van der Laan L, van Spaendonck K, Horstink MW, Goris RJ.The Symptom Checklist-90 Revised questionnaire: no psychological profiles in complex regional pain syndrome-dystonia. Journal Of Pain And Symptom Management 1999;17(5):357-62.

181. Geertzen JH, de Bruijn H, de Bruijn Kofman AT, Arendzen $\mathrm{JH}$. Reflex sympathetic dystrophy: early treatment and psychological aspects. Arch Phys Med Rehabil 1994;75(4):442-6.

182. Geertzen J, Bruijn de-Kofman A, Bruijn de $H$, Van de Wiel H, Dijkstra P. Stressfuil Life Events and Psychological Dysfunction in Complex Regional Pain Syndrome. Clin J Pain 1998;1 4:143-147. 
Complex regional pain syndrome, Diagnosis, pathogenesis and treatment

183. Lipowski ZJ. Somatization: the concept and its clinical application. American journal Of Psychiatry 1988;145(11):1358-68

184. Kurlan R, Brin MF, Fahn S. Movement disorder in reflex sympathetic dystrophy: a case proven to be psychogenic by surveillance video monitoring. Mov Disord 1997; 12(2):243-5.

185. Kurvers H. Reflex Sympathetic Dystrophy, a clinical and experimental study: University of Maastricht, 1997.

186. Oerlemans $H$, Oostendorp R, de Boo T, van der Laan L, Severens J, Goris R. Randomised controlled clinical trial of adjuvant physiotherapy or occupational therapy in reflex sympathetic dystrophy/ complex regional pain syndrome 1 of the upper extremity. Reflex sympathetic dystrophy: development of measurement instruments and outcome of a randomised controlled clinical study on physiotherapy and occupational therapy.Thesis. Nijmegen: University of Nijmegen, 1999: 301.

187. Jadad AR, Carroll D, Glynn CJ, McQuay HJ. Intravenous regional sympathetic blockade for pain relief in reflex sympathetic dystrophy: a systematic review and a randomized, double-blind crossover study. J Pain Symptom Manage $1995 ; 10(1): 13-20$.

188. Loh L, Nathan P. Painful peripheral states and sympathetic blocks. J Neurol Neurosurg Psychiatry 1978;41:664-671.

189. Kozin. Reflex sympathetic dystrophy syndrome: a review. Clinical and Experimental Rheumatology 1992;1 0:401 - 409.

190. Carr D, Cepeda M, Lau J. What is the evidence for the therapeutic role of local anesthetic sympathetic blockade in RSD or causalgia? An attempted metaanalysis [abstract]. Eighth worid congress on pain 1996, Vancouver: 406.

191. Gobelet C, Meier JL, Schaffner W, Bischof-Delaloye $A$, Gerster JC, Burckhardt P. Calcitonin and reflex sympathetic dystrophy syndrome. Clinical Rheumatology 1986;5(3):382-8.

192. Bickerstaff DR, Kanis JA. The use of nasal calcitonin in the treatment of post-traumatic algodystrophy, British Journal Of Rheumatology 1991;30(4):291- 4.

193. Gobelet C, Waldburger M, Meier JL. The effect of adding calcitonin to physical treatment on reflex sympathetic dystrophy. Pain 1992;48(2):171-5.

194. Hamamci N, Dursun E, Ural C, Cakci A. Calcitonin treatment in reflex sympathetic dystrophy; a preli- minary study. British Journal Of Clinical Practice $1996 ; 50(7): 373-5$

195. Christensen K, Jensen EM, Noer I. The reflex dystrophy syndrome response to treatment with systemic corticosteroids. Acta Chirurgica Scandinavica 1982; 1 48(8):653-5.

196. Braus DF, Krauss JK, Strobel J. The shoulder-hand syndrome after stroke: a prospective clinical trial. Ann Neurol 1994;36(5):728-33.

197. Fialka V, Resch, K.L., Ritter-Dietrich, D. Alacamlioglu Y., Chen, O. et al. Acupuncture for Reflex Sympathetic Dystrophy. Arch Intern Med 1993;153:661-665.

198. Korpan MI, Dezu Y, Schneider B, Leitha T, FialkaMoser V.Acupuncture in the treatment of posttraumatic pain syndrome. Acta Orthopaedica Belgica 1999;65(2):197-201.

199. Kho K. The impact of acupuncture on pain in patients with sympathetic reflex dystrophy. Pain Clinic 1995;8(1):59-61.

200. Blanchard J, Ramamurthy S, Walsh N, Hoffman J, Schoenfeld L. Intravenous regional sympatholysis: a double-blind comparison of guanethidine, reserpine, and normal saline. Journal Of Pain And Symptom Management 1990;5(6):357-61.

201. Ramamurthy S, Hoffman J. Intravenous regional guanethidine in the treatment of reflex sympathetic dystrophy/causalgia: a randomized, double-blind study. Guanethidine Study Group. Anesthesia And Analgesia 1995;81(4):718-23.

202. Jadad AR, Carroll D, Glynn CJ, McQuay HJ Intravenous regional sympathetic blockade for pain relief in reflex sympathetic dystrophy: a systematic review and a randomized, double-blind crossover study. Journal Of Pain And Symptom Management $1995 ; 10(1): 13-20$.

203. Rauck RL, Eisenach JC, Jackson K, Young LD, Southern ]. Epidural clonidine treatment for refractory reflex sympathetic dystrophy. Anesthesiology 1993;79(6):1163-9; discussion 27A.

204. Zuurmond WW, Langendijk PN, Bezemer PD, Brink $H E$, de Lange JJ, van loenen AC. Treatment of acure reflex sympathetic dystrophy with DMSO $50 \%$ in a fatty cream. Acta Anoesthesiol Scand 1996;40(3):3647.

205. Adami S, Fossaluzza V, Gatti D, Fracassi E, Braga V. Bisphosphonate therapy of reflex sympathetic dystrophy syndrome. Ann Rheum Dis $1997 ; 56(3): 201-4$ 
206. Verdugo RJ, Ochoa JL. 'Sympathetically maintained pain.' I. Phentolamine block questions the concept. Neurology 1994;44(6):1003-10.

207. Kemler MA, Barendse GA, van Kleef $M$, et al. Spinal cord stimulation in patients with chronic reflex sympathetic dystrophy. N Engl J Med 2000;343(9):618-24.

208. Forouzanfar T, Koke A, van Kleef M, Weber W. Treatment of complex regional pain syndrome type I. Eur J Pain 2002;6(2):105-22.

209. Perez RS, Kwakkel G, Zuurmond WW, de Lange JJ. Treatment of reflex sympathetic dystrophy (CRPS type 1): a research synthesis of 21 randomized clinical trials.J Pain Symptom Manage 2001;21 (6):511-26.

210. Schurmann M, Vogel T, Gartner A, Andress HJ, Grad G. [Experiences with calcitonin treatment of patients with type I complex regional pain syndrome (CRPS L-Sudeck disease)]. Z Orthop thre Grenzgeb 2001;139(5):452-7.

211. Bickerstaff DR, Kanis JA. The use of nasal calcitonin in the treatment of post-traumatic algodystrophy. BrJ Rheumatol 1991;30(4):291 - 4.

212. Franchi $F$, Chiarini P, Matassi $L$, et al. Effects of calcitonin on limb blood vessels in human obstructive arterial disease. International Journal of Clinical Pharmacology Research 1983;3(2):1 15-28.

213. Vinik Al. Diabetic neuropathy: pathogenesis and therapy. American Journal Of Medicine 1999;107(2B):17S-265.

214. Simanski C, Lempa M, Koch G, Tiling T, Neugebauer $E$. Therapy of phantom pain with salmon calcitonin and effect on postoperative patient satisfaction]. Chirurg 1999;70(6):674-81.

215. Wall GC, Heyneman CA. Calcitonin in phantom limb pain. Annals Of Pharmacotherapy 1999;33(4):499-501.

216. Goicoechea C, Ormazábal MJ, Alfaro MJ, Martín MI. Effect of salmon-calcitonin on the analgesic effect of selective mu, delta and kappa opioid agonists in mice. Neuroscience Letters 1999;262(1):25-8.

217. Vik A, Yatham LN. Calcitonin and bipolar disorder: a hypothesis revisited. Journal Of Psychiatry And Neuroscience 1998;23(2):109-17.

218. Braga PC. Calcitonin and its antinociceptive activity: animal and human investigations 1975-1992. Agents Actions 1994;41(3-4):121-31.

219. Devor. Corticosteroids suppress ectopic discharge originating in experimental neuromas. Pain 1985;22(2):127-37.
220. Kozin F, Ryan LM, Carrera GF, Soin JS. The Reflex Sympathetic Dystrophy Syndrome (RSDS) III. Scintigraphic Studies, Further evidence for the Therapeutic Efficacy of Systemic Corticosteroids, and Proposed Diagnostic Criteria. American Journal of Medicine 1981;70:23-30.

221. Amadio P, Mackinnon S, Wyndell H, Brody G, Terzis J. Reflex Sympathetic Dystrophy Syndrome: Consensus Report of an Ad Hoc Committee of the American Association for Hand Surgery on the Definition of Reflex Sympathetic Dystrophy Syndrome. Plastic and Reconstructive Surgery 1990;87(2):371-375.

222. Holder L, Cole L, Myerson M. Reflex sympathetic dystrophy in the foot: clinical and scintigraphic criteria. Radiology 1992;184:531-5.

223. Gibbons J], Wilson PR. RSD score: criteria for the diagnosis of reflex sympathetic dystrophy and causalgia. Clin J Pain 1992;8(3):260-3.

224. Veldman PH, Jacobs PB. Reflex sympathetic dystrophy of the head: case report and discussion of diagnostic criteria.J Trauma 1994;36(1):119-21.

225. Van Dasselaar N, Zuurmond W, al. e. Recommendations for the approach of reflex sympathetic dystrophy patients. The National Project on Quality Assurance of Invasive Anesthesiological Pain Control. Utrecht:The Netherlands WHO Collaborating Centre for Quality Assuranc in HealthCare (CBO), 1993.

226. Wilson P, Low P, Bedder M, Covington E, Rauck R. Diagnostic Algorithm for Complex Regional Pain Syndromes . In: Jänig W, Stanton-Hicks M, eds. Reflex Sympathetic Dystrophy:A Reappraisal. Seattle: IASP Press, 1996: 93-105. 
Interobserver Reliability of Diagnosis in Patients with Complex Regional Pain Syndrome 


\section{Interobserver Reliability of Diagnosis in Patients with Complex Regional Pain}

\section{Syndrome}

Anton C. van de Vusse, Suzanne G.M. Stomp-van den Berg, Henrica C.W. de Vet,

Wilhelm E.J.Weber

published in: European Journal of Pain 7 (2003) 259-265 
Interobserver Reliability of Diagnosis in Patients with Complex Regional Pain Syndrome

\section{Summary}

Complex Regional Pain Syndrome type I (CRPS-I), formerly reflex sympathetic dystrophy (RSD), is a chronic pain syndrome of unknown aetiology. Its diagnosis is a clinical one, for which several criteria systems have been defined. Despite their widespread use, the reliability of these criteria has never been studied.

In this inter-observer study twenty-five CRPS patients were interviewed and examined by six physicians. Through structured questionnaires signs, symptoms, and diagnosis were recorded, after which observer agreement for these was calculated with kappa statistics.

Physicians' agreement in assessment of signs and symptoms in CRPS patients varied greatly. More importantly, final diagnosis of CRPS showed poor observer agreement (kappa: 0.20). Kappa values were higher, had physicians applied IASP criteria, but still insufficient. The application of Bruehl's criteria results in a fair kappa of 0.38 , but then frequency of CRPS diagnosis in our study population decreased from $73 \%$ to $43 \%$ in comparison with physicians' own diagnosis. We conclude that, using current criteria systems, the diagnosis of CRPS is not reliable.

\section{Introduction}

Complex Regional Pain Syndrome type I (CRPS-I), formerly reflex sympathetic dystrophy (RSD), is a chronic pain syndrome of unknown aetiology. It is usually characterised by pain, swelling, autonomic dysregulation and chronic functional impairment after a trauma of the affected limb. The diagnosis of CRPS is a clinical one. A gold standard in the form of an objective test is not available. ${ }^{1-12}$ Although diagnostic criteria for CRPS have been formulated $13-15$, none is generally used. The International Association has developed the most official criteria system for the Study of Pain, IASP 16. As far as we know three validation studies on these CRPS criteria have been published 17-19. These studies address the validity of IASP criteria as to their specificity in delineating CRPS from other neuropathic pain syndromes. However, the distinction between CRPS and other neuropathic pain syndromes, e.g. postherpetic neuralgia and diabetic polyneuropathy, is not a diagnostic problem in daily clinical practice. The main clinical problem is inter-physician variability in CRPS diagnosis. This is due to the variability in observed signs, symptoms and the amount of signs, symptoms and credibility in patients needed to reach the diagnosis CRPS. Until now, inter-physician agreement studies of diagnosis in CRPS patients have not been done. Herein we report a study with 6 physicians examining 25 patients, to assess inter-observer variability in diagnosing CRPS. 


\section{Subject and methods}

\section{Subjects}

Twenty-five patients who visited our outpatient clinic for pain management in the preceding four years participated in the study. They had been at random selected from a database with patients once diagnosed as CRPS or Reflex Sympathetic Dystrophy. All patients were informed about this diagnosis and had received some treatment for it and remained to have pain and other symptoms despite CRPS treatment. All patients gave informed consent. The Institutional Review Board of the University Hospital Maastricht approved the study.

\section{Study design}

Six physicians (three anaesthesiologists, two surgeons and one neurologist) with known experience on CRPS participated in the study. They were instructed to take a semi-structured interview and perform a physical examination of the patient scoring absence or presence of signs and symptoms by yes/no. ${ }^{20}$ The observers were free to ask additional questions to obtain adequate information. Finally they estimated the patient's pain and filled in a diagnosis according to their own clinical view. No instructions were given about CRPS diagnostic criteria. Physicians were not allowed to discuss any aspect of the study with each other. The items for interview and physical examination had been selected by collecting symptoms and signs from published RSD criteria 13-15,21, the IASP classification of pain ${ }^{16}$ and the Neuropathic Pain Scale 22(list available upon request). After interview and examination physicians were asked to give their diagnosis. They were instructed to select one of the following: CRPS 1,CRPS 2 , CRPS 3 (pain and sensory, motor and/or tissue abnormalities not otherwise specified), (diabetic) polyneuropathy, radiculopathy, myofascial pain, nerve entrapment ${ }^{23}$, somatoform pain disorder, (idiopathic) pain not otherwise specified. The questionnaire contained 35 CRPS symptoms and 27 CRPS signs (See tables 1 and 2). The study was set up in three sessions with six patients and one session with seven patients. To limit the fluctuation in time of signs between successive physical examination, the six observers successively saw all patients within approximately 2 hours, but examination varied from 10-20 minutes per patient. Because some patients had more than one affected extremity, physicians were asked to focus on the most affected limb. Test results like EMG, laser Doppler flow-metry, and threephase bone scanning were not provided. Temperature difference of the skin of both extremities was measured manually.

Diagnostic criteria for CRPS type I are identical to CRPS type II in which nerve damage is proven. Therefore we consider CRPS patients in this report as patients with either CRPS type I or type II. Preliminary data suggest that CRPS type I patients do not differ from CRPS type II patients in signs, symptoms and therapy results results 19,24 . We compared expert-based diagnosis with diagnosis using criteria systems (the official IASP criteria and the most recently proposed CRPS criteria of Bruehl et al). ${ }^{16,19}$ 
Interobserver Reliability of Diagnosis in Patients with Complex Regional Pain Syndrome

\section{Statistical analysis}

Data were analysed in the following steps.

1. Analyses of inter-observer agreement on signs and symptoms by group kappa and percentage of agreement, measured by a generalised kappa statistics for more than two raters (group kappa). ${ }^{25}$ In the group kappa coefficient, the average observed agreement is compared to the average chance agreement, with the average taken over all pairs of expert-physicians and over all patients. Kappa values range from -1 to 1 . Positive values show certain agreement beyond chance agreement. Kappa values were classified as slight $(\mathrm{kappa}=0.00-0.20)$, fair $(\mathrm{kappa}=0.21-0.40)$, moderate $(\mathrm{kappa}=0.41$ $0.60)$, substantial (kappa $=0.61-0.80)$ and almost perfect agreement (kappa $=0.81-1.0) .{ }^{26}$

2. Analysis of interobserver agreement in expert-based diagnosis (group kappa).

3. By applying the official IASP criteria ${ }^{16}$ and the CRPS criteria of Bruehl et al. ${ }^{19}$ on our data sets we compared criteria-based diagnosing with expert-based diagnosing (see appendix I and II for criteria sets). IASP and Bruehl diagnostic criteria were applied in the 150 data sets .16,19 This resulted in new interobserver agreement values for criteria-based diagnosing and CRPS prevalences. These were compared with kappa value for inter-observer agreement in expert-based CRPS diagnosis. 27

4. IASP and Bruehl diagnostic criteria were applied to the 150 data sets containing signs and symptoms. ${ }^{19}$ This resulted in new frequencies of CRPS diagnoses. These were compared with expertbased CRPS frequencies.

5. The value of patient's symptoms in CRPS diagnosis is unknown. We analysed the effect on the frequency of CRPS diagnosis, when reported symptoms instead of objective signs were applied in criteria systems.

\section{Results}

Twenty-five patients with a mean age of $42.3 \mathrm{yrs}$ (23-65 yrs) participated of whom eighteen had upper extremity involvement and seven lower extremity involvement. Twenty-three patients were women. Duration of symptoms had a median of 39 months (range 5-168 mo.). Therefore some of these patients will be considered by some as late stage CRPS, although it is unclear how to differentiate between acute stage and late stage CRPS. All patients would consider themselves as having CRPS, because at least once a physician considered them as having CRPS and treated him/her as such.

All patients were diagnosed as CRPS-I by at least one observer. CRPS type I was diagnosed in $99(67 \%)$ assessments, CRPS II in 11 (7\%), CRPS III in 15 (10\%), somatoform disorder in 17 (11\%), and myofascial pain or idiopathic pain not otherwise specified in 8 cases.

\section{Observer agreement in signs and symptoms}

Kappa values, observer agreements and frequencies of potential diagnostic criteria are shown in table 1 (interview) and table 2 (physical examination). Kappa values of signs and symptoms ranged from fair to moderate. Kappa value has not been calculated in those instances with a prevalence of findings being less than $10 \%$ or more than $90 \%$. These kappa values would have been affected by the extreme prevalences. In these cases, only percentages of agreement uncorrected for chance agreement are given. ${ }^{28}$ 


\section{Interobserver agreement in CRPS diagnosis}

We expected kappa values would increase if experts had applied criteria systems. To evaluate the validity of these criteria systems, we applied physicians' findings in the interview and examination to diagnose according to IASP and Bruehl's diagnostic criteria. Table 3 shows that kappa values for diagnosing CRPS and idiopathic, CRPS-like, pain syndromes between the different pairs of observers resulted in a group kappa of 0.20 ( $\mathrm{Cl}: 0.06-0.33)$ in expert-based diagnosis, but if IASP was applied, kappa value rose to 0.29 (Cl: $0.03-0.55)$. If Bruehl's diagnostic criteria were applied kappa value rose to 0.38 ( $\mathrm{Cl}: 0.18$ $0.58)$ (see table 3 ).

\section{Frequency of CRPS diagnosis}

Since signs in CRPS can fluctuate in time, physicians, in general, use both reported symptoms and physical examination for diagnosis. We analysed the validity of the use of subjective reported symptoms (symptom-based) in diagnosing. Bruehl's diagnostic criteria consist of two parts: symptoms and signbased criteria. We applied these Bruehl's criteria, but we both calculated CRPS-frequency when the signs and symptom criteria were synchronously applied, when only reported symptoms were applied and when only the sign-based criteria were applied (table 4). Symptom-based IASP criteria resulted in a CRPS frequency of $98 \%$. Frequency of CRPS diagnosis with Bruehl's criteria did not change much, if besides sign-based criteria also the symptom-based criteria were applied. When Brueh's criteria were applied on our 150 data sets, 65 times CRPS-1/II would be diagnosed, but symptoms were essential in only 2 out of 150 patient assessments (1.3\%) to meet the Bruehl's diagnostic criteria for CRPS.

\section{Discussion}

CRPS is a clinical diagnosis for which criteria have been formulated. Until now inter-physician agreement of the diagnostic process had not been studied. In this study we tried to assess the reliability and validity of CRPS diagnostic criteria. To this end we asked 6 different experienced physicians to interview and examine 25 possible CRPS patients. We felt that this set-up most closely resembles daily practice, although certain biases cannot be ruled out. One possible bias is caused by patient selection: all patients were chronic CRPS patients. Another bias may be caused by repetitive examination of the affected limb by different observers. We do not think that they seriously affected our conclusions, as the last examination in each session did not differ significantly form the first ones (data not shown)

We found that interobserver agreement is reasonable for symptoms, but low for signs in our population with possible CRPS patients. Assessments of edema, hair growth and mechanical allodynia showed moderate agreement. Kappa values for signs should preferably be more than 0.40 (moderate agreement), when dealing with criteria for a diagnosis. ${ }^{29}$ Kappa value for edema in our population was comparable with kappa value (0.47) for edema in juvenile rheumatoid arthritis. ${ }^{30}$ Perhaps kappa values would have been higher in a population of recent CRPS patients, although Oerlemans et al were not able to find agreement in subjective reports of skin temperature and objective measurements in patients with more acute CRPS. 31 
Interobserver Reliability of Diagnosis in Patients with Complex Regional Pain Syndrome

Reaching a final diagnosis of CRPS, according to the experts, reached a kappa value of only 0.20 (Table 3). Diagnosing CRPS in our study was thus as reliable as diagnosing pneumonia with stethoscope and percussion, but without $X$-ray. ${ }^{32}$ This poor observer agreement is less than other difficult clinical diagnoses as medical fitness for a job (kappa $=0.37$ ) and shoulder disorders (kappa $=0.45) .33,34$ The application of standardized instruments to measure for example edema, skin temperature or sensory abnormalities might improve diagnostic reliability further, but until now these results have been disappointing. 35

Since the application of criteria systems often improves observer agreement in diagnosis, we calculated kappa's for diagnosis when IASP and newly proposed criteria of Bruehl were applied to the data (Table 3) . Agreement did indeed rise to almost moderate level if IASP or Bruehl=s criteria were applied. Bruehl's criteria resulted in a fair kappa value of 0.38 and the specificity of CRPS diagnosis increased too. CRPS frequency decreased to $43 \%$ in comparison to frequency of CRPS $(73 \%)$ in experts= diagnosis (Table 4). Therefore, the option to increase specificity might be beneficial for research goals, but the concordant decrease in sensitivity probably limits the clinical value of Bruehl's criteria. In an effort to identify signs and symptoms with a major impact on the CRPS diagnostic process, we performed a logistic regression analysis on our data-set (data not shown). We were not able to find any signs or symptoms crucial for the diagnosis of CRPS. This accords with Veldman who found that sympathic signs and symptoms (like hyperhidrosis, hypertrichosis, and changed nailgrowth) as single entities do not contribute significantly to the diagnosis of CRPS. ${ }^{21}$

The remaining question is whether, with our current knowledge, valid CRPS criteria for clinical practice can be developed at all. Further studies are needed to develop other methods to diagnose CRPS. Until that time it might be appropriate to restrict clinical trials of CRPS to patients who fulfill Bruehl's criteria.

\section{Acknowledgements}

We would like to thank the following physicians who participated in the study: Prof. M. Sluyter, Dr. G. Barendse, Dr. H. van Suijlekom (anaesthesiologists) and Dr.W.Weber, (neurologist) from the 'Pain Management and Research Centre', Dr. M. Kemler and Dr. G.J. Eggink from the 'CRPS clinic', Dept. of Surgery; University Hospital of Maastricht, The Netherlands. 


\section{Appendix I IASP Diagnostic criteria in CRPS}

Diagnostic criteria in Complex Regional Pain Syndrome type I (Stanton Hicks et al. 1995)

1. The presence of an initiating noxious event, or a cause of immobilization.

2. Continuing pain, allodynia, or hyperalgesia with which the pain is disproportionate to any inciting event.

3. Evidence at some time of edema, changes in skin blood flow, or abnormal sudomotor activity in the region of the pain.

4. This diagnosis is excluded by the existence of conditions that would otherwise account for the degree of pain and dysfunction.

Note: Criteria 2-4 must be satisfied (Merskey and Bogduk 1994)

\section{Appendix II Criteria of Bruehl: research diagnostic criteria for CRPS}

1. Continuing pain which is disproportionate to any inciting event

2. At least one symptom in each of the following categories

Sensory: reports of hyperesthesia

Vasomotor: reports of temperature asymmetry and/or skin colour changes and/or skin colour asymmetry

Sudomotor/oedema: reports of decreased range of motion and/or motor dysfunction (weakness, tremor, dystonia) and/or trophic changes (hair, nail, skin)

3. At least one sign in two or more of the following categories

Sensory: evidence of hyperalgesia (to pinprick) and/or allodynia (to light touch)

Vasomotor: evidence of temperature asymmetry and/or skin colour changes and/or asymmetry

Sudomotor/oedema: evidence of oedema and/or sweating changes and/or sweating asymmetry

Motor/trophic: evidence of decreased range of motion and/or motor dysfunction (weakness, tremor, dystonia)

and/or trophic changes (hair, nail, skin) 
Interobserver Reliability of Diagnosis in Patients with Complex Regional Pain Syndrome

Table 1 Group kappa, interobserver agreement for CRPS symptoms and frequency of symptoms in experts' diagnosis (\%)

\begin{tabular}{|c|c|c|c|}
\hline & $\begin{array}{l}\text { group } \\
\text { kappa }\end{array}$ & $\begin{array}{l}\text { observer } \\
\text { agrmnt }\end{array}$ & $\begin{array}{l}\text { frequency } \\
\text { in subjects }\end{array}$ \\
\hline continuous (spontaneous) pain & - & 0.97 & 0.94 \\
\hline dysesthesia & - & 0.93 & 0.96 \\
\hline functional impairment & - & 0.94 & 0.96 \\
\hline cold or warm sensation in affected limb & - & 0.94 & 0.97 \\
\hline pain aggravates with cold and/or heat & - & 0.92 & 0.94 \\
\hline decreased range of motion & - & 0.91 & 0.96 \\
\hline start after phys.l trauma or relevant disease & - & 0.90 & 0.95 \\
\hline pain outside original affected area & - & 0.90 & 0.95 \\
\hline loss of strength & - & 0.97 & 0.99 \\
\hline aggravation of pain with stress & 0.86 & 0.94 & 0.36 \\
\hline anhydrosis/hyperhidrosis & 0.80 & 0.91 & 0.67 \\
\hline changed nailgrowth & 0.79 & 0.90 & 0.65 \\
\hline superficial pain & 0,73 & 0.88 & 0.67 \\
\hline burning pain & 0.71 & 0.86 & 0.60 \\
\hline sympathetic block diminished complains & 0.69 & 0.90 & 0.21 \\
\hline pain upon soft touch (mechanical allodynia) & 0.67 & 0.85 & 0.65 \\
\hline throbbing pain & 0.66 & 0.86 & 0.70 \\
\hline (spontaneous pain) in one extremity & 0.65 & 0.87 & 0.75 \\
\hline changed hair growth & 0.59 & 0.82 & 0.31 \\
\hline spontaneous sensations (paresthesias) & 0.58 & 0.80 & 0.60 \\
\hline color changes & 0.57 & 0.86 & 0.79 \\
\hline deep pain & $0.55 !$ & 0.90 & 0.88 \\
\hline hypersensibility to touch (hyperesthesia) & 0.51 & 0.81 & 0.73 \\
\hline sharp pain & 0.50 & 0.80 & 0.72 \\
\hline cold pain & 0.47 & 0.75 & 0.63 \\
\hline swelling (edema) & 0.40 & 0.75 & 0.72 \\
\hline tremor & 0.37 & 0.72 & 0.32 \\
\hline start after immobilization & 0.35 & 0.72 & 0.31 \\
\hline skintemperature asymmetry & $0.33 !$ & 0.81 & 0.83 \\
\hline concentrate to move (motor neglect) & 0.30 & 0.70 & 0.69 \\
\hline guarding' of affected extremity & $0.29 !$ & 0.83 & 0.87 \\
\hline provoked pain last longer (hyperpathia) & $0.28 !$ & 0.85 & 0.89 \\
\hline hypesthesia & $0.25 !$ & 0.77 & 0.81 \\
\hline limbmovements are painful (acute) & $0.25 !$ & 0.82 & 0.86 \\
\hline the use of limb aggravates pain (delayed) & $0.21 !$ & 0.81 & 0.86 \\
\hline
\end{tabular}

Dash(-) indicates kappo cannot be calculated (frequency of $<10 \%$ or $>90$ of patients).

Exclomation point (!) indicates frequency of $10 \%-20 \%$ or $80 \%-90 \%$ (see Methods). 
Table 2 Group kappa, interobserver agreement for CRPS signs and frequency (\%) of signs in experts diagnosis

\begin{tabular}{|c|c|c|c|}
\hline & $\begin{array}{l}\text { group } \\
\text { kappa }\end{array}$ & $\begin{array}{l}\text { obsrver } \\
\text { agrmnt }\end{array}$ & $\begin{array}{l}\text { frequency } \\
\text { in subjects }\end{array}$ \\
\hline functional impairment & - & 0.96 & 0.95 \\
\hline decreased range of motion & - & 0.94 & 0.93 \\
\hline no dermatome related symptoms & - & 0.93 & 0.96 \\
\hline changed reflexes & - & 0.88 & 0.08 \\
\hline cervical, or in case of legpain lumbar, & & & \\
\hline ipsilateral pressure pain paravertebrally & 0.58 & 0.79 & 0.53 \\
\hline changed hair growth & $0.54 !$ & 0.88 & 0.16 \\
\hline tremor & $0.53 !$ & 0.91 & 0.11 \\
\hline pain after with movement (passive/active) & $0.51 !$ & 0.90 & 0.89 \\
\hline pain upon soft touch (mechanical allodynia) & 0.50 & 0.77 & 0.64 \\
\hline edema & 0.41 & 0.73 & 0.35 \\
\hline changed nailgrowth & 0.37 & 0.70 & 0.39 \\
\hline hypersensibility & 0.34 & 0.67 & 0.58 \\
\hline color changes & 0.33 & 0.67 & 0.54 \\
\hline sympathetic disregulation & 0.28 & 0.67 & 0.65 \\
\hline dysesthesia & 0.27 & 0.71 & 0.73 \\
\hline thoracal paravertebral pressure pain & $0.25 !$ & 0.81 & 0.14 \\
\hline anhydrosis/hyperhidrosis & 0.23 & 0.65 & 0.33 \\
\hline skintemperature asymmetry & 0.23 & 0.62 & 0.59 \\
\hline dystrophy or atrophy cutis/subcutis/muscles & 0.22 & 0.61 & 0.47 \\
\hline guarding of affected extremity & 0.20 & 0.67 & 0.73 \\
\hline dystonia & 0.15 & 0.63 & 0.30 \\
\hline pain aggravates with cold and/or heat & 0.11 & 0.68 & 0.80 \\
\hline sensory deficit & 0.11 & 0.66 & 0.75 \\
\hline hyperpathia & 0.10 & 0.66 & 0.77 \\
\hline hypesthesia & 0.08 & 0.54 & 0.57 \\
\hline loss of strength & $0.02 !$ & 0.77 & 0.87 \\
\hline neurological disorder in affected extremity & 0.02 & 0.47 & 0.49 \\
\hline credibility of patients' complaints & 0.22 & 0.71 & 0.76 \\
\hline pain behavior & 0.12 & 0.56 & 0.40 \\
\hline diagnosis & 0.20 & 0.57 & 0.73 \\
\hline
\end{tabular}

Dash(-) indicates kappa cannot be calculated (frequency of $<10 \%$ or $>90$ of patients). Exclamation point (!) indicates frequency of $10 \%-20 \%$ or $80 \%-90 \%$ (see Methods). 
Interobserver Reliability of Diagnosis in Patients with Complex Regional Pain Syndrome

Table 3 Kappa value in CRPS diagnosis. C.I. is confidence interval.

Observ. agreement is observer agreement

$\begin{array}{lrrr}\text { Expert-based diagnosis } & \text { Kappa } & \text { C. } .(95 \%) & \text { observ. agreement } \\ \text { IASP sign-based criteria } & 0.20 & 0.06-0.33 & 0.57 \\ \text { Bruehl sign-based criteria } & 0.29 & 0.03-0.55 & 0.74 \\ \text { Bruehl sign and symptom based } & 0.35 & 0.15-0.55 & 0.68 \\ & 0.38 & 0.18-0.58 & 0.74\end{array}$

Table 4 Frequency of CRPS diagnosis in 150 datasets.

\begin{tabular}{lll}
\hline Expert-based diagnosis* & $110 / 150=$ & CRPSI/I! (73\%) \\
IASP-symptom based & $147 / 150=$ & CRPS $1 / 11(98 \%)$ \\
IASP-sign based & $114 / 150=$ & CRPS $1 / I 1(76 \%)$ \\
Bruehl-symptom based & $130 / 150=$ & CRPS $1 / / 1(87 \%)$ \\
Bruehl-sign based & $67 / 150=$ & CRPS $1 / / 1(45 \%)$ \\
Bruehl complete & $65 / 150=$ & CRPS $1 / / 1(43 \%)$ \\
\end{tabular}

*expert (view) based diagnosis is an experience-bosed diagnosis without any application of criteria systems. 


\section{References}

1. Blumberg H, Hoffmann U. Der "Ischämie-Test": ein neues Verfahren in der klinischen Diagnostik der sympathischen Reflexdystrophy (Kausalgie, $M$. Sudeck). Der Schmerz 1992;6:196-198.

2. Casale R, Elam M. Normal sympathetic nerve activity in a reflex sympathetic dystrophy with marked skin vasoconstriction. J Auton Nerv Syst 1992;41 (3):215-9.

3. Glynn C, Casale R. Morphine injected around the stellate ganglion does not modulate the sympathetic nervous system nor does it provide pain relief. Pain 1993;53(1):33-7.

4. Low PA, Amadio PC, Wilson PR, McManis PG, Willner $C L$. Laboratory findings in reflex sympathetic dystrophy: a preliminary report. Clin / Pain 1994;1 0(3):235-9.

5. Kurvers HA, Jacobs MJ, Beuk RJ, et al. Reflex sympathetic dystrophy: evolution of microcirculatory disturbances in time. Pain 1995;60(3):333-40.

6. Lee GW,Weeks PM. The role of bone scintigraphy in diagnosing reflex sympathetic dystrophy.J Hand Surg Am 1995;20(3):458-63.

7. Bruehl S, Lubenow TR, Nath H, Ivankovich $O$. Validation of thermography in the diagnosis of reflex sympathetic dystrophy. Clin-j-Poin 1996;1 2(4):316-25.

8. Baron R, Blumberg $H$, Jänig W. Clinical Characteristics of Patients with Complex Regional Pain syndrome in Germany with Special Emphasis on Vasomotor Function. In: Jänig W, Stanton-Hicks $M$, eds. Reflex Sympathetic Dystrophy. A Reappraisal. Seattle: IASP Press, 1996: 25.

9. Birklein F, Sittl R, Spitzer A, Claus D, Neundorfer B Handwerker HO. Sudomotor function in sympathetic reflex dystrophy. Pain 1997;69(1-2):49-54.

10. Gulevich SJ, Conwell TD, Lane J, et al. Stress infrared telethermography is useful in the diagnosis of complex regional pain syndrome, type 1 (formerly reflex sympathetic dystrophy). Clin J Pain 1997;13(1):50-9.

11. Masson C,Audran M, Pascaretti $C$, et al. Further vascular, bone and autonomic investigations in algodystrophy. Acta-Orthop-Belg 1998;64(1):77-87.

12. Sandroni P, Low PA, Ferrer T, Opfer Gehrking TL, Willner CL, Wilson PR. Complex regional pain syndrome I (CRPS 1): prospective study and laboratory evaluation. Clin-J-Pain 1998;14(4):282-9.

13. Kozin F, Ryan LM, Carrera GF, Soin JS. The Reflex Sympathetic Dystrophy Syndrome (RSDS) III. Scintigraphic Studies, Further evidence for the Therapeutic Efficacy of Systemic Corticosteroids, and Proposed Diagnostic Criteria. American Journal of Medicine 1981;70:23-30.

14. Bonica J. Causalgia and other reflex sympathetic dystrophyies. In: Bonica J, ed. The management of pain.
Philadelphia: Lea \& Febiger, 1990: 220-243.

15. Amadio P, Mackinnon S, Wyndell H, Brody G, Terzis ]. Reflex Sympathetic Dystrophy Syndrome: Consensus Report of an Ad Hoc Committee of the American Association for Hand Surgery on the Definition of Reflex Sympathetic Dystrophy Syndrome. Plastic and Reconstructive Surgery 1990;87(2):371-375.

16. Merskey H. Bogduk N. Classification of chronic pain. Descriptions of chronic pain syndromes and definitions of pain terms. 2 ed. Seattle: IASP Press, 1994.

17. Galer B, Bruehl S, Harden N. IASP Diagnostic Criteria for Complex Regional Pain Syndrome:A Preliminary Empirical Validation Study. Clin J Pain 1998;14:48-54.

18. Harden RN, Bruehl S, Galer BS, et al. Complex regional pain syndrome: are the IASP diagnostic criteria valid and sufficiently comprehensive? Pain 1999;83:211-219.

19. Bruehl S, Harden RN, Galer BS, et al. External validation of IASP diagnostic criteria for complex regional pain syndrome and proposed research diagnostic criteria. Pain 1999;81 (1-2):147-154.

20. Suylekom JAv, Vet HCWd, Berg SGMvd, Weber WEJ. Interobserver reliability of diagnostic criteria for Cervicogenic Headache. Cephalalgia 1999;19:181723.

21. Veldman PH, Reynen HM, Arntz IE, Goris RJ. Signs and symptoms of reflex sympathetic dystrophy: prospective study of 829 patients. Lancet 1993;342(8878): 1012-6.

22. Galer BS, Jensen MP. Development and preliminary validation of a pain measure specific to neuropathic pain: the Neuropathic Pain Scale. Neurology 1997;48(2):332-8.

23. Boas R. Complex Regional Pain Syndromes: Symptoms, Signs and Differential Diagnosis. In: Jänig W, Stanton-Hicks M, eds. Reflex Sympathetic Dystrophy : a reappraisal. Seattle: IASP press, 1996: 79-92.

24. Alexeyev W, Novikov AV, Yakhno NN. Are there differences in principle between type I and type II of Complex regional pain syndrome. Vienna: IASP Press, 1999.

25. Schouten HJA. Nominal scale agreement among observers. Psychometrika 1986;51:453-466.

26. Landis JR, Koch GG. The measurement of observer agreement for categorical data. Biometrics 1977;33(2):159-74.

27. Cohen J. A coefficient of agreement for nominal scales. Educ Psychol Meas 1960;20:37-46.

28. van Triet EF, Dekker J, Kerssens J], Curfs EC. Reliability of the assessment of impairments and 
Interobserver Reliability of Diagnosis in Patients with Complex Regional Pain Syndrome

disabilities in survey research in the field of physical therapy. Int-Disabil-Stud 1990;1 2(2):61-5.

29. Bogduk N. Musculoskeletal Pain: Towards Precision

Diagnosis. In: Jensen T,Turner J, Wiesenfled-Hallin Z, eds. Proceedings of the 8th World Congress on

Pain. Seattle: IASP Press, 1997: 507-525.

30. Guzmán J, Burgos-Vargas R, Duarte-Salazar C,

Gómez-Mora P. Reliability of the articular examination in children with juvenile rheumatoid arthritis: interobserver agreement and sources of disagreement. Journal of Rheumatology 1995;22(12):2331-6.

31. Oerlemans HM, Perez RS, Oostendorp RA, Goris RJ. Objective and subjective assessments of temperature differences between the hands in reflex sympathetic dystrophy. Evaluation of three methods to rate impairment in patients with complex regional pain syndrome I of one upper extremity. Clin Rehobil 2000;74(3):331-9.

32. Wipf JE, Lipsky BA, Hirschmann JV, et al. Diagnosing pneumonia by physical examination: relevant or relic? Arch Intern Med 1999;1 59(10):1082-7.

33. de Kort WL, Uiterweer HW, van Dijk FJ. Agreement on medical fitness for a job. Sc J Work, Environment Health 1992;18(4):246-51.

34. de Winter AF, Jans MP, Scholten RJ, Devillé W, van Schaardenburg $D$, Bouter LM. Diagnostic classification of shoulder disorders: interobserver agreement and determinants of disagreement. Ann Rheum Dis 1999;58(5):272-7.

35. Oeriemans HM, Oostendorp RA, de Boo T, Perez RS, Goris RJ. Signs and symptoms in complex regional pain syndrome type 1/reflex sympathetic dystrophy: judgment of the physician versus objective measurement. Clin J Pain 1999;1 5(3):224-32. 
Interobserver Agreement on Differential Diagnosis of Complex Regional Pain Syndrome type 1

Anton C. van de Vusse, Suzanne G.M. Stomp-van den Berg, Wilhelm E.J.Weber

Published in:The Pain Clinic, 15 (2), 2003: pp. 143-149 
Interobserver agreement on differential diagnosis of Complex Regional Pain Syndrome type 1

\begin{abstract}
Summary
Complex Regional Pain Syndrome type I (CRPS I) is a controversial clinical diagnosis. It is unknown which differential diagnoses are important in chronic pain patients suspected of having CRPS I. In this study 25 patients with possible CRPS I were interviewed and examined by 6 CRPS-experts. On average, one out of four CRPS-experts disagreed with the diagnosis when CRPS I was diagnosed by a colleague. CRPS I could not be diagnosed with much certainty. Idiopathic and somatoform pain syndromes are important differential diagnoses in CRPS I.
\end{abstract}

Keywords: Reflex Sympathetic Dystrophy; Interobserver agreement; Somatoform Disorders; Differential Diagnosis

\title{
Introduction
}

Complex Regional Pain Syndrome type I (CRPS I) is a clinical diagnosis. It is controversial because a gold standard for diagnosis in the form of an objective test is not available..$^{1-12}$. The main clinical problem is interphysician variability in CRPS diagnosis. This is due to interphysician differences of interview and physical examination, but also due to disagreement about which signs and how many signs are needed to reach the diagnosis of CRPS. A diagnostic problem in chronic CRPS is that signs are often less prominent in comparison to the acute phase. ${ }^{13.14}$ We sought to answer the following question: when doctors do not agree on the diagnosis CRPS I, which differential diagnoses are involved? Many diagnoses have been proposed as possible differential diagnoses (table 1), but it has not been studied to which extent they are clinically relevant in the daily practice of diagnosing CRPS I.

In this study we describe how six CRPS experts diagnose 25 chronic pain patients suspected for CRPS I and upon which they differ.We designed the study to test the extent of agreement in diagnosing possible and definite CRPS patients and to find out which differential diagnoses are important in this.

\section{Patients and methods}

Six physicians ( 3 anesthesiologists, 2 surgeons and 1 neurologist) with known experience on CRPS I were invited to participate in the study. The physicians, who all worked in a university outpatient pain or CRPS-clinic, saw each patient during 10-20 minutes for a semi-structured interview and a physical examination; details of the study set-up have been described previously. ${ }^{15.16}$ Although dichotomous questions were used to assess signs and symptoms, the observers were free to ask additional questions to obtain adequate information after which they filled in the most adequate diagnosis according to their own clinical view. No instructions were given about criteria to diagnose CRPS.

Twenty-five patients were at random selected from a tertiary care database with patients at least once diagnosed and informed about CRPS I or reflex sympathetic dystrophy (RSD). All patients had received treatment, though remained to have complaints. They all gave informed consent.

Physicians were able to choose from CRPS I and 8 differential diagnoses: CRPS II (CRPS with evidence of nerve damage) CRPS III (idiopathic pain with sensory, motor and/or tissue abnormalities not other- 
wise specified), myofascial pain, peripheral neuropathy (e.g. diabetic), radiculopathy, nerve entrapment, somatoform (pain) disorder, 'pain not otherwise specified'. 17,18 Also, an open answer possibility for other diagnoses was given.

The study was set up in three sessions with six patients and six physicians each session and one session with seven patients and six physicians. ${ }^{15,16}$ To limit the variation of signs between successive physical examination, every patient was seen within 90 minutes by the six observers successively. Physician assessment was standardised by a semi-structured interview and physical examination on 52 possible signs and symptoms.

Physicians in this study focussed on clinical signs as in bedside evaluation and had no access to any laboratory test results like electromyogram, laser Doppler flowmetry or three-phase bone scanning. Frequency distributions of diagnoses were calculated to assess most important differential diagnoses. To measure interphysician agreement in diagnosis we calculated kappa values. 15,19

CRPS experts diagnose CRPS with yet unknown mechanims. These might be helpful in future criteria systems. We applied logistic analysis(stepwise, forward procedure) of expert-based diagnosis to find significantly predicting signs and symptoms for CRPS, CRPS-III and somatoform disorder. All signs and symptoms were taken as independent variables.

\section{Results}

In this study twenty-five patients participated with a mean age of 42.3 years ( $23-65$ yrs). Twenty-three of them were women. Duration of symptoms had a median of 39 months (5-168 mo.) and record based searches revealed that the patients had been seen by at least five physicians (5-13) prior to participation and no serious other pathology like diabetes mellitus, arthritis or vascular pathology had been found to explain the symptoms. Because some patients had possibly more than one affected extremity, they were asked to focus on the most affected limb. Eighteen patients with upper extremity pain and concomitantly seven patients with lower extremity pain were included.

All patients were diagnosed as having CRPS I by at least one observer. In table 2 the frequency distributions of the diagnoses are shown for the six physicians. In 150 assessments, patients were diagnosed as CRPS I in $67 \%$ ( $N=99)$. The two surgeons diagnosed CRPS in $80 \%$, which is more than the four others who diagnosed CRPS I in $59 \%$ ( $p<0.05$, chi-square analysis). Sometimes patients were diagnosed as idiopathic pain patient with sensory, motor and/or tissue abnormalities (CRPS III) or somatoform pain disorder, while CRPS II and the other diagnoses were diagnosed even less frequently. The category 'other' was formed by differential diagnoses: idiopathic pain not otherwise specified $(N=7)$ and myofascial pain $(N=1)$.

In order to assess which regional pain syndrome is most difficult to distinguish from the others we calculated the frequency distribution of diagnosis (table 3). As one observer diagnosed CRPS III or a somatoform pain syndrome, simultaneously the other observers agreed in a mean of respectively $13 \%$ and $25 \%$.When CRPS I was diagnosed, $75 \%$ agreement in diagnosis was found. When an observer diagnosed CRPS II $(N=11)$, none of the five colleagues assigned a somatoform syndrome in the same patient and vice versa, when an observer diagnosed a somatoform syndrome, none of the other colleagues diagnosed CRPS II. 
Interobserver agreement on differential diagnosis of Complex Regional Pain Syndrome type 1

Kappa values for interphysician agreement ranged from 0.05 to 0.30 (table 4).

It is unknown which signs and symptoms mainly influence diagnostic judgment in CRPS specialists. A logistic regression was applied to reveal significant factors. The fifty-three items measure were analyzed, which included 35 reported symptoms and 28 signs. ${ }^{15}$ Besides CRPS signs, physicians were also asked to rate patients's pain, to judge pain behavior amd credibility of patients' complaints and answer whether the pain was located to one extremity and if they had seen the patient before. These factors were also included in the logistic regression analysis. Figure 1 and 2 show which factors contribute significantly in CRPS I/II and CRPS III. No symptom or sign is exclusively present in either form of CRPS. As expected, sympathetic dysfunction, dystrophic change and severity of complaints are important contributors to the CRPS diagnosis.

Sensibility changes as hypersensitivity, dysesthesia and a discrepancy between reported and objective hypestesia are are the other significant factors for the CRPS diagnosis. More logistic regression analyses (Fig. 3) revealed that reported burning pain, reported color differences, lack of spontaneous pain, lack of sympathetic dysregulation, lack of sensory dysfunction and lack of credibility are important predictors for the diagnosis of 'somatoform disorder'.

\section{Discussion}

CRPS is a clinical diagnosis for which criteria have been formulated. Until now, interphysician agreement of the diagnostic process had not been studied. Our study population consisted of possible CRPS patients, by at random inviting patients who had ever been diagnosed as CRPS/ RSD.

Our results show that differential diagnoses are important in CRPS I, because CRPS I cannot be diagnosed with much reliability. ${ }^{15,16}$ In our population of patients suspected of having CRPS I, patients were also diagnosed as having CRPS II (5\%), CRPS III (7\%) or somatoform disorders (9\%). Physicians differ in their clinical differential diagnosis in patients suspected of CRPS I. Especially idiopathic pain with sensory, motor and/or tissue abnormalities (CRPS III) and somatoform disorders are diagnosed unequally by the participating physicians, which might reveal differences between medical disciplines. It appeared that in some patients physician 6 (neurologist) preferred to diagnose somatoform disorders, where physician 4 (anesthesiologist) preferred to diagnose CRPS III. The surgeons, both working at the CRPS clinic, diagnosed CRPS I more often than the other physicians who worked at a general pain clinic. The latter are presumably more familiar with other chronic, (e.g., idiopathic and somatoform) pain patients than surgeons. Kappa values for interphysician agreement showed low agreement in CRPS diagnosis with a range of $0.05-0.30$, where only a kappa value of more than 0.40 can be considered as moderate. 20 Kappa values in our study population cannot be directly extrapolated to a general population, but the complaints of patients about disbelief and contradictory information from their own physicians can be understood and explained by these low kappa values. If one considers that CRPS patients are often seen by physicians, who are probably less focused on CRPS than the experts in this study, even more disagreement can be expected at other settings.

In an effort to identify signs and symptoms with a major impact on the CRPS diagnosis, we performed a logistic regression analysis. We can conclude as Veldman 14 that sympathetic signs and symptoms (like hyperhidrosis, hypertrichosis and changed nailgrowth) as single entities do not contribute significantly to the diagnosis of CRPS in our population. 
The diagnosis of somatoform pain syndrome (range 0-24\%) and a rarely used non-official diagnosis as 'CRPS III-idiopathic pain with sensory, motor and/or tissue abnormalities' (range 0-28\%) were in this study more often assigned than one would expect. ${ }^{21,22}$ Somatoform disorder is normally a diagnosis, which cannot be assigned by one physician after one examination.18 Therapy is often unsuccessful. We think it is therefore underreported in favor of other (less stigmatizing) diagnoses. Because this study asked physicians explicitly for the most likely diagnosis, we think that the large representation of idiopathic and somatoform diagnoses in possible CRPS patients, reveals the true opinion of pain experts. The concept of CRPS $11117,21,22$ should be re-evaluated as some physicians might want to use an "escape diagnosis' to represent a group of patients which have symptoms and signs that cannot be explained by any neurological or mental entity.

In this population more than $10 \%$ of the diagnoses were assigned as a somatoform disorder. We did not find patients simultaneously diagnosed as

CRPS II and somatoform pain syndrome. This is logical as a diagnosis of CRPS II can only be reached in the context of proven nerve damage ${ }^{17}$, thus ruling out a somatoform pain syndrome. This accords with recent findings by Ochoa and co-workers ${ }^{23,24}$, who found that signs of nerve damage argue against and the presence of movement disorders argues in favour of a somatoform disorder in patients suspected of having CRPS.

Chronic idiopathic pain is a burden for patient, physician and society as treatment is, per definition, unsatisfactory. Treatment results and patient satisfaction might improve with better diagnosing. In the future more attention should be focused on how to distinguish CRPS I from somatoform ${ }^{25}$ and idiopathic pain syndromes, for example by focusing on differences in diagnosis between medical disciplines.

\section{Acknowledgements}

The following physicians participated in the study: Prof. M. Sluyter, Dr. G. Barendse, Dr. H. van Suylekom (anesthesiologists) and Dr.W.Weber, (neurologist) from the 'Pain Management and Research Centre', Dr. G.J. Eggink from the 'CRPS clinic', Dept. of Surgery; University Hospital of Maastricht and Dr. M. Kemler (Dept. of Surgery, University Hospital Groningen), The Netherlands. 
Interobserver agreement on differential diagnosis of Complex Regional Pain Syndrome type 1

table 1. Differential diagnosis in CRPS of the extremities as mentioned in the literature

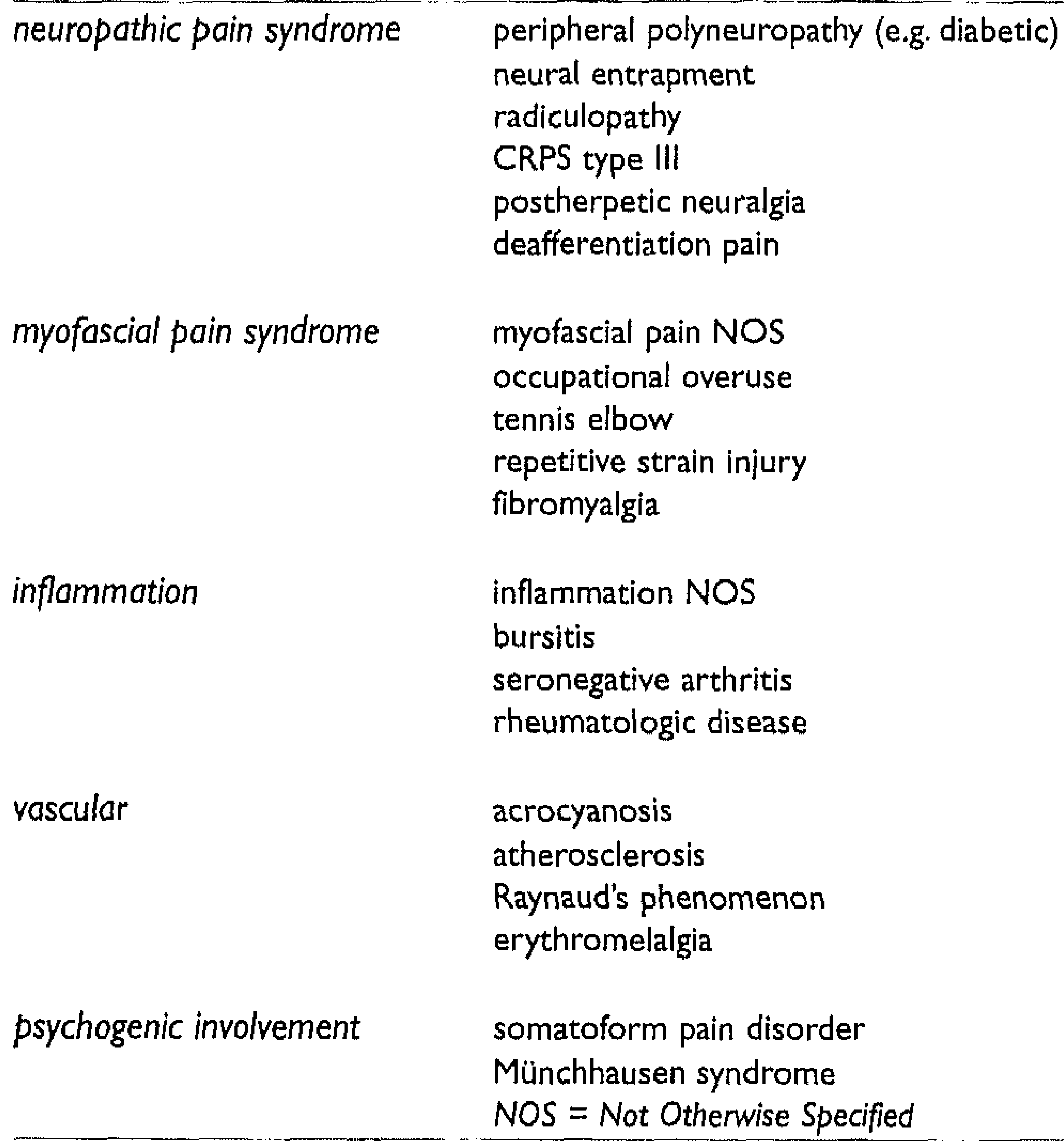

table 2. Frequency distributions of diagnosis of the 6 CRPS specialists

\begin{tabular}{llllll}
\hline physicion & CRPSI & CRPS II & CRPS III & Somatoform & Other \\
& & & & & \\
1 (anesthesiologist) & .60 & .12 & .08 & .20 & .00 \\
2 (surgeon) & .80 & .08 & .08 & .04 & .00 \\
3 (surgeon) & .80 & .08 & .12 & .00 & .00 \\
4 (anesthesiologist) & .52 & .00 & .28 & .04 & .16 \\
5 (anesthesiologist) & .76 & .08 & .04 & .12 & .00 \\
6 (neurologist) & .52 & .08 & .00 & .24 & .16 \\
Total & .67 & .07 & .10 & .11 & .05 \\
\hline
\end{tabular}

CRPS III is idiopathic pain with sensory, motor and/or tissue abnormalities. 
table 3. Frequency distribution (\%) of the clinical diagnosis of 5 observers, conditional on the judgment of the other observer

\begin{tabular}{lllllll}
\hline & $\begin{array}{l}\text { Cases } \\
(\mathrm{N}=150)\end{array}$ & CRPS I & CRPS II & CRPS III & Somatoform & Other \\
& & & & & & \\
CRPS I & 99 & $75 \%$ & $5 \%$ & $7 \%$ & $9 \%$ & $4 \%$ \\
CRPS II & 11 & $44 \%$ & $40 \%$ & $11 \%$ & $0 \%$ & $5 \%$ \\
CRPS III & 15 & $47 \%$ & $8 \%$ & $13 \%$ & $.21 \%$ & $11 \%$ \\
Somatoform & 17 & $49 \%$ & $0 \%$ & $19 \%$ & $25 \%$ & $7 \%$ \\
Other & 8 & $55 \%$ & $8 \%$ & $20 \%$ & $12 \%$ & $5 \%$ \\
\hline
\end{tabular}

a CRPS III is 'pain and sensory, motor and/or tissue abnormalities not otherwise specified'. Somatoform is somatoform disorder

table 4. Kappa values between physicians in diagnosing patients suspected for having CRPS

\begin{tabular}{|c|c|c|c|c|c|}
\hline & $\begin{array}{l}\text { Physician } 2 \\
\text { (surg.) }\end{array}$ & $\begin{array}{l}\text { physician } 3 \\
\text { (surg.) }\end{array}$ & $\begin{array}{l}\text { physician } 4 \\
\text { (anesth.) }\end{array}$ & $\begin{array}{l}\text { physician } 5 \\
\text { (anesth.) }\end{array}$ & $\begin{array}{l}\text { physician } 6 \\
\text { (neur.) }\end{array}$ \\
\hline physician 1 (anest.) & 0.27 & 0.12 & 0.15 & 0.29 & 0.30 \\
\hline physician 2 (surg.) & & 0.30 & 0.07 & 0.05 & 0.15 \\
\hline physician 3 (surg.) & & & 0.13 & 0.26 & 0.17 \\
\hline physician 4 (anesth.) & & & & 0.18 & 0.25 \\
\hline physician 5 (anesth.) & & & & & 0.23 \\
\hline
\end{tabular}

Anesth is anesthesiologist. Surg. is surgeon. Neur. is neurologist 
Interobserver agreement on differential diagnosis of Complex Regional Pain Syndrome type 1

Figure 1. Signs and symptoms relevant in expert-based CRPS diagnosis as found after logistic regression. The frequencies of these signs and symptoms in CRPS, CRPS type III and somatoform disorder as diagnosed by experts is given. CRPS $1 / 11$ is the lower bar

signs and symptoms relevant in CRPSI/II diagnosis

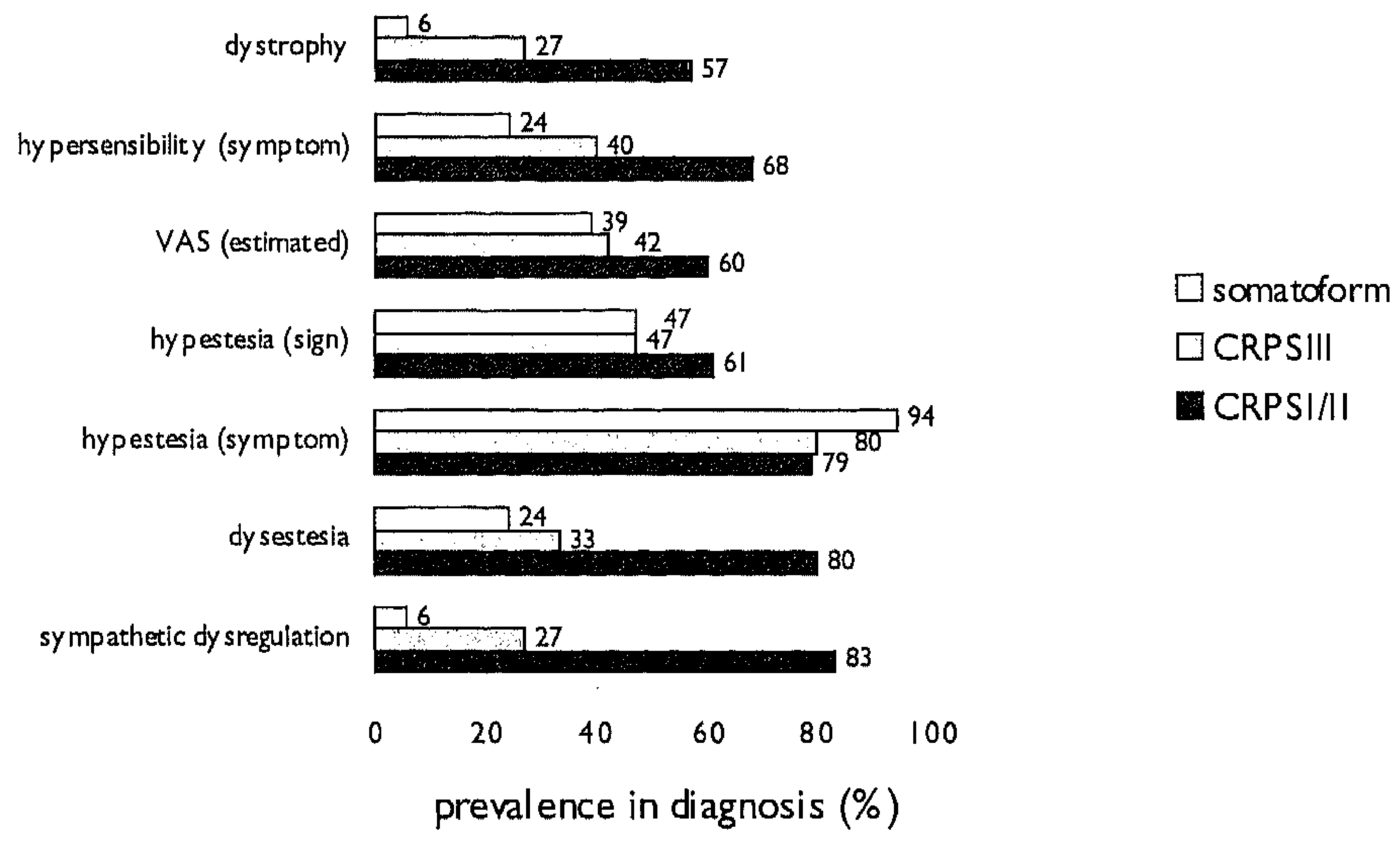


Figure 2. Signs and symptoms relevant in expert-based CRPS type III diagnosis as found after logistic regression. The frequencies of these signs and symptoms in CRPS, CRPS type III and somatoform disorder as diagnosed by experts is given. CRPS type III is represented by the bar in the middle.

signs and sy mptoms relevant in CRPSHIl diagnosis

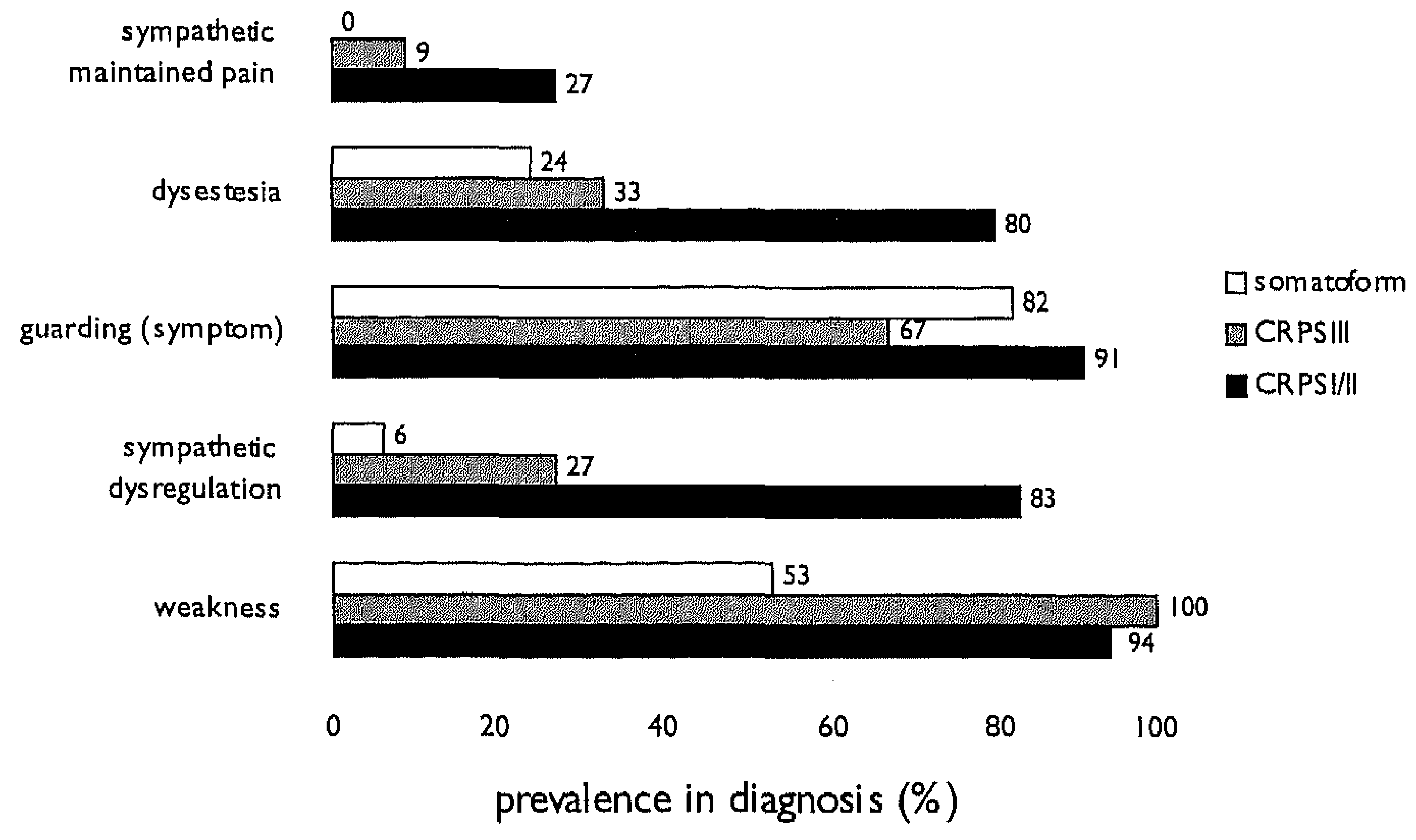


Interobserver agreement on differential diagnosis of Complex Regional Pain Syndrome type 1

Figure 3. Signs and symptoms relevant in expert-based somatoform disorder as found after logistic regression. The frequencies of these signs and symptoms in CRPS, CRPS type III and somatoform disorder as diagnosed by experts is given. Somatoform disorder is reprented by the upper bar.

signs and symptoms relevant in somatoform diagnosis

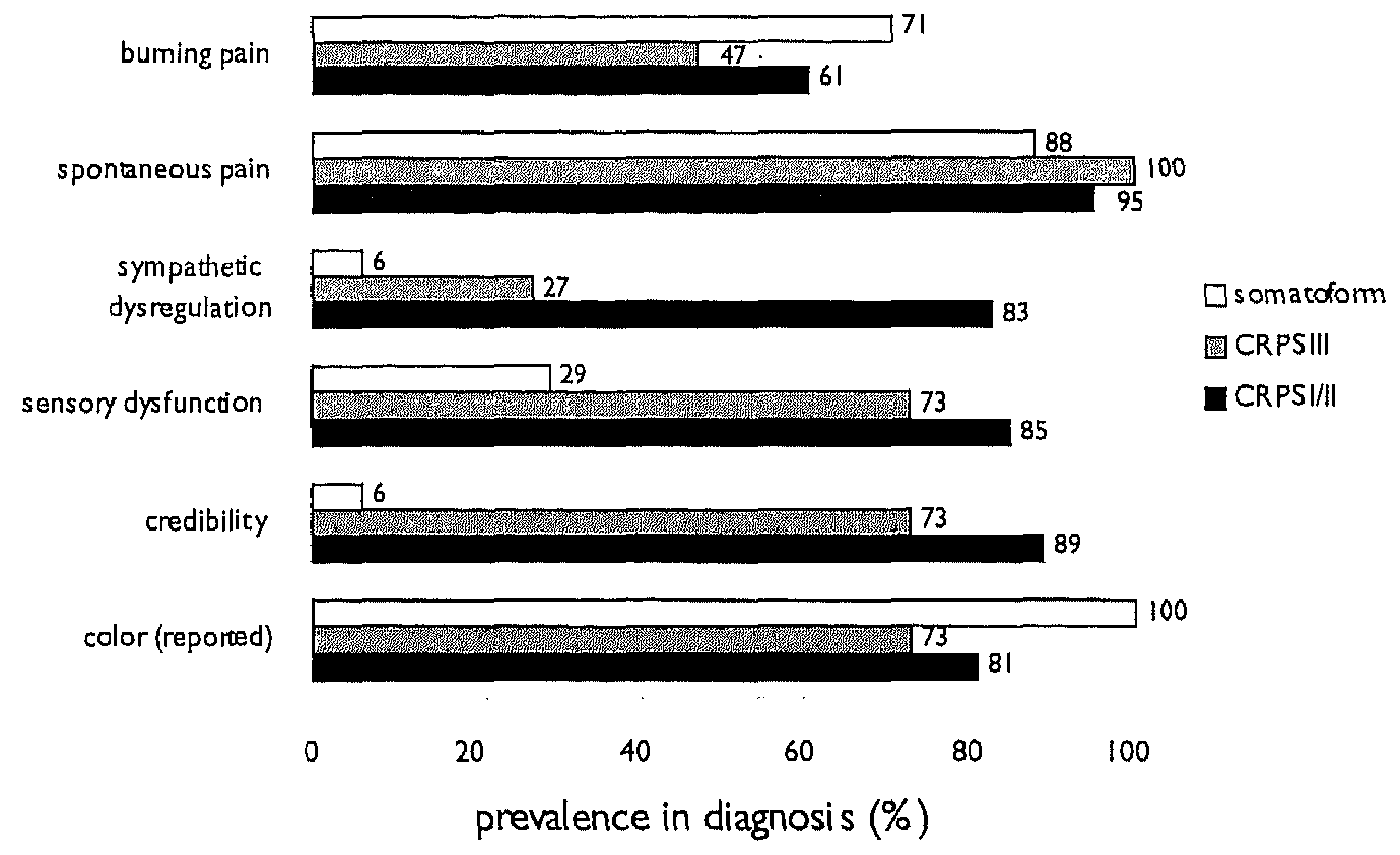




\section{References}

1. Casale R, Elam M. Normal sympathetic nerve activity in a reflex sympathetic dystrophy with marked skin vasoconstriction. J Auton Nerv Syst 1992;41(3):215-9.

2. Glynn C, Casale R. Morphine injected around the stellate ganglion does not modulate the sympathetic nervous system nor does it provide pain relief. Pain 1993;53(1):33-7.

3. Low PA, Amadio PC, Wilson PR, McManis PG, Willner $\mathrm{CL}$. Laboratory findings in reflex sympathetic dystrophy: a preliminary report. Clin J Pain 1994;10(3):235-9.

4. Kurvers HA, Jacobs MJ, Beuk RJ, et al. Reflex sympathetic dystrophy: evolution of microcirculatory disturbances in time. Pain 1995;60(3):333-40.

5. Lee GW, Weeks PM. The role of bone scintigraphy in diagnosing reflex sympathetic dystrophy. J Hand Surg Am 1995;20(3):458-63.

6. Bruehl $S$, Lubenow TR, Nath $H_{1}$ Ivankovich $O$. Validation of thermography in the diagnosis of reflex sympathetic dystrophy. Clin-j-Pain 1996;1 2(4):316-25.

7. Baron $R$, Blumberg $H$, Jänig W. Clinical Characteristics of Patients with Complex Regional Pain syndrome in Germany with Special Emphasis on Vasomotor Function. In: Jänig W, Stanton-Hicks M, eds. Reflex Sympathetic Dystrophy. A Reappraisal. Seattle: IASP Press, 1996: 25.

8. Birklein F, Sittl R, Spitzer A, Claus D, Neundorfer B, Handwerker $H O$. Sudomotor function in sympathetic reflex dystrophy. Pain 1997;69(1-2):49-54.

9. Gulevich SJ, Conwell TD, Lane J, et al. Stress infrared telethermography is useful in the diagnosis of complex regional pain syndrome, type I (formerly reflex sympathetic dystrophy). Clin J Poin 1997;13(1):50-9.

10. Masson C, Audran M, Pascaretti C, et al. Further vascular, bone and autonomic investigations in algodystrophy. Acta-Orthop-Belg 1998;64(1):77-87.

11. Sandroni P, Low PA, Ferrer T, Opfer Gehrking TL, Willner CL, Wilson PR. Complex regional pain syndrome I (CRPS I): prospective study and laboratory evaluation. Clin-J-Pain 1998;14(4):282-9.

12. Blumberg H, Hoffmann U. Der "Ischämie-Test": ein neues Verfahren in der klinischen Diagnostik der sympathischen Reflexdystrophy (Kausalgie, $M$. Sudeck). Der Schmerz 1992;6:196-198.

13. Harden RN, Bruehl S, Galer BS, et al. Complex regional pain syndrome: are the IASP diagnostic criteria valid and sufficiently comprehensive? Pain 1999;83:211-219.

14. Veldman PH, Reynen HM, Arntz. IE, Goris RJ. Signs and symptoms of reflex sympathetic dystrophy: prospective study of 829 patients. Lancet 1993;342(8878):1012-6.
15. van de Vusse AC, van den Berg GM, de Vet $H C$, Weber WEJ. Clinical reliability of diagnostic criteria in Complex Regional Pain Syndrome. Eur J Poin (in press).

16. van de Vusse AC, Stomp-van den Berg GM, Weber WEJ. Discrepancy between complaints and objective signs in Complex Regional Pain Syndrome: a multi-observer study. Pain Clinic 2002;13:245-9.

17. Merskey H, Bogduk N. Classification of chronic pain Descriptions of chronic pain syndromes and definitions of pain terms. 2 ed. Seattle: IASP Press, 1994.

18. APA.American Psychiatric Association: Diagnostic and Statistical Manual of Mental Disorders. Third Edition, Revised ed.Washington, DC: American Psychiatric Association, 1987.

19. Landis JR, Koch GG. The measurement of observer agreement for categorical data. Biometrics 1977;33(2):159-74.

20. McCombe PF, Fairbank JC, Cockersole BC, Pynsent PB. 1989 Volvo Award in clinical sciences. Reproducibility of physical signs in low-back pain [see comments]. Spine 1989;14(9):908-18.

21. Boas R. Complex Regional Pain Syndromes: Symptoms, Signs and Differential Diagnosis. In: Jänig W, Stanton-Hicks M, eds. Reflex Sympathetic Dystrophy : a reappraisal. Seattle: IASP press, 1996: 79-92.

22. Galer B, Bruehl S, Harden N. IASP Diagnostic Criteria for Complex Regional Pain Syndrome:A Preliminary Empirical Validation Study. Clin / Pain 1998; 14:48-54.

23. Ochoa J,Verdugo R, Campero M. Pathophysiological spectrum of organic and psychogenic disorders in neuropahtic pain patients fitting the description of causalgia or reflex sympathetic dystrophy. In: Gebhart G, Hammond D, Jensen T, eds. Proceedings of the 7th World Congress on Pain. Seattle: IASP Press, 1994: 483-494.

24. Verdugo RJ, Ochoa JL. Abnormal movements in complex regional pain syndrome: assessment of their nature. Muscle Nerve 2000;23(2):198-205.

25. Gould R, Miller BL, Goldberg MA, Benson DF. The validity of hysterical signs and symptoms. Journol of Nervous And Mental Disease 1986;174(10):593-7. 
Discrepancy between Complaints and Objective Signs in Complex Regional Pain Syndrome: a multi-observer study

Anton C. van de Vusse, Suzanne Stomp-van den Berg, and Wilhelm EJ. Weber

Published in:The Pain Clinic 13, 2002, pp. 245-9 


\section{Summary}

Complex Regional Pain Syndrome of Reflex Sympathetic Dystrophy (CRPS) is a controversial diagnosis based on clinical criteria, i.e. signs and symptoms. Symptoms are reported complaints of the patient. Signs are features found by physical examination. The clinical impression in CRPS is that symptoms cannot always be confirmed upon physical examination. We studied the predictive value of symptoms for the presence of signs.

6 CRPS experts saw a study population of 25 patients, in the past diagnosed as having reflex sympathetic dystrophy. In these patients physicians were often not able to confirm CRPS symptoms by physical examination. Signs, which can be exaggerated by the patient, like pain and limb function related signs were found more often than behaviourally independent signs like oedema.

The discrepancy in prevalence of signs and symptoms in CRPS has important implications for the applicability of clinical diagnostic criteria for CRPS.

\section{Introduction}

Complex Regional Pain Syndrome (CRPS) or Reflex Sympathetic Dystrophy (RSD) is a controversial diagnosis. Its symptoms are usually continuing pain, swelling, autonomic disregulation and chronic functional impairment after a trauma of the affected limb. Diagnostic criteria are identical to causalgia in which additionally nerve damage is proven. The diagnosis of CRPS is based on clinical observations. A gold standard in the form of an objective test is not available despite many efforts 1-12. A main clinical problem is inter-physician variability in CRPS diagnosis. This is due to the variability in observed signs, symptoms and the amount of signs, symptoms and credibility in patients, needed to reach the diagnosis CRPS.

In CRPS patients one often sees a clinical mismatch between symptom presentation and objective findings ${ }^{13}$. As this mismatch is a prerequisite for the diagnosis of somatoform disorder, this might be the most important differential diagnosis of CRPS. ${ }^{14}$ The possibility of a somatoform pain disorder emerges when one can conclude that the symptoms are in excess of what would be expected from the physical findings, especially when credibility of the patient is doubtful. ${ }^{1516}$ The aim of this study was to formally assess the possible discrepancy between signs and symptom presentation in a chronic pain patient population suspected of CRPS.

\section{Patients and methods}

We here report a study where six physicians with known experience on CRPS examined 25 patients during four afternoon sessions. By doing so we aimed to reduce the impact of temporal changes in signs (recurrences) and observer-bias in physical signs. We chose to study inter-observer reliability among 6 different physicians, as it can be doubted whether predictive values of CRPS symptoms analyzed in a single-observer study have sufficient external validity. ${ }^{17}$ To minimize inter-observer variability the six participating physicians used a semi- structured interview containing 18 signs and symptoms. Assessment by sex specialists in this study of 25 possible CRPS patients resulted in a collection of 150 data sets. All patients gave informed consent.

\section{Patient selection}

Patients were selected at random from a database of patients ever diagnosed as CRPS at the Maastricht University Hospital Pain Management and Research Centre, a tertiary outpatient clinic of 
pain management. The only criterion was that patient's pain syndrome had ever been diagnosed as Complex Regional Pain Syndrome type one or Reflex Sympathetic Dystrophy and was informed about their diagnosis. Despite treatment, all patients continued to have complaints. To check whether all patients still had CRPS complaints, physicians were asked to assign a diagnosis to each patient after finishing the interview and examination.

Statistical analysis was conducted with SPSS (SPSS 7.5 for Windows). Predictive power for absence and presence of subjective symptoms to predict the presence or absence of objective signs in physical examination was conducted. Positive predictive value (PPV) was defined as true positive plus false-positive rates. This indicates the probability that the presence of a CRPS-symptom in the interview is followed by positive findings in physical examination.

\section{Results}

Twenty-five patients with a mean age of 42.3 years (23-65 years) participated of whom eighteen had upper extremity involvement and seven lower extremity involvement. Twenty-three patients were women. Duration of symptoms had a median of 39 months (range 5-168 months). A retrospective patient file search revealed that the patients had visited a mean of at least eight physicians (range 5-13) prior to participation.

In our study all patients were diagnosed as CRPS by at least one physician ${ }^{16}$. In $67 \%$ of the total number of assessments CRPS was diagnosed. All six physicians diagnosed eight patients (32\%) as CRPS. Another eight patients were diagnosed as CRPS by four or five physicians, and six CRPS by only two or three physicians and three remaining patients by only one physician. Other diagnoses were causalgia (CRPS-II), pain and sensory/motor/tissue abnormalities not otherwise specified (CRPS-III), somatoform pain syndrome, and more rarely pain 'not otherwise specified' and myofascial pain syndrome (Table 1). ${ }^{18}$ We studied how often symptoms coincided with findings in physical examination. Mainly pain related symptoms as pain during movement, after touch and hyperpathy were confirmed in physical examination, as represented by the positive predictive value (Table 2). Supposedly 'objective' symptoms as tremor, edema, discoloration of the skin and hyperhidrosis were less often substantiated upon examination (Table 2).

\section{Discussion}

CRPS is a difficult clinical diagnosis lacking a gold standard laboratory test. Criteria- systems may have a high sensitivity, but specificity remains a problem.19 For as far as we know this is the first published study on predictive values of symptoms in possible CRPS patients in relation to their signs. Also it is one of the few studies in which physicians saw patients 'in vivo', instead of via videotapes or patient's records, at almost the same time. Because patients were interviewed six times, this study aimed to give more insight in general practice where patients are also seen by several physicians during their illness. This study material has limitations. All patients were diagnosed as CRPS by at least one observer and $88 \%$ by at least two physicians. The study population was small with 25 patients. The study population might be representative for chronic pain patients strongly suspected of CRPS, but not for acute CRPS patients. Frequency of signs and symptoms were probably lower than in patients with acute CRPS. Frequencies of signs were, besides oedema, similar or higher than in one comparable study in which CRPS patients were diagnosed according to IASP criteria. 14 
Discrepancy between complaints and objective signs in Complex Regional Pain Syndrome: a multi-observer study

We show here that the value of symptoms in predicting CRPS signs is low. Symptom exaggeration might be a partial explanation. Since sign exaggeration is also possible in CRPS, CRPS-signs were divided in pain behaviour related signs as allodynia, pain upon movement, functional impairment, dysesthesia etc. and in more objective signs as discoloration, swelling, nail-growth, hyperhidrosis and tremor. Pain and limb function related symptoms had a reasonable positive predictive value between $79.2 \%$ and $96.5 \%$, but the other symptoms like changed skin temperature, edema, hyperhidrosis and discoloration of the skin did predict objective findings in only $46.0 \%-66.9 \%$. One can deduct from table 2 that positive predictive value is highest in those signs where patient pain behaviour possibly could influence its observer's opinion where lowest values are found in behaviour independent signs.

The relative lack of objective signs in most patients gives difficulties in CRPS diagnosis. If one decides to focus on objective signs for diagnosing CRPS, one often chooses to ignore patients' complaints. This may lead to underdiagnosis of CRPS. Fluctuating signs like edema and skin temperature and colour change may as well cause the discrepancy between signs and symptoms. Clinical physicians will therefore not always avoid symptom-based diagnosis in case of negative findings in a patient. Even patients with rheumatoid arthritis reported 'excessively swollen' or 'stretched' joints, while the physician was not able to find swollen joints. ${ }^{20}$

Nevertheless, the discrepancy between symptom presentation and objective findings together with a low specificity of criteria put CRPS back in line with other much criticised syndromes as somatoform pain disorder, fibromyalgia, carpal tunnel syndrome, chronic fatigue syndrome and perhaps irritable bowel syndrome. ${ }^{21}$ In particular, somatoform pain disorder is potentially the principal differential diagnosis of CRPS, as the discrepancy between sign and symptom presentation is actually the main diagnostic criterion for somatoform pain disorder.15 Putting CRPS next to this syndrome explains at least partially the debate and scepticism around this diagnosis. ${ }^{22}$

Where exclusive sign-based diagnosis may lead to underdiagnosis and undertreatment, focussing on CRPS symptoms in diagnosis renders the diagnostic outcome vulnerable for suggestion, malingering and overdiagnosis. Future CRPS criteria will be widely available in our present information society and patients will be seen by several physicians. This gives the patient often more knowledge on symptom presentation than physicians and leaves him/her more vulnerable for suggestion. This may lead to overrepresentation of symptoms.

Our results indicate that in CRPS the most objective signs are the least likely to be found in physical examination. So theoretically, one wonders whether a subgroup of patients with CRPS symptoms do consciously or subconsciously, exaggerate their symptoms and several signs. It is too early to conclude that a subgroup of CRPS patients has a psychological problem, just because CRPS signs are often absent or possibly exaggerated..23 For the moment we only know that many CRPS patients have symptoms and signs that cannot be explained by any neurological, inflammatory or even psychiatric entity. More research should be done to evaluate any fluctuation in CRPS signs in individual patients to explain the sign/symptom discrepancy.

\section{Acknowledgements}

We would like to thank the participating physicians Gerard Barendse, Marius Kemler, Menno Sluyter, Gert-jan Eggink, Wim Weber en Hans van Suijlekom. 
Table $1 \quad$ Assigned diagnoses in study population

CRPS

Causalgia

Pain and sens./motor/tissue-abnormalities NOS

Pain NOS

Somatoform pain syndrome

Myofascial pain syndrome

Two pain syndromes

Total
99

11

15

6

1

150

Frequencies of 150 diagnosis in population $(N=25)$. NOS is 'not otherwise specified'. 
Discrepancy between complaints and objective signs in Complex Regional Pain Syndrome: a multi-observer study

Table 2 Positive predictive value (PPV, \%) and negative predictive value (NPV, \%) of subjective CRPS symptoms (\%) for CRPS signs (\%).

\begin{tabular}{lllllll}
\hline & & & & & \\
& symptoms & signs & PPV & NPV & sensitivity & specificity \\
Functional impairment & & & & & & \\
Impairment of movement & 0.96 & 0.95 & 96.5 & 50 & 97.9 & 37.5 \\
Limbmovements are painful (acute) & 0.96 & 0.93 & 96.5 & 83.3 & 99.3 & 50 \\
Loss of strength & 0.86 & 0.89 & 94.5 & 47.6 & 91.7 & 58.8 \\
Pain upon soft touch (mechanical allodynia) & 0.99 & 0.87 & 89.1 & 100 & 100 & 15.8 \\
Pain aggravates with cold and/or heat & 0.65 & 0.64 & 88.5 & 81.1 & 89.5 & 79.6 \\
Provoked pain last longer (hyperpathia) & 0.89 & 0.80 & 83.6 & 77.8 & 98.3 & 23.3 \\
Guarding of affected extremity & 0.87 & 0.77 & 83.5 & 76.5 & 96.5 & 37.1 \\
Hypersensitivity & 0.73 & 0.73 & 79.2 & 70 & 94.5 & 34.1 \\
Dysesthesia & 0.96 & 0.73 & 69.7 & 85.7 & 99 & 52.4 \\
Changed skintemperature & 0.83 & 0.59 & 66.9 & 80 & 94.2 & 33.3 \\
Hypestesia & 0.81 & 0.55 & 64.8 & 78.6 & 92.9 & 33.8 \\
Discoloration of skin & 0.79 & 0.54 & 61.9 & 80.6 & 92.4 & 35.7 \\
Changed nailgrowth & 0.65 & 0.39 & 58.2 & 98.1 & 98.3 & 55.4 \\
Swelling (edema) & 0.72 & 0.35 & 54.4 & 92.9 & 94.2 & 39.8 \\
Changed hair growth & 0.31 & 0.16 & 48.9 & 99 & 95.8 & 81 \\
Anhydrosis/hyperhidrosis & 0.67 & 0.33 & 46 & 92 & 92 & 46 \\
Tremor & 0.32 & 0.11 & 31.3 & 99 & 93.8 & 75.4 \\
- & & & & & \\
\hline - & & & &
\end{tabular}




\section{References}

1. Blumberg $H$, Hoffmann U. Der "Ischämie-Test": ein neues Verfahren in der klinischen Diagnostik der sympathischen Reflexdystrophy (Kausalgie, $M$. Sudeck). Der Schmerz 1992;6:196-198.

2. Casale R, Elam M. Normal sympathetic nerve activity in a reflex sympathetic dystrophy with marked skin vasoconstriction. J Auton Nerv Syst 1992;41(3):215-9.

3. Glynn C, Casale R. Morphine injected around the stellate ganglion does not modulate the sympathetic nervous system nor does it provide pain relief. Pain 1993;53(1):33-7.

4. Low PA, Amadio PC, Wilson PR, McManis PG, Willner $C L$. Laboratory findings in reflex sympathetic dystrophy: a preliminary report. Clin J Pain 1994;10(3):2359.

5. Kurvers HA, Jacobs MJ, Beuk RJ, et al. Reflex sympathetic dystrophy: evolution of microcirculatory disturbances in time. Pain 1995;60(3):333-40.

6. Lee GW, Weeks PM. The role of bone scintigraphy in diagnosing reflex sympathetic dystrophy. I Hand Surg Am 1995;20(3):458-63.

7. Bruehl S, Lubenow TR, Nath $H$, Ivankovich O.Validation of thermography in the diagnosis of reflex sympathetic dystrophy. Clin-f-Pain 1996;12(4):316-25.

8. Baron R, Blumberg H, Jänig W. Clinical Characteristics of Patients with Complex Regional Pain syndrome in Germany with Special Emphasis on Vasomotor Function. In: Jänig W, Stanton-Hicks M, eds. Reflex Sympathetic Dystrophy. A Reappraisal. Seattle: IASP Press, 1996: 25.

9. Birklein F, Sittl R, Spitzer A, Claus D, Neundorfer B, Handwerker HO. Sudomotor function in sympathetic reflex dystrophy. Pain 1997;69(1-2):49-54.

10. Gulevich SJ, Conwell TD, Lane J, et al. Stress infrared telethermography is useful in the diagnosis of complex regional pain syndrome, type I (formerly reflex sympathetic dystrophy). Clin J Pain 1997;13(1):50-9.

11. Masson C, Audran M, Pascaretti C, et al. Further vascular, bone and autonomic investigations in algodystrophy. Acta-Orthop-Belg 1998;64(1):77-87.

12. Sandroni P, Low PA, Ferrer T, Opfer Gehrking TL, Willner $\mathrm{CL}$, Wilson PR. Complex regional pain syndrome I (CRPS 1): prospective study and laboratory evaluation. Clin- J-Pain 1998;1 4(4):282-9.

13. Verdugo RJ, Ochoa JL. Abnormal movements in complex regional pain syndrome: assessment of their nature. Muscle Nerve 2000;23(2):198-205.

14. Harden RN, Bruehl S, Galer BS, et al. Complex regional pain syndrome: are the IASP diagnostic criteria valid and sufficiently comprehensive? Pain 1999;83:211-219.

15.APA.American Psychiatric Association: Diagnostic and Statistical Manual of Mental Disorders. Third Edition,
Revised ed. Washington, DC: American Psychiatric Association, 1987.

16. van de Vusse AC, SGM. Stomp-van den Berg, de Vet HC, Weber WEJ. Interobserver reliability of Diagnosis in Patients with Complex Regional Pain Syndrome. Eur J. Pain 7 (2003) 259-265.

17. McCombe PF, Fairbank JC, Cockersole BC, Pynsent PB. 1989 Volvo Award in clinical sciences. Reproducibility of physical signs in low-back pain [see comments]. Spine 1989;14(9):908-18.

18. Boas R. Complex Regional Pain Syndromes: Symptoms, Signs and Differential Diagnosis. In: Jänig W, Stanton-Hicks M, eds. Reflex Sympathetic Dystrophy : a reappraisal. Seattle: IASP press, 1996: 79-92.

19. Galer B, Bruehl S, Harden N. IASP Diagnostic Criteria for Complex Regional Pain Syndrome:A Preliminary Empirical Validation Study. Clin J Pain 1998;14:48-54.

20. McCabe C, Blake D, Skevington S. Correspondence: Cortical origins of pathological pain. Lancet 2000;355:318-319.

21. Homan MM, Franzblau A, Werner RA, Albers JW, Armstrong T], Bromberg MB. Agreement between symptom surveys, physical examination procedures and electrodiagnostic findings for the carpal tunne syndrome. Scandinavian Journal Of Work, Environment And Health 1999;25(2):115-24.

22. Ochoa J, Verdugo R, Campero M. Pathophysiological spectrum of organic and psychogenic disorders in neuropahtic pain patients fitting the description of causalgia or reflex sympathetic dystrophy. In: Gebhart $G$, Hammond $D_{1}$ Jensen T, eds. Proceedings of the 7th World Congress on Pain. Seattle: IASP Press, 1994: 483-494.

23. Gould R, Miller BL, Goldberg MA, Benson DFThe validity of hysterical signs and symptoms. Journal of Nervous And Mental Disease 1986;1 174(10):593-7. 


\section{HLA-DQ1 associated with reflex sympathetic dystrophy}

A.C. van de Vusse, MD*; M.A. Kemler, MD*; E.M. van den Berg-Loonen, PhD;

G.A.M. Barendse, MD; M. van Kleef, PhD; and W.E.J. Weber, PhD

*Both authors contributed equally.

Published in: Neurology (1999) 53: 1350-51 
HLA-DQ1 associated with reflex sympathetic dystrophy

\section{Summary}

Reflex sympathetic dystrophy (RSD) is a relatively common invalidating disorder of unknown pathophysiology. From a cohort of 52 patients, carefully selected to fulfill the recently formulated diagnostic criteria for RSD, venous blood samples were taken for typing of class I and II major histocompatibility antigens. The frequency of HLA-DQI was found to be significantly increased compared with control frequencies. The association provides an indication for an organic basis of RSD. Introduction.

Reflex sympathetic dystrophy (RSD) is a disabling disease of unknown pathophysiology that usually starts following trauma to an extremity. The affected limb is characterized by pain, impaired function and shows signs like oedema, skin colouring changes, hypoesthesia, allodynia, and altered growth of hairs and nails. Genetic factors are likely to be involved. In a rat model of RSD, sensitiveness of rats to develop neuropathic pain has been found inheritable. 1 To test the hypothesis that there is a genetic predisposition to RSD, we investigated the relationship between RSD and the human leucocyte antigen (HLA) system.

\section{Methods.}

Fifty-two unrelated Dutch patients with a definite diagnosis of RSD according to the criteria given by the International Association for the Study of Pain were selected for study. The criteria are listed in Table 1. Serological HLA typing was performed by the standard microcytotoxicity assay for both class 1 and class II major histocompatibility (MHC) antigens 3,4. Class I typing was routinely carried out for 18 A-locus, 33 B-locus and 8 C-locus antigens. Class II typing detected DR1 to DRI6 and DQ1 to DQ4. The results obtained in the patient group were compared to the frequencies in a random control group of 295 unrelated healthy individuals, representative of the Dutch population overall. They were mainly recruited from hospital staff and blooddonors. The presence of a particular HLA type does not depend on age or sex, but is dependent on race. All patients and controls were of Caucasian origin.

\section{Results.}

The frequency of DQ1 was found to be increased from $42 \%$ in the normal population to $69 \%$ among patients with RSD (Bonferroni corrected 2, $p=0.02$ ). All other $M H C$ antigens did not differ significantly from control frequencies (Table 2). 


\section{Discussion.}

Previously, an association between RSD and DR15(2) has been found in a small sample of patients ${ }^{5}$. This association is compatible with our observation since DQ1 is closely linked with DR 15(2). The biological significance of this association is not clear and we do not know whether the association is due to the serologically detectable HLA antigens themselves or whether other genetic factors linked to the MHC region but different from the antigens may be more directly involved in determining the susceptibility to RSD.

The linkage shown by our results between the MHC and RSD suggests an organic basis of this disorder. It is of interest that the neurologic disorders multiple sclerosis and narcolepsy are associated with the same HLA antigens ${ }^{6}$. These HLA antigens possibly relate to factors involved in repair of damaged neural tissue. The demonstrated association should prompt further research to better understand how RSD could be linked to a particular HLA antigen and how this association could be shared with other neurological disorders such as multiple sclerosis and narcolepsy.

\section{Table 1. Diagnostic criteria for reflex sympathetic dystrophy}

1. The presence of an initiating noxious event, or a cause of immobilization.

2. Continuing pain, allodynia, or hyperalgesia with which the pain is disproportionate to any inciting event.

3. Evidence at some time of edema, changes in skin blood flow, or abnormal sudomotor activity in the region of the pain.

4. This diagnosis is excluded by the existence of conditions that would otherwise account for the degree of pain and dysfunction.

Diagnostic criteria for reflex sympathetic dystrophy as stated by the International Association for the Study of Pain.2 Criteria 2 to 4 must be sotisfied. 
HEA-DQ1 associated with reflex sympathetic dystrophy

Table 2. Frequencies of class I and II major histocompatibility antigens of patients with reflex sympathetic dystrophy and controls

\begin{tabular}{|c|c|c|c|c|c|c|c|c|c|}
\hline \multirow[t]{3}{*}{ antigen } & \multirow{2}{*}{\multicolumn{2}{|c|}{$n=52$}} & \multirow{2}{*}{\multicolumn{2}{|c|}{$n=295$}} & \multirow[t]{3}{*}{ antigen } & \multirow{2}{*}{\multicolumn{2}{|c|}{$n=52$}} & \multirow{2}{*}{\multicolumn{2}{|c|}{$n=295$}} \\
\hline & & & & & & & & & \\
\hline & $\mathrm{n}$ & $\%$ & $\mathrm{n}$ & $\%$ & & $n$ & $\%$ & $n$ & $\%$ \\
\hline $\mathrm{Al}$ & 22 & 41 & 85 & 29 & B35 & 9 & 17 & 54 & 18 \\
\hline $\mathrm{A} 2$ & 20 & 39 & 131 & 44 & B37 & 1 & 2 & 13 & 4 \\
\hline$A 3$ & 14 & 26 & 98 & 33 & $B 60(40)$ & 5 & 9 & 33 & 11 \\
\hline $\mathrm{A} 23(9)$ & 2 & 4 & 19 & 6 & B6I (40) & 0 & 0 & 11 & 4 \\
\hline $\mathrm{A} 24(9)$ & 12 & 23 & 51 & 17 & B41 & 0 & 0 & 6 & 2 \\
\hline $\mathrm{A} 25(10)$ & 1 & 2 & 9 & 3 & $B 42$ & 0 & 0 & 0 & 0 \\
\hline A26 (10) & 3 & 6 & 16 & 5 & $B 46$ & 0 & 0 & 1 & 0 \\
\hline A34 (10) & 0 & 0 & 0 & 0 & B47 & 0 & 0 & 2 & 1 \\
\hline A66 (10) & 0 & 0 & 2 & 1 & B48 & 0 & 0 & 0 & 0 \\
\hline A11 & 8 & 15 & 25 & 9 & $\mathrm{~B} 53$ & 0 & 0 & 5 & 2 \\
\hline A29 (19) & 1 & 2 & 21 & 7 & $B 70$ & 0 & 0 & 0 & 0 \\
\hline $\mathrm{A} 30$ (19) & 2 & 4 & 20 & 7 & $B 73$ & 0 & 0 & 0 & 0 \\
\hline A31 (19) & 3 & 6 & 18 & 6 & & & & & \\
\hline $\mathrm{A} 32$ (19) & 3 & 6 & 22 & 8 & $C_{w 1}$ & 2 & 4 & 15 & 5 \\
\hline A33 (19) & 1 & 2 & 4 & 1 & $C w 2$ & 10 & 19 & 44 & 15 \\
\hline A74 (19) & 0 & 0 & 0 & 0 & $C w 3$ & 15 & 29 & 103 & 35 \\
\hline$A 28$ & 5 & 9 & 29 & 10 & Cw4 & 9 & 17 & 82 & 28 \\
\hline \multirow[t]{2}{*}{ A 36} & 0 & 0 & 0 & 0 & Cw5 & 8 & 15 & 40 & 14 \\
\hline & & & & & Cw6 & 6 & 12 & 51 & 17 \\
\hline 851 (5) & 6 & 11 & 34 & 12 & $C_{w 7}$ & 30 & 58 & 153 & 52 \\
\hline B52 (5) & 0 & 0 & 4 & 1 & Cw8 & 2 & 4 & 13 & 4 \\
\hline B7 & 13 & 25 & 62 & 21 & & & & & \\
\hline $\mathrm{B} 8$ & 10 & 19 & 62 & 21 & DR 1 & 8 & 15 & 52 & 18 \\
\hline B44 (12) & 14 & 27 & 62 & 21 & DR15 (2) & 13 & 25 & 38 & 13 \\
\hline$B 45(12)$ & 0 & 0 & 7 & 2 & DR $16(2)$ & 3 & 6 & 4 & 1 \\
\hline B13 & 1 & 2 & 16 & 5 & DR3 & 9 & 17 & 40 & 14 \\
\hline B14 & 3 & 6 & 13 & 4 & DR4 & 17 & 32 & 52 & 18 \\
\hline B62 (15) & 8 & 15 & 36 & 12 & DRII (5) & 6 & 11 & 40 & 14 \\
\hline B63 (15) & 1 & 2 & 6 & 2 & DR12 (5) & 2 & 4 & 10 & 3 \\
\hline B75 (15) & 0 & 0 & 1 & 0 & DRI3 (6) & 11 & 20 & 50 & 17 \\
\hline B38 (16) & 3 & 6 & 11 & 4 & DR14 (6) & 4 & 7 & 15 & 5 \\
\hline B39 (16) & 5 & 9 & 14 & 5 & DR7 & 14 & 26 & 43 & 15 \\
\hline B57 (17) & 5 & 9 & 14 & 5 & DR8 & 8 & 15 & 17 & 6 \\
\hline B58 (17) & 0 & 0 & 3 & 1 & DR9 & 1 & 2 & 4 & 1 \\
\hline B18 & 6 & 11 & 26 & 9 & DR 10 & 2 & 4 & 8 & 3 \\
\hline B49 (21) & 2 & 4 & 10 & 3 & & & & & \\
\hline $\mathrm{B} 50(21)$ & 0 & 0 & 5 & 2 & DQ1 & 36 & 69 & 124 & 42 \\
\hline B55 (22) & 3 & 6 & 14 & 5 & DQ2 & 15 & 29 & 69 & 23 \\
\hline $\mathrm{B} 56(22)$ & 0 & 0 & 7 & 2 & $\mathrm{DQ}^{3}$ & 30 & 58 & 106 & 36 \\
\hline $\mathrm{B} 27$ & 6 & 11 & 17 & 6 & DQ4 & 7 & 13 & 11 & 4 \\
\hline
\end{tabular}

Data given as numbers of patients and percentages. Only DQl frequencies of RSD patients and controls differed statistically significant at the Bonferroni corrected $p<0.05$ level. 


\section{References}

1. Devor M, Rabor P. Heritability of symptoms in an experimental model of neuropathic pain. Pain 1990;42:5167.

2. Merskey $H$, Bogduk N. Classification of chronic pain Descriptions of chronic pain syndromes and definitions of pain terms. 2 ed. Seattle: IASP Press, 1994.

3. Terasaki PI, McClelland JD. Microdroplet assay of human serum cytotoxins. Nature 1964;204:998-1000.

4. van Rood JJ, van Leeuwen A, J.S. P. Simultaneous detection of two cell populations by two colour fluorescence and application to the recognition of $B$-cell determinants. Nature 1976;262:795-797.

5. Mailis A, Wade J. Profile of Caucasian women with possible genetic predisposition to reflex sympathetic dystrophy: a pilot study. Clin J Pain 1994;10(3):210-7.

6. Tiwari JL, Terasaki Pl. HLA and disease associations. New York: Springer Verlag, 1985 
Screening of patients with complex regional pain syndrome type I for antecedent infections 


\section{Screening of Patients with Complex}

\section{Regional Pain Syndrome type I for}

\section{Antecedent Infections}

Anton C. van de Vusse M.D., Valère J. Goossens M.D. ,

Marius A. Kemler M.D., Wilhelm E.J.Weber Ph.D .

Published in: Clinical Journal of Pain (2001) 17:110-114 
Screening of patients with complex regional pain syndrome type I for antecedent infections

\section{Summary}

This study was designed to investigate whether Complex Regional pain syndrome type I (CRPS I) could be linked to any previous infection.

Fifty-two patients with CRPS I of one extremity were screened for the presence of antibodies against mostly neurotropic microorganisms.

Of these 52 patients none had antibodies against Treponema pallidum, Borrelia burgdorferi or HTLV-1.

Only four patients were positive for Campylobacter jejuni. For cytomegalovirus, Epstein-Barr virus, herpes simplex virus and Toxoplasma gondii, seroprevalences were similar to control values. The total seroprevalence of parvovirus B19 was $77 \%$, which was significantly higher than in an independent Dutch population group (59\%). Seroprevalence in lower extremity CRPS I $(94 \%)$ was significantly higher than in upper extremity CRPS I patients (68\%). In this study all patients were seropositive for varicella zoster virus (VZV) antibodies, but a high prevalence of $\mathrm{VZV}$ antibodies is similar to its prevalence in a normal population (>90\%).

In this study we found a significantly higher seroprevalence of Parvovirus B19 in CRPS I and this is most striking in lower extremity CRPS I patients. Further serologic research in other geographic areas is needed to provide additional information about a potential role of Parvovirus B19 or other microorganisms in the etiopathogenesis of CRPS I.

\section{Introduction}

Complex regional pain syndrome type I (CRPS I) is a seriously disabling neuropathic pain syndrome. Its etiopathogenesis remains an enigma. 'Antecedent infections have been implicated in its pathogenesis, because some of its key features (e.g., edema, pain, vasomotor abnormalities) point to an ongoing inflammatory process. ${ }^{2,3}$ Also, its association with human leucocyte antigen DQ1 suggests an involvement of the immunological system ${ }^{4}$. In other neurological disorders of unknown origin progress has been made as to the role of infections like in Bell's palsy ${ }^{5,6}$, multiple sclerosis ${ }^{7-9}$, and Alzheimer's dementia ${ }^{10}$. The role of Campylobacter jejuni, cytomegalovirus (CMV) and Epstein-Barr virus (EBV) in the onset of certain forms of Guillain-Barrè syndrome is a recent example of research along these lines. 11,12

Antecedent infections may have predisposed patients in such a way that a minor trauma resulted in CRPS I. A systematic analysis of the serologic status of CRPS I patients as to antecedent infections has to our knowledge not been carried out.We report herein a systemic serological screening for 10 different microbiological organisms, of 52 strictly diagnosed CRPS I patients.

\section{Patients and results}

\section{Sample and data collection}

All medical specialists known to treat patients with CRPS I (such as anesthesiologists, surgeons, and neurologists) working in the south of The Netherlands were asked to refer patients fulfilling the standardized diagnostic algorithm (table 1) to the Maastricht University Hospital.The algorithm closely resembles the criteria for Chronic Regional Pain Syndrome type 1 as stated by the International Association for the Study of Pain (IASP). ${ }^{13}$ The final decision whether patients could enroll the study 
was based on rechecking the diagnostic criteria. A physical examination was conducted by two physicians separately, as well as a psychological test (SCL-90). ${ }^{14}$ Patients with CRPS I $(n=52)$ were asked to supply venous blood for further research. The patients, mostly sent by other centers, suffered from chronic CRPS I in one extremity in which no therapeutic modality had yielded resolution of the symptoms. The diagnosis was made by two physicians separately ${ }^{13}$. In addition patientts were selected who had suffered from CRPS I for at least 6 months, during which period the symptoms had been unresponsive to all conventional treatments, such as nonsteroidal antiinflammatory drugs, opoids, antidepressants, anticonvulsants, sympathetic blocks, transcutaneous electric nerve stimulation, and physical theraPy. Pain, as measured on a $10 \mathrm{~cm}$ Visual Analogue Score had to be at least $5 \mathrm{~cm}{ }^{15}$.

Patients with other conditions affecting function were not included in the study. Informed consent was obtained from all patients according to the Declaration of Helsinki. The study protocol had been approved by the Ethical Committee of our institution.

Eventually, 54 patients were considered eligible for the study and 56 were excluded, 40 were not eligible and 16 refused to participate. No blood was drawn from two of the patients included in the study. The reason for this is not known. All 52 remaining patients were white, Dutch-speaking adults (18-65 years of age) suffering from severe CRPS I affecting either one arm $(n=34)$ or one leg $(n=18)$. Possibly involved pathogens were identified by a Medline search from 1966 - 1997 (keywords: serological, virus, infection, serology and dystrophy; neurotropic and infection or virus), based upon the hypothesis that neurotropic microorganisms could play a role in the etiopathogenesis of CRPS I.Ten $\mathrm{ml}$ of serum was frozen and stored at a temperature of $-20 \mathrm{C}$. Serological status was measured according to standard laboratory procedures of our microbiology department. Detection of $\lg G$-antibodies was done with microimmunofluorescence for herpes simplex virus (HSV), varicella zoster virus (VZV) and EBV-virus capsid antigen (each distributed by Gull, 's Hertogenbosch, The Netherlands). Screening was done with dilution 1:10. Quantification was done with dilutions $1: 100,200,400,800$ and 1600. For antiParvovirus B19 IgG antibodies a qualitative immunofluorescent assay (Biotrin, Dublin, Ireland) with dilution 1:64 was done. Campylobacter serology was done with complement fixation and with ELISA methodology (both from Virion, W, rzburg, Germany). Anti-CMV and Toxoplasma gonḍii IgG antibodies were quantitatively measured by Axsym (Abbott, Hoofddorp, The Netherlands).TPHA for Treponema pallidum and anti-human T-lymphocyte virus -1 (HTLV-1) antibodies were investigated by agglutination (Fujirebio, Tokyo, Japan) and anti -Borrelia burgdorferi IgG antibodies with ELISA (IDEIA Dako, Cambridgeshire, United Kingdom).

Statistical analysis on CRPS I extremity subgroup seroprevalences was performed using either a twotailed Chi square or a Fisher's Exact Test (SPSS, $p<0.05$ ).

\section{Results}

Fifty-two patients ( 37 females and 15 men) participated, with a mean age of 38.9 years (21-65 yrs) and a mean CRPS I duration of 37.7 months (9-120 months). Thirty-four had CRPS I of their arm and 18 had CRPS I of their leg. The CRPS I was precipitated by trauma in 25 patients, by surgery in 23 patients and had started spontaneously in the last four patients. All patients suffered severe pain and functional impairment, which made them unfit for work. Of 34 patients with an affected hand, 20 were unable to use their hand for any daily activity; 13 were using a splint. Of 18 patients with an affected foot, 7 were wheelchair-dependent and 8 were using crutches. 
Screening of patients with complex regional pain syndrome type I for antecedent infections

All patients were seropositive for VZV and 50 patients (96\%) were seropositive for EBV. For parvovirus $B 19$ and for HSV the prevalence of antibodies in this group of patients was $77 \%$ and $73 \%$ respectively. $A$ lower prevalence was found for CMV (40\%), T. gondii (23\%) and C. jejuni (8\%). All patients were negative for T. pallidum, B. burgdorferi and HTLV-1 antibodies. Data are given in table 2 and 3.

For levels of detectable antibodies, the median immunofluorescence titer was 100 (range 10-800) for VZV, 200 (range 10-1600) for HSV and 400 (range 100-1600) for EBV. For VZV, HSV and EBV respectively 21, 18 and 15 patients had an above-median titer.The median results for CMV and Toxoplasma were $>250 \mathrm{IU} / \mathrm{ml}$ and $23 \mathrm{lU} / \mathrm{ml}$, respectively.Prevalence of Parvovirus $\mathrm{B} 19$ infection in lower extremity CRPS is $94 \%$ and higher than expected. The prevalence is significantly more than the $68 \%$ seroprevalence of B19 parvovirus in patients with upper extremity CRPS I $(p=0.04)$. The total seroprevalence in our CRPS population is $77 \%$. This is partially due to the high prevalence in lower extremity CRPS, significantly higher than the $59 \%$ seroprevalence of Parvovirus B19 in a Dutch population group $(n=353, P$ $=0.01)^{16}$

\section{Discussion}

CRPS 1 is a seriously disabling neuropathic pain syndrome of unknown pathophysiology. Although (neurogenic) inflammation has been hypothesized to play a role in the pathogenesis of the disorder 17,18 , a systemic search for a microbiological infection as a possible causative mechanism has, to our knowledge, not been performed. In the past, studies along these lines have probably been hampered by lack of diagnostic criteria and budgetary restrictions. We report a systematic serologic analysis of 52 carefully diagnosed CRPS I patients. Our ratio of lower versus upper extremity CRPS I patients (18:34) is comparable to the normal ratio of 1:2. ${ }^{19-21}$ There is an extensive list both of possible neurotropic infections in the Western World (northwestern Europe) and of pathogens ever associated with CRPS I or neurologic diseases. Most of these infections are longlasting or latent infections, often present since childhood. Also, in our study group the duration of the CRPS I had been so long that the IgM antibodieswere not expected anymore. For both these reasons, only lgG serology was done. For epidemiological reasons, we did not screen for pathogens as rabies, JC virus, poliovirus, mumps and HIV. Ethical reasons also kept us from screening for HIV.

No association was found between CRPS I and T. pallidum, B. burgdorferi or HTLV-1 since all patients were seronegative. In contrast, lgG antibodies against VZV (100\%) and EBV (96\%) were present in almost all patients. However, this high seroprevalence is not significantly different from the high seroprevalence $(>90 \%$ ) worldwide 22,23 or from a seroprevalence of about $75 \%$ in an independent Dutch control group ${ }^{16}$. Because of this high seroprevalence, much larger studies or studies in other geographic areas would have to be done to prove or even exclude an eventual correlation between CRPS I and VZV or EBV. The seroprevalence of HSV in the CRPS I patients was $73 \%$, which is almost the same as the seroprevalence of $68 \%$ in the Dutch control group. ${ }^{16}$ The percentages are also comparable with a seroprevalence of $30-50 \%$ in higher socioeconomic groups and increased prevalence to $80-100 \%$ in lower socioeconomical groups. ${ }^{23}$ in female CRPS I patients, the seroprevalence of EBV, HSV and parvovirus B19 was $9-14 \%$ higher than in male patients. For CMV and for Toxoplasma gondii the seroprevalence was higher in men. These differences are not statistically significant, possibly because of the low number of patients.

The worldwide seroprevalence of antibodies against CMV ranges from 40 to 100 percent depending on 
the socioeconomic composition of the population. ${ }^{23}$ The prevalence of $40 \%$ found in our CRPS I patients is lower than a prevalence of $51 \%$ found in the Dutch control group. ${ }^{16}$ Although in our study only 21 (40\%) CRPS I patients were positive for specific anti-CMV antibodies, the titer distribution was skewed by high anti-CMV antibody titers. Thirteen patients had a level of more than $250 \mathrm{IU} / \mathrm{ml}$ and six patients had a level between 120 and $250 \mathrm{lU} / \mathrm{ml}$. Only two young women (age 27 and 29 years) had levels of 16 and $59 \mathrm{lU} / \mathrm{ml}$. The high anti-CMV antibody levels in CRPS I patients probably does not indicate an etiological role. It is more likely that these high antibody levels are a reflection of a potential reactivation of a latent CMV infection during acute or chronic clinical CRPS I.

The worldwide variation in prevalence of anti-T. gondii antibodies ranges from only 3 to more than $90 \%$ of healthy adults depending of the selected population. ${ }^{23}$ Again, the seroprevalence of $23 \%$ for anti-T. gondii antibodies in our CRPS I patients is comparable to a prevalence of $22 \%$ found in all patients investigated in our hospital in 1997 (unpublished data). Also, the level of antibodies was in accordance with the normal distribution mentioned in unpublished data from Abbott, Hoofddorp, The Netherlands.

Only four patients had detectable antibodies against $C$. jejuni. However, in two patients this was accompanied with a high titer (128) of complement binding antibodies, suggesting a recent infection in patients with an already pre-existing CRPS I. This means that at the onset of CRPS I probably only two patients were seropositive for anti-C. jejuni antibodies.

The seroprevalence of parvovirus $B 19$, in our patient population of $77 \%$ is higher than the $30 \%-60 \%$ mentioned in literature $22-24$ and the $59 \%$ found in patients from the Dutch control group. ${ }^{16}$ Strikingly, we found in patients with lower extremity involvement (table 3 ) that the seroprevalence for parvovirus B19 is more than $94 \%$. This is significantly more $(p=0.039)$ than the $68 \%$ seroprevalence of $B 19$ parvovirus in patients with upper extremity CRPS I. In the lower extremity CRPS I group there is a predominance of women. Women have a slightly higher seroprevalence of anti- parvovirus B19 antibodies than men. 25 However, this female overrepresentation does not completely explain this difference, because similarly higher seroprevalences for EBV and HSV in women did not result in significant differences between upper and lower extremity subgroups.

The most common manifestation of Parvovirus B19 is an erythema infectiosum, also known as fifth disease, with a mild febrile illness and a maculopapular rash ("slapped cheek"appearance) of variable intensity. Besides the erythema, prodromal symptoms and influenza-like illness are also possible, as are arthropathy, transient aplastic crisis, and pregnancy complicated by hydrops fetalis or fetal death. There is evidence that Parvovirus B19 infection induces the production of autoantibodies. ${ }^{26,27}$ It may be associated with rheumatoid arthritis 28 and transient systemic lupus erythematosus-like symptoms. ${ }^{29}$

Central nervous system involvement is a rare but well-documented complication of Parvovirus B19 infection in children and adults. Parvovirus $B 19$ has been associated with encephalitis 30 , encephalopathy ${ }^{31-33}$, aseptic meningitis 34,35 , ocular neuropathy ${ }^{36}$, and fetal brain infection. ${ }^{37}$ In addition, brachial plexus neuropathy $32,38-40$, recurrent paresthesias ${ }^{41}$, and numbness and tingling of fingers 42 are associated with Parvovirus B19 infection.

A possible role of Parvovirus B19 in the etiopathogenesis of CRPS I is also suggested by a case report. ${ }^{28}$ The prevalence of symptoms in Parvovirus infection is unknown. Parvovirus infection can manifest in subclinical infection or clinical arthralgia. Because many CRPS I patients report diffuse pain without sympathetic dysregulation before CRPS onset, Parvovirus might be a direct precursor of CRPS 
Screening of patients with complex regional pain syndrome type I for antecedent infections

I. A prospective study for antecendent arthralgias in CRPS I would be interesting. A subclinical Parvovirus infection may well precede CRPS by a period of several months or even years, because auto-immunological mechanisms through tissue mimicry can manifest slowly.

\section{Conclusion}

In this study we did not find a clear association between CRPS I and any of the investigated microorganisms. For parvovirus B19 we found a significantly higher seroprevalence in CRPS I and this is most striking in lower extremity CRPS I patients. Because of high seroprevalences of VZV, EBV and HSV in CRPS I patients as well as in a control group, an association between herpesviridae and CRPS I could not be excluded. CMV has probably no etiological role in CRPS I, but reactivation of a foregoing latent CMV infection during CRPS I is possible. Low seroprevalences were found for T. gondii and $C$. jejuni. No antibodies were found against T. Pallidum, B. burgdorferi and HTLV-1. Further serological research in other geographic areas will have to give additional information about a potential role of parvovirus B19 or other microorganisms in the etiopathogenesis of CRPS I. 
Table 1. CRPS I criteria for study inclusion

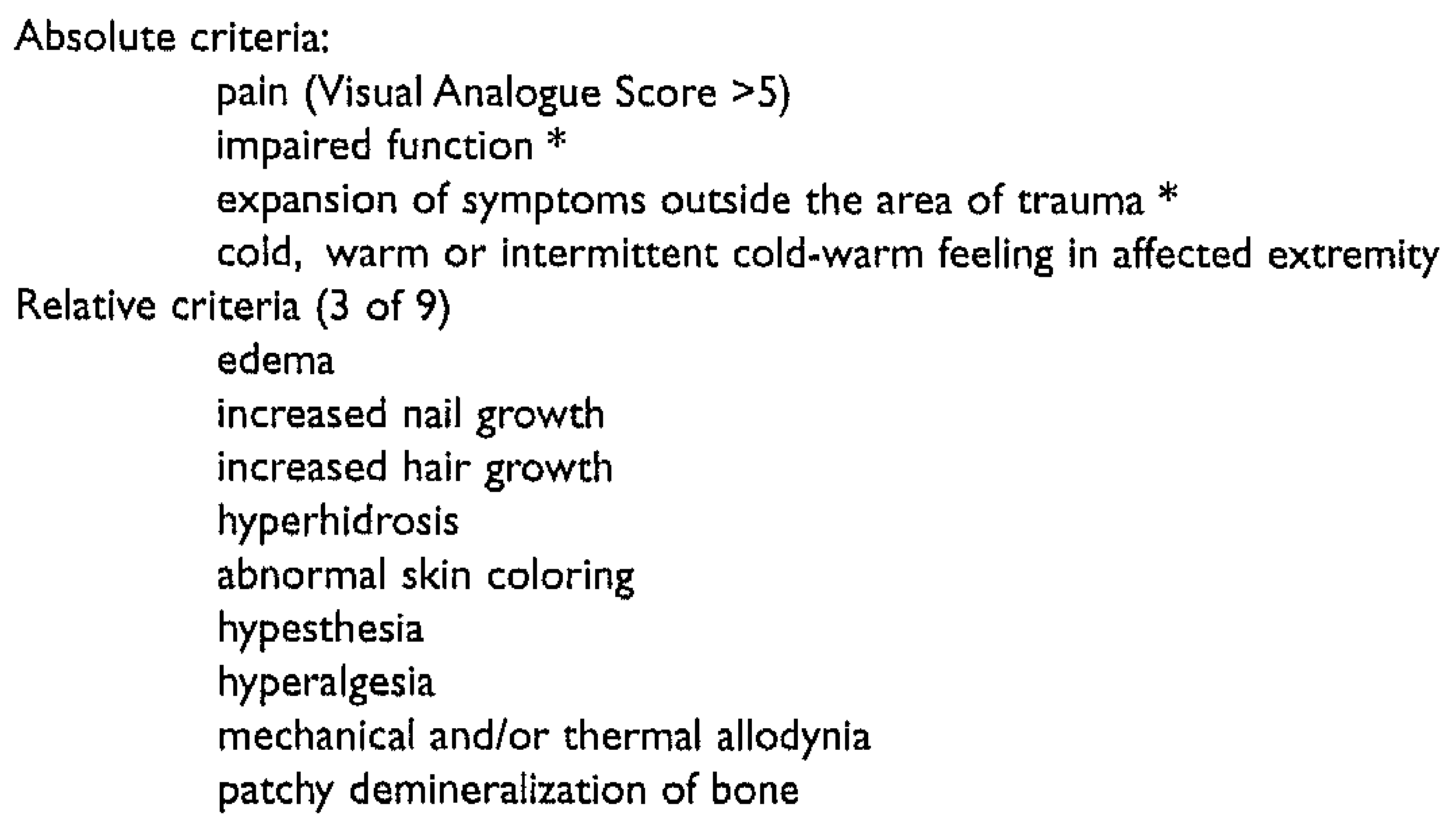

* Indicates those additional to those of the International Association for the Study of Pain

Table 2. Qualitative and quantitative serologic screening in Reflex Sympathetic Dystrophy

\begin{tabular}{lllllllll}
\hline Age, y & $\begin{array}{l}\text { No. of } \\
\text { patients }\end{array}$ & CJ & $\begin{array}{l}\text { Toxo } \\
\text {-plasma (\%) }\end{array}$ & CMV (\%) & HSV (\%) & P-B19 (\%) & EBV (\%) & VZV \\
$20-30$ & 11 & 1 & 0 & $4(36 \%)$ & $7(64 \%)$ & $9(82 \%)$ & 9 & 11 \\
$30-40$ & 18 & 0 & $2(11 \%)$ & $7(39 \%)$ & $13(72 \%)$ & $14(78 \%)$ & 18 & 18 \\
$40-50$ & 12 & 1 & $5(42 \%)$ & $4(33 \%)$ & $8(67 \%)$ & $10(83 \%)$ & 12 & 12 \\
$>50$ & 11 & 2 & $5(45 \%)$ & $6(55 \%)$ & $10(91 \%)$ & $7(64 \%)$ & 11 & 11 \\
$\begin{array}{l}\text { Total,\% } \\
\text { Median }\end{array}$ & 52 & 4 & $12(23 \%)$ & $21(40 \%)$ & $38(73 \%)$ & $40(77 \%)$ & $50(96 \%)$ & $52(100 \%)$ \\
titer & - & - & 23 & $>250$ & 200 & - & 400 & 100 \\
Range & & & $14-88$ & $16->250$ & $10-1600$ & & $100-1600$ & $10-800$ \\
\hline
\end{tabular}

C], Campylobacter jejuni; CMV, cytomegalovirus; HSV, herpes simplex virus; P-B19, parvovirus B19; EBV, Epstein-Barr virus 
Screening of patients with complex regional pain syndrome type I for antecedent infections

Table 3. Percentage of seroprevalence in CRPS I subgroups

\begin{tabular}{|c|c|c|c|c|c|c|c|}
\hline & $\begin{array}{l}\text { no.of } \\
\text { patients }\end{array}$ & Toxopl. & CMV & HSV & P-B19 & EBV & VZV \\
\hline women (\%) & 37 & 3 & $\begin{array}{l}6 \\
(16 \%)\end{array}$ & $\begin{array}{l}28 \\
(76 \%)\end{array}$ & $\begin{array}{l}30 \\
(81 \%)\end{array}$ & $\begin{array}{l}37 \\
(100 \%)\end{array}$ & $\begin{array}{l}37 \\
(100 \%)\end{array}$ \\
\hline $\operatorname{men}(\%)$ & 15 & 1 & $\begin{array}{l}6 \\
(40 \%)\end{array}$ & $\begin{array}{l}10 \\
(67 \%)\end{array}$ & $\begin{array}{l}10 \\
(67 \%)\end{array}$ & $\begin{array}{l}13 \\
(87 \%)\end{array}$ & $\begin{array}{l}15 \\
(100 \%)\end{array}$ \\
\hline lower extremity (\%) & 18 & $\begin{array}{l}3 \\
(17 \%)\end{array}$ & $\begin{array}{l}12 \\
(50 \%)\end{array}$ & $\begin{array}{l}14 \\
(78 \%)\end{array}$ & $\begin{array}{l}17 \\
(94 \%)^{*}\end{array}$ & $\begin{array}{l}18 \\
(100 \%)\end{array}$ & $\begin{array}{l}18 \\
(100 \%)\end{array}$ \\
\hline upper extremity (\%) & 34 & $\begin{array}{l}9 \\
(28 \%)\end{array}$ & $\begin{array}{l}12 \\
(35 \%)\end{array}$ & $\begin{array}{l}24 \\
(71 \%)\end{array}$ & $\begin{array}{l}23 \\
(68 \%)^{*}\end{array}$ & $\begin{array}{l}32 \\
(94 \%)\end{array}$ & $\begin{array}{l}34 \\
(100 \%)\end{array}$ \\
\hline
\end{tabular}

*Significance : $p<0.04$ (two-tailed Fisher's Exact Test) 


\section{References}

1. Jänig W. The Puzzle of "Reflex Sympathetic Dystrophy": Mechanisms, Hypotheses, Open Questions. In: Jänig W, Stanton-Hicks M, eds. Reflex Sympathetic Dystrophy. A Reappraisal. Seattle: IASP Press, 1996: 1-24.

2. Neumann RA, Aberer E, Stanek G. Evidence for spirochetal origin of Südeck's atrophy (algodystrophy, reflex sympathetic dystrophy). Arch Orthop Trauma Surg 1989;108(5):314- 6 .

3. Gila L, Guerrero A, Astarloa R, Marti P, Gutierrez JM. [Reflex sympathetic dystrophy. A new manifestation of Lyme disease?]. Enferm-Infecc-Microbiol-Clin $1990 ; 8(1): 32-5$

4. Kemler MA, van de Vusse AC, van den Berg-Loonen EM, Barendse GAM, van Kleef M, Weber WE]. HLADQ1 associated with reflex sympathetic dystrophy. Neurology 1999;53:1350- 1351.

5. Imarhiagbe D, Prodinger WM, Schmutzhard E. [Infective pathogens as a possible etiology of idiopathic peripheral facial paralysis]. Wien Klin Wochensch 1993;105(21):611-3.

6. Gianoli G], Kartush JM. Delayed facial palsy after acoustic neuroma resection: the role of viral reactivation. Am J Otol 1996;17(4):625-9.

7. Dekaban GA, Hudson AJ, Rice GP. Absence of HTLV-I and HTLV-II proviral genome in the brains of patients with multiple sclerosis and amyotrophic lateral sclerosis. Can-f-Neurol-Sci 1992;19(4):458-61.

8. Andersen O, Lygner PE, Bergstrom T, Andersson $M$, Vahlne A.Viral infections trigger multiple sclerosis relapses: a prospective seroepidemiological study. J Neurol 1993;240(7):417-22.

9. Berti R, Soldan S, Sechiero P, et al. Association of HHV-6 and multiple sclerosis. 2nd symposium on the neurovirology and neuroimunnology of schizophrenia and bipolar disorder 1996, Bethesda, Maryland.

10. Ball MJ, Kaye JA, Steiner I. Neocortical temporal lobe sclerosis masquerading as Alzheimer dementia: does herpes virus encephalopathy protect against Alzheimer's disease? Clin Neuropathol 1997;16(1):112.

11. Mishu B, Blaser MI. Role of infection due to Campylobacter jejuni in the initiation of GuillainBarre syndrome. Clin-Infect-Dis 1993;1 7(1):104-8.

12. Jacobs B, Rothbarth P, Van der Meché F, et al. The spectrum of antecedent infections in Guillain-Barré syndrome: a case-control study. Neurology 1998;51:1110-1115.

13. Merskey H, Bogduk N. Classification of chronic pain Descriptions of chronic pain syndromes and definitions of pain terms. 2 ed. Seattle: IASP Press, 1994.

14. Derogatis L, Lipman R, Covi L. An ourpatient rating scale-preliminary report. Psychopharmacological Bull 1973;9:13-28.

15. Collins SL, Moore RA, McQuay HJ. The visual analogue pain intensity scale: what is moderate pain in millimetres? Poin 1997;72(1-2):95-7.

16. Doornum v. GTT. [Annual reports Regional Laboratory for Community Health GG \& GD]. Amsterdam: Streeklaboratorium voor de Volksgezondheid. GG \& GD, 1995/1996/1997.

17. Veldman PH, Reynen HM, Arntz IE, Goris RJ. Signs and symptoms of reflex sympathetic dystrophy: prospective study of 829 patients. Lancet 1993;342(8878):1012-6

18. van der Laan L, Goris R]. [Sudeck's syndrome. Was Sudeck right?]. Unfallchirurg 1997;100(2):90-9.

19. Goris R], Reynen JA, Veldman P. [The clinical symptoms in post-traumatic dystrophy]. Ned Tijdschr Geneesk 1990;134:2138-2141.

20. Baron R, Blumberg $H$, Jänig W. Clinical Characteristics of Patients with Complex Regional Pain syndrome in Germany with Special Emphasis on Vasomotor Function. In: Jänig W, Stanton-Hicks $M$, eds. Reflex Sympathetic Dystrophy. A Reappraisal. Seattle: IASP Press, 1996: 25.

21. Veldman PHJM, Goris RJA. Multiple Reflex Sympathetic Dystrophy: Which Patients are at Risk for Developing a Recurrence of Reflex Sympathetic Dystrophy in the Same or Another Limb. Pain 1996;64:463-6.

22. Topley, Wilson. Principles of Bacteriology, Virology and Immunity. 8 ed. London: Hodder \& Stoughton, 1990.

23. Mandell GL, Douglas RG, Bennett JH. Principles and Practise of Infectious Diseases. 4 ed. NYC , New York: Churchill livingstone, 1995.

24. Gessel v. PH, Wildschut HIJ, Cohen-Overbeek TE, Vermeij-Keers C. Parvovirus-B19-infectie in de zwangerschap: een oorzaak van non-immune hydrops foetalis. Ned T $\vee$ G 1999;143(1):3-7.

25. Weiland HT. Parvoviridae. In: Wilterdink J, ed. Medische virologie. Houten: Bohn Stafleu Van Loghum, 1992: 98.

26. Kerr JR, Boyd N. Autoantibodies following parvovirus B19 infection.J Infect 1996;32(1):41- 47.

27. Lunardi $C, T$ iso $M$, Borgato $L$, et al. Chronic parvovirus $B 19$ infection induces the production of antivirus antibodies with autoantigen binding properties. Eur J Immunol 1998;28(3):936- 48.

28. Golstein MA, Semaille P, Steinfeld $S$. Rheumatic manifestations due to human parvovirus B19.A report of four cases. Rev Rheum Engl Ed 1996;63(11):854-8

29. Tanaka A, A S, Sawai K, Kuwahara T. Human parvovirus $B 19$ infection resembling systemic lupus erythe- 
Screening of patients with complex regional pain syndrome type I for antecedent infections

matosus. Intern Med 1998;37(8):708-710.

30. Balfour $H$, Schiff $G$, Bloom ]. Encephalitis associated with erythema infectiosum. J Pediatr 1970;77:133. 136.

31. Hall C, Horner F. Encephalopathy with erythema infectiosum. Am J Dis Child 1977;1 31:65-7.

32. Walsh K, Armstrong R, Turner A. Brachial plexus neuropathy associated with human parvovirus infection. Br Med / 1988;296:896.

33. Umene K, Nunoue T.A new genome type of human paryovirus $B 19$ preent in sera of patients with encephalopathy. J Gen Virol 1995;76:2645-51.

34. Cassinotti P, Schultze D, Schlageter P, Siegl G. Persistent human parvovirus B19 infection following an acute infection with meningitis in an immunocompentent patient. Eur ] Clin Microbiol infect Dis 1993;12:701-4

35. Okumara $A$, Ichikawa T. Aseptic meningitis caused by human parvovirus B19. Arch Dis Child 1993;68:7845.

36. Coorridan P, Laws D, AJ M, Murray P.Tonic pupils and human parvovirus (B19) infection. J Clin NeuroOphtalmol 1991;11:109-10.

37. Isumi H, Nunoue T, Nishida A, Takashima S. Fetal brain infection with human parvovirus $B 19$. Pediatr Neurol 1999;21:661-3.

38. Denning D, Amos A, Rudge P, Cohen B. Neuralgic amyotrophy due to parvovirus infection.J Neurol Neurosurg Psychiatry 1987;50:641 -2.

39. Pellas F, Olivares ], Zandotti C, Delarque A. Neuralgic amyotrophy after parvovirus B19 infection. Lancet 1993;342:503-4.

40. Puechal X, Hillequin P, Kahan A, Menkes C. Neuralgic amyotrophy and poliarthritis caused by parvovirus infection. Ann Rheum Dis 1998;57:262.

41. Faden H, Gary G, Andersen L. Chronic parvovirus infection in a presumably healthy woman. Clin Infect Dis 1992;15:595-7.

42. Faden $H$, Gary W, Korman M. Numbness and tingling of fingers associated with parvovirus B19 infection. Clin Infect Dis 1990;161:354-5. 


\section{Randomised controlled trial of gabapentin in Complex Regional Pain Syndrome type 1}

Anton. C. van de Vusse, M.D., Suzanne. G. M. Stomp-van den Berg, *Alfons H.F. Kessels, M.D., and Wilhem E.J.Weber, M.D., Ph.D.

Submitted for publication 
Randomised controlled trial of gabapentin in Complex Regional Pain Syndrome type 1

\section{Article abstract}

To study the efficacy of the anticonvulsant gabapentin as treatment for pain in patients with complex regional pain syndrome type 1 (CRPS1).

We did a randomized double blind placebo controlled crossover study with two three-weeks treatment periods with gabapentin and placebo separated by a two-weeks washout period. Patients started at random with gabapentin or placebo, which was administered in identical capsules three times daily. We included 58 patients with CRPS type 1.

Patients reported significant pain relief in favor of gabapentin in the first period. Therapy effect in the second period was less; finally resulting in no significant effect combining results of both periods. The CRPS patients had sensory deficits at baseline. We found that this sensory deficit was significantly reversed in gabapentin users in comparison to placebo users.

Gabapentin had a mild effect on pain in CRPS I. It significantly reduced the sensory

deficit in the affected limb.A subpopulation of CRPS patients may benefit from gabapentin.

\section{INTRODUCTION}

Complex Regional Pain Syndrome type one (CRPS I) or formerly Reflex Sympathetic Dystrophy (RSD) is a disabling syndrome, in which a painful limb is accompanied by varying symptoms like edema, hyperhidrosis, hypertrichosis, allodynia, coloring of the skin and, over time, atrophy of the involved tissue. Spontaneous recovery does occur and several therapies have been described, but for some patients CRPS I is a chronic disabling disease.' Neuropathic pain is a prominent feature of CRPS I, occurring in $75 \%$ of cases, and many researchers go as far as classifying CRPS I as a neuropathic pain syndrome. ${ }^{2-6}$ Gabapentin (Neurontin ${ }^{\circledR}$, Pfizer) is an anticonvulsant with a proven analgesic effect in various neuropathic pain syndromes. ${ }^{7-15}$ Anecdotal reports suggest that gabapentin may also be an effective analgesic in CRPS patients. 3,8,16-27 To study this hypothesis, we conducted a double blind, placebo-controlled crossover trial of gabapentin in 58 patients with Complex Regional Pain Syndrome type 1.

\section{METHODS}

\section{Study population}

This study complied with the Declaration of Helsinki regarding investigations in humans after approval of the protocol by the Institutional Review Board of University Hospital Maastricht, the Netherlands. Patients were recruited from a database with patients who, in recent years, had been diagnosed with complex regional pain syndrome type $l$ in our hospital. All patients had been treated in our pain management and research center (dept. of Anesthesiology, University Hospital Maastricht, The Netherlands) and had received treatments like sympathetic blocks, ${ }^{28}$ mannitol infusions, ${ }^{29,30}$ transcutaneous neuromodulation. All participating patients fulfilled the IASP criteria ${ }^{32}$ for the diagnosis of CRPS type I and were included when aged between 18 - 75 years old and when they had a visual analog score (VAS) for pain > 3. Apart from IASP criteria, all patients had functional loss and pain outside the original traumati- 
zed area. Patients were excluded in case of a posstbility of health risk or confounding by other diseases of syndromes, like e.g. pregnancy, known kidney andior severe liver disease, another (2nd) chronic pain syndrome, known nerve damage in the affected area, active infection or diabetes mellitus. Patients were participating in 8-week periods from 19-11-1998 until 2-12-1999. Gabapentin was not registered as a drug in the Netherlands before or during the trial. After the trial the producing pharmaceutical company supplied gabapentin for compassionate use if indicated.

\section{Treatment}

Since our patient population consisted of chronic CRPS I patients with a multiple years' duration of pain complaints refractory to various treatments, we assumed that their pain complaints would be more or less stable. We therefore tundertook a double blind, randomized crossover study. Randomization of patients took place after baseline measurements and written informed consent. The assignment scheme was generated by our hospital pharmacy from a table of random numbers. The closed envelopes containing the assignments were prenumbered and kept at the pharmacy. The first treatment group received gabapentin. followed by a washout period and placebo treatment. The second treatment group received placebo treatment, which was followed by a washout period and gabapentin treatment. Each medication period lasted three weeks separated by the two-weeks washout period.

Medication was stocked and delivered to the patient at the hospital pharmacy. Both the gabapentin capsules and the identical placebo capsules were delivered immediately before the start of the two medication periods. Left over medication was recollected and counted.

The gabapentin (GBP) dose was slowly increased to reduce adverse side effects:

600 mg's GBP AN once a day on day $1-2$

600 mg's GBP b.i.d. on day 3-4

$600 \mathrm{mg}$ 's GBP t.i.d on day 5-21

Placebo dose was identically titrated. Patients were allowed to take their usual analgesics and were told preferably not to change the usual dose.

\section{Follow-up measurements}

The patients were reevaluated at the hospital three weeks (T1), five weeks (T2) and eight weeks (T3) after randomization. During the trial, the patient noted her/his pain rate of the past $24 \mathrm{hr}$ (VAS) and the use of additional analgesics in a diary. During each hospital visit the following assessments were done:

Global perceived effect (GPE) on pain indicating: worst ever; much worse; somewhat worse; not improved/not worse; somewhat improved; much improved and best ever.

GPE on function was scored on an analogous scale.

Neuropathic pain scale (NPS), a 10 item qualitative evaluation of neuropathic pain. ${ }^{33}$

Sensibility through Von Frey monofilament skin application each on 9 areas corresponding to cutaneous nerve branches and dermatomes of either both hands or both feet. ${ }^{34}$ Stimulus placement of filaments was as follows: one second for placement, one second for bending and one second for removal. (handset with resp. 0.0677, 0.4082, 2.052 and 3.632 grams calculated force. North Coast Medical, Inc., San José. USA).

Mechanic allodynia test with brush strokes and static pressure with the finger tip, ${ }^{35}$ on 9 areas corres- 
Randomised controlled trial of gabapentin in Complex Regional Pain Syndrome type 1

ponding to cutaneous nerve branches and dermatomes of either both hands or both feet.

Edema, discoloration, and changed skin temperature were scored after physical examination on a three point scale indicating no, some or overt presence of each sign, the latter two signs in comparison to the healthy or healthiest limb. Physical examination in CRPS is well comparable to instrumental evaluation of signs with volumeter, infrared thermometer and goniometer. ${ }^{36}$

Impairment and disability tests: Symptom Checklist-90-Revised (SCL-90-R), ${ }^{37}$ Brief Pain Inventory, ${ }^{38}$ adapted for CRPS to measure the influence of CRPS in general on daily life by 0-10 scale ranging from 0 ('CRPS has not interfered') to 10 ('CRPS completely interfered'), 'range of motion' as a parameter of limb function.

\section{Side effects during treatment}

A blinded independent investigator (SSvdB) tested sensibility, allodynia and range of motion tests. A physician (AvdV), who examined each patient, did all the other measurements throughout the trial. Patient, investigator and physician were unaware of the treatment received. We tested blinding by questioning physician and participants after each medication period.

\section{Statistical Analysis}

The statistical analysis of VAS-scores was determined per patient using estimating medication and period effect through linear regression analyses. Possible relationship of patient characteristics and outcome was tested by Pearson R's test. Mann-Whitney analyses were used for monofilament sensitivity on log-transformed data. Three point scales and seven point scales were dichotomized and like the SCL90-R, NPS and CRPS-Brief Inventory questionnaires intra-individual paired tested (McNemar, t-test, Bonferroni-Holm corrected for multiple tests). Student t-tests and regression analysis were used to test treatment effect, which is calculated in crossover studies as ((AT1-AT0)-(AT3-AT2))/2+((BT3-BT2))$B T 1-B T 0) / 2$, where $A$ represents data of placebo starters and $B$ data of gabapentin starters both before $(T 0, T 2)$ and after $(T 1, T 3)$ treatments. ${ }^{39}$ Blinding was tested with Chi-square analyses. Possible related factors to therapy effect were analyzed with forward stepwise logistic regression. Data analyses required complete data sets. Patients who were not completing one or two treatments were excluded for analyses. We tested two-tailed, with $\alpha=0.05$ as a level of significance (Excel 2000, SPSS 10.0 for Windows).

\section{RESULTS}

\section{Demographics}

After randomization 58 patients were enrolled, with a mean age of 44.0 (range 24-75) resulting in 29 patients in the gabapentin-placebo arm and 29 patients in the placebo-gabapentin arm; 49 patients completed the gabapentin period, 50 patients the placebo period, 46 patients completed both periods and were used for further within-patient paired analysis (Table 1). Twelve patients discontinued treatment of which 6 during the placebo treatment, 2 during washout and 4 during GBP treatment. Three of these four GBP users discontinued due to side effects (Table 1). Between randomization and start of (placebo) medication one patient withdrew after rereading the information letter about possible side effects. 
These patients were excluded from analysis, since intra-individual testing was necessary for most of the data-analyses. Patients, who could not be used for analysis, did not differ in their characteristics from the total group nor comparing between the two arms of treatment (Tables 2 and 3). When comparing the placebo-GBP arm and GBP-placebo arm on sexes, age and pain level before period 1 or 2, duration of illness, SCL-90- R score, we could not find a difference between the two arms (Tables 2 and 3). SCL$90-R$ score revealed increased values on any subscale comparing to standard norms, indicating personal distress (Table 3). We found relative higher scores on somatic and sleeping complaints. The SCL-90-R scores were identical to control chronic pain patients $(N=143)$, besides higher score on sleeping complaints (T. Forouzanfar, data not published). Trial medication was returned and counted afterwards, but revealed no lack of compliance in any patient.

\section{Blinding}

After each medication period both patient and physician were asked about their ideas concerning study medication in the past period. The treating physician guessed the used medication correctly more often after both phases than can be explained by coincidence $(p=0.000)$. Blinding for patients was sufficient in the first phase, but not anymore after the second phase $(p=0.2$ versus $p=0.000)$.

\section{Response to Treatment}

Pain

Comparing gabapentin and placebo users in terms of pain relief, there was a significant pain relief in favor of gabapentin in the first period. Therapy effect in the second period was less, finally resulting in no significant effect combining results of both periods. There was an unexpected increase of pain level above baseline in the washout period for both the gabapentin starters and placebo starters (Figure 1). Global perceived pain relief as measured by the seven-point scale showed a significant effect for gabapentin, and also more pronounced in the first period. This measurement also found a significant effect in the second period, with an effect being defined as a patient scoring 'much improvement'. Statistical analysis of global perceived effect showed significant more treatment effect $(p=0.002)$ with $43 \%$ versus 17 $\%$ reported pain relief respectively during gabapentin compared to placebo treatment. $13 \%$ of patients reported aggravation of pain during gabapentin vs. $9 \%$ during placebo treatment (Figure 2 and table 4). Stepwise forward logistic regression analysis of baseline value of pain level, age, sex, duration of illness, location of illness, mono- or bilateral CRPS, trial arm and all items of CRPS-BI, NPS and SCL-90-R was performed. Only the level of self care was related to perceived pain relief during GBP.The neuropathic pain scale, indicating different aspect of pain, improved significantly in terms of less hot and more comfortable, but not when corrected for multiple tests (Bonferroni-Holm correction). We found that during gabapentin use, patients reported equal use of co-medication comparing to baseline assessment and placebo-use with a non-significant trend towards less medication during GBP use.

\section{Sensory tests}

Each participant was tested throughout the study on response to mechanical stimuli with von Frey filaments. The CRPS patients had sensory deficits at baseline. Application of smaller filaments was not felt in multiple skin areas. We found, with Mann-Whitney analyses, that this sensory deficit was significantly reversed in gabapentin users in comparison to placebo users $(p=0.027)$. This difference was found in 
Randomised controlled trial of gabapentin in Complex Regional Pain Syndrome type 1

patients with upper and lower extremity CRPS, but was still significant in the subgroup of lower extremity CRPS $(p=0.011)$ as seen in table 5.

Mechanical allodynia to static and dynamic stimuli (soft touch and brush) was measured by a mean of 11 -point scales (range $0-10$ ) of 9 areas of the hand/feet corresponding to cutaneous nerve branches. We found no effect of gabapentin on allodynia in comparison to placebo.

\section{Other symptoms}

No difference was found on the parameters edema, discoloration, range of motion of wrist/ankle and fingers/toes between placebo and GBP. 10 patients out of 45 improved in relative skin temperature during placebo use compared to 18 patients out of 45 in gabapentin, which is two sided tested not sig. nificantly different (McNemar analysis, $p=0.096$ ).

\section{Limb dysfunction and quality of life}

The reported function improvement was, with 10 positive responders during GBP versus 7 positive responders during placebo, not significantly different $(N=46)$ between the two treatments. The SCL-90 showed no significantly better scores during gabapentin treatment. CRPS-BI showed improvement of sleep between placebo treatment and gabapentin treatment, but this effect disappeared after Bonferroni-Holm correction.

\section{Adverse effects}

Dizziness, somnolence and lethargy were significantly more often reported during gabapentin use than during placebo. Before washout $95 \%$ of patients $(n=21)$ reported side effects during gabapentin use versus $58 \%$ in placebo treatment $(n=14)$. After washout this was respectively $63 \%(n=15)$ in GBP and $32 \%(n=7)$ in placebo use. For more details on side effects see table 6 . Since a high incidence of side effects can produce a stronger placebo effect, we analyzed the possible correlation between side effects and pain relief. There was a small relation between perceived side effects and pain relief in placebo users in period 2 ( $p=0.04$, Pearson's $R$ value is 0.4 ), but, whether in period 1 or period 2 , no relationship was found during the use of gabapentin ( $P=0.2$ in period $1, P=0.4$ in period 2 ).

\section{DISCUSSION}

To evaluate gabapentin treatment as a treatment for pain in CRPS, we conducted a placebo-controlled crossover study. We conclude from our trial that overall, gabapentin did not relieve pain as compared to placebo on pain visual analogue scores, our primary outcome measure. Gabapentin relieved pain in a subgroup of patients and gave a significant global perceived pain relief. The effect was mild and there was no patient in which gabapentin completely eliminated pain.

Moreover, the frequency of side effects as dizziness, somnolence and lethargy was higher during gabapentin treatment than with placebo. These side effects probably also account for the relative lack of blinding we observed in our study. This does not mean that the study was biased; our population were chronic CRPS patients who all had undergone numerous unsuccessful treatments, and clearly wanted 
the drug to work. Any possible bias would therefore have been positive towards gabapentin.

Although we did not find a significant pain reducing effect when analyzing the complete trial, we did find a significant effect in the first half of the trial. In fact, the difference in outcome between the two trial halves is striking. There was a reverse carry-over effect resulting in increasing pain above baseline after the washout period for both gabapentin and placebo starters. The increase of pain intensity above baseline level in the second period (before the start of placebo treatment) cannot be explained pharmacologically. Gabapentin has no known biological dependency or tolerance mechanism. It can be a period effect, although this would more likely result in a regression to the middle instead of increasing pain. Perhaps this is a reversed placebo effect in which the expectation and/or the actual perception of not receiving gabapentin anymore might increase pain intensity. Kemler and de Vet found that treatment allocation in a trial can influence pain intensity in CRPS. ${ }^{40}$ The decreasing therapy effect after washout is found in other crossover pain trials. ${ }^{41}$ Expectation and attention have been shown to be powerful influences on pain pathways in the brain, 42 and perhaps a crossover design is not suited to study treatments in chronic pain patients.

We found a decreased sensory deficit in gabapentin users compared to placebo users. We did not expect this, but found in the literature several cases in which gabapentin decreased the area of hypesthesia in neuropathic pain syndromes. ${ }^{43}$ This has, to our knowledge, never been described for any other medication. Numbness or mechanical hypesthesia is a frequently found complaint for approximately $75 \%$ of CRPS patients, which can improve in time spontaneously and after placebo treatment. It is possible that the somatosensory findings and pain outside the original area of trauma can be attributed to referred pain mechanisms. Gabapentin has been reported to alleviate referred pain. ${ }^{45}$ Since many CRPS patients have mechanical hypesthesia, we hypothesize that gabapentin influences some common neural pathway for 'referred' sensations, whether mechanical sensation or pain.

Gabapentin had a mild effect on pain in patients with CRPS I. It significantly reduced the sensory deficit in the affected limb. A subpopulation of CRPS patients may benefit from gabapentin, but then for each individual patient the benefit has to be weighed against the frequently occurring side effects.

\section{Acknowledgements}

We would like to thank Inge Lamé for her support in data management, Drs. Brad Galer and Mark Jensen for the NPS and CRPS-Brief Pain Inventory. Parke-Davis kindly supplied gabapentin and matching placebo capsules.

\section{Conflicts of interest:}

Parke-Davis (now a Warner-Lambert/Pfizer division) has had no role in the writing of this manuscript. Drs. Van de Vusse and Weber have received financial support from Parke-Davis to attend one congress. 
Randomised controlled trial of gabapentin in Complex Regional Pain Syndrome type 1

Table 1 Selection of patients participating in the trial

\begin{tabular}{|c|c|c|c|}
\hline Filescreening ( $n=188$ ) & & & Not invited for screening $(n=37)$ \\
\hline Screened $(n=151)$ & & & Not randomized $(n=93)$ \\
\hline & & & $\begin{array}{l}\text { withdrew consent }(n=41) \\
\text { other signif. diagnosis (e.g. CRPS } 1,(n=20) \\
\text { age }(n=5) \\
\text { insufficient pain score }(n=14) \\
\text { other criteria }(n=13)\end{array}$ \\
\hline \multicolumn{4}{|l|}{ Randomized $(n=58)$} \\
\hline withdrawn $(n=12)$ & placebo & GBP & wash-out \\
\hline adverse effects $(n=3)$ & 0 & 3 & 0 \\
\hline treatment failure $(n=0)$ & 0 & 0 & 0 \\
\hline illness $(n=1)$ & 1 & 0 & 0 \\
\hline lost to follow up $(n=2)$ & 2 & 0 & 0 \\
\hline wanted to drive $\operatorname{car}(n=3)$ & 2 & 1 & 0 \\
\hline holiday trip $(n=1)$ & 1 & 0 & 0 \\
\hline personal reasons $(n=1)$ & 0 & 0 & 1 \\
\hline start other treatment $(n=1)$ & 0 & 0 & 1 \\
\hline
\end{tabular}


Table 2. Patient characteristics

\begin{tabular}{|c|c|c|c|c|}
\hline & Placebostarter & GBPstarter & & \\
\hline & & & Excluded from analysis & \\
\hline & & & Placebo starter & GBPstarter \\
\hline & $N=24$ & $N=22$ & $N=5$ & $N=7$ \\
\hline $\operatorname{Sex}(F / M)$ & $21 / 4$ & $18 / 4$ & $3 / 2$ & $6 / 1$ \\
\hline Age in years & $42( \pm 13)$ & $47( \pm 14)$ & $40( \pm 11)$ & $43( \pm 11)$ \\
\hline Duration in months & $43( \pm 36)$ & $44( \pm 21)$ & $83( \pm 39)$ & $45( \pm 30)$ \\
\hline VASO & $64.2( \pm 16)$ & $62.5( \pm 18)$ & $62( \pm 10)$ & $67( \pm 12)$ \\
\hline VAS2 & $67( \pm 20)$ & $64( \pm 21)$ & & \\
\hline upper extremity pain & $3 R \quad 8 L \quad 3 R L=14$ & $8 R$ 7L $4 R L=18$ & $2 R$ OL IRL & 2R 4L ORL \\
\hline lower extremity pain & $2 R \quad 7 L \quad 4 R L=13$ & $3 R \quad 3 L O R L=6$ & 2R IL ORL & IR IL IRL \\
\hline
\end{tabular}

R/L/RL represents no. of patients that report pain in resp. right, left or bilateral extremities.

A few patients had upper and lower extremity pain. VAS is pain level on visual analogue scale.VASO is day 1 , VAS2 is day 35 (post wash-out) 
Randomised controlled trial of gabapentin in Complex Regional Pain Syndrome type 1

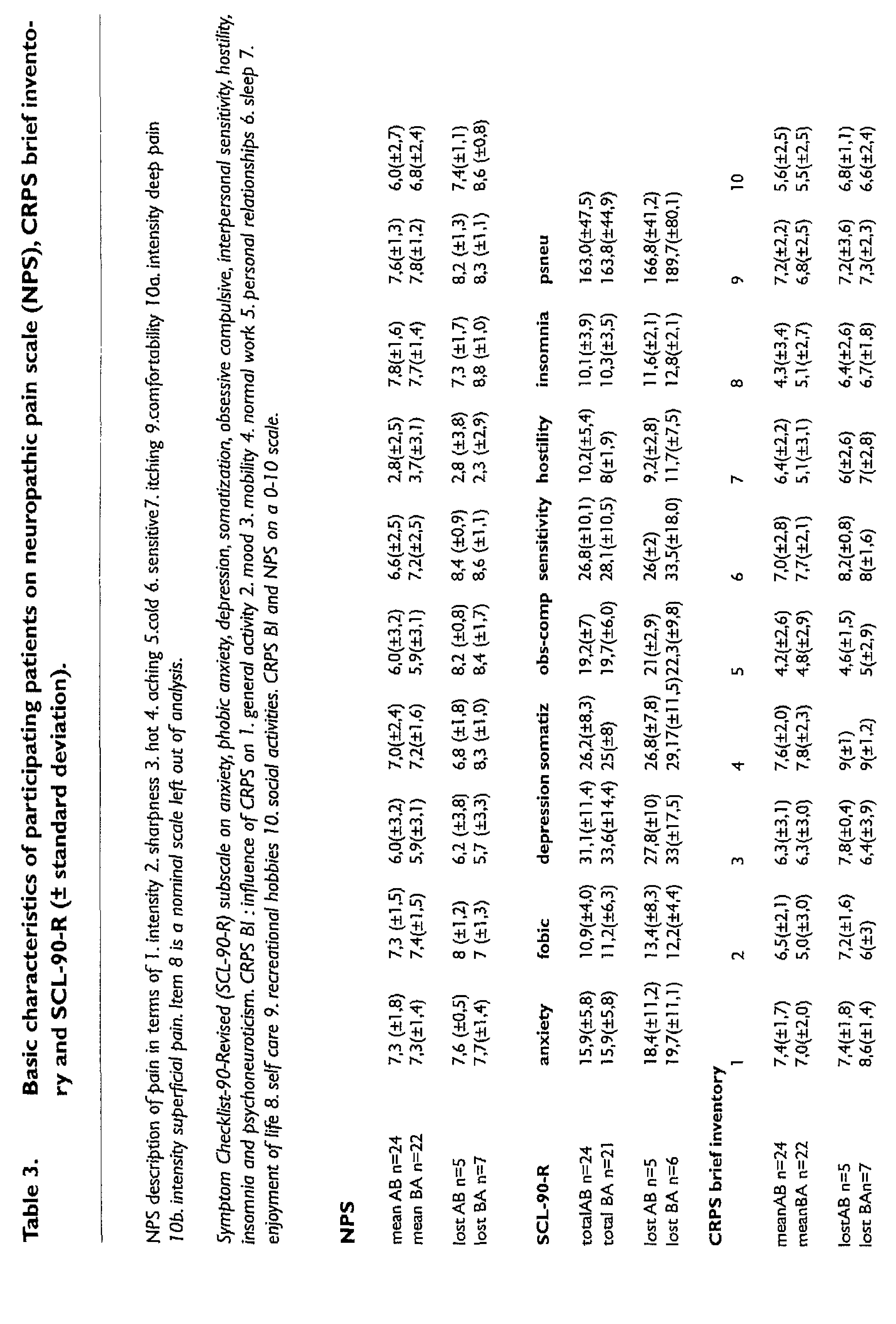


Table $4 \quad$ Patients (\%) with global perceived effect on pain

$a$ in the four arms of treatment and

b totals for the two treatments.

\begin{tabular}{llllll}
\hline treatment period & GBP- 1 & placebo-1 & wash-out & GBP- 2 & placebo-2 \\
$\begin{array}{l}\text { \% some improvement }(\mathrm{n}) \\
\% \text { much improvement }(\mathrm{n})\end{array}$ & $45 \%(10)$ & $13 \%(3)$ & 1 & $8 \%(2)$ & $13 \%(3)$ \\
$\%$ total $(\mathrm{n} / \mathrm{N})$ & $59 \%(13 / 22)^{\alpha}$ & $17 \%(4 / 24)$ & 1 & $21 \%(5)$ & $4 \%(1)$ \\
& & & & & \\
& total GBP & total placebo & & \\
& & & & \\
$\%$ some improvement & $26 \%(12 / 46)$ & $13 \%(6 / 46)$ & & $18 \%(4 / 22)$ \\
$\%$ much improvement & $17 \%(8 / 46)^{\beta}$ & $4 \%(2 / 46)$ & & \\
$\%$ total (n/N) & $43 \%(20 / 46)^{*}$ & $17 \%(8 / 46)$ & & \\
worsened & $13 \%(6 / 46)$ & $9 \%(4 / 46)$ & &
\end{tabular}

GBP-1 is gabapentin treatment before wash-out. GBP-2 is gabapentin treatment after wash-out ' $\alpha$ ' is significant, $P<0.005$, ' $\beta$ ' is $P<0.10$ McNemar two sided tested gabapentin versus placebo.

Table 5. Mann-Whitney scores of monofilament application in CRPS patients testing cutaneous sensibility thresholds

\begin{tabular}{llll}
\multicolumn{1}{l}{$\begin{array}{l}\text { Mean ranking } \\
\text { hand }\end{array}$} & feet & total \\
& & & \\
& $12.0(\mathrm{~N}=12)$ & $5.5(\mathrm{~N}=10)$ & $16.8(\mathrm{~N}=22)$ \\
placebo & $15.6(\mathrm{~N}=15)$ & $12.0^{*}(\mathrm{~N}=3)$ & $25.0^{*}(\mathrm{~N}=18)$ \\
gabapentin & &
\end{tabular}


Randomised controlled trial of gabapentin in Complex Regional Pain Syndrome type 1

Table 6. Side effects as mentioned after treatment

$\begin{array}{llll}\text { adverse effects } & \text { Gabapentin (N=54) } \mathbf{n}(\%) & \text { Placebo(N=51) n (\%) } & \text { significance } \\ \text { dizziness } & 20(37.0) & 2(3.9) & P=0.0000 \\ \text { somnolence } & 15(27.8) & 3(5.9) & \mathrm{P}=0.003 \\ \text { lethargy } & 11(20.4) & 1(2.0) & \mathrm{P}=0.003 \\ \text { nausea } & 10(18.5) & 5(9.8) & \text { n.s. } \\ \text { headache } & 8(14.8) & 3(5.9) & \text { n.s. } \\ \text { stomach problems } & 4(7.4) & 3(5.9) & \text { n.s. } \\ \text { 'drunken' } & 4(7.4) & 0(0) & \text { n.s. } \\ \text { disturbed gait } & 4(7.4) & 0(0) & \text { n.s. } \\ \text { water retention } & 1(1.9) & 3(5.9) & \text { n.s. }\end{array}$

Data on all patients who started treatment and returned for assessment after 3 weeks, with or without completing 3 weeks of treatment. n.s. is 'not significant' 
Figure 1 VAS for pain in both groups at start (T0), three weeks (T1), five weeks (T2), and eight weeks (T3) after randomization. T0-1 is the first treatment period, and $T 2-3$ the second

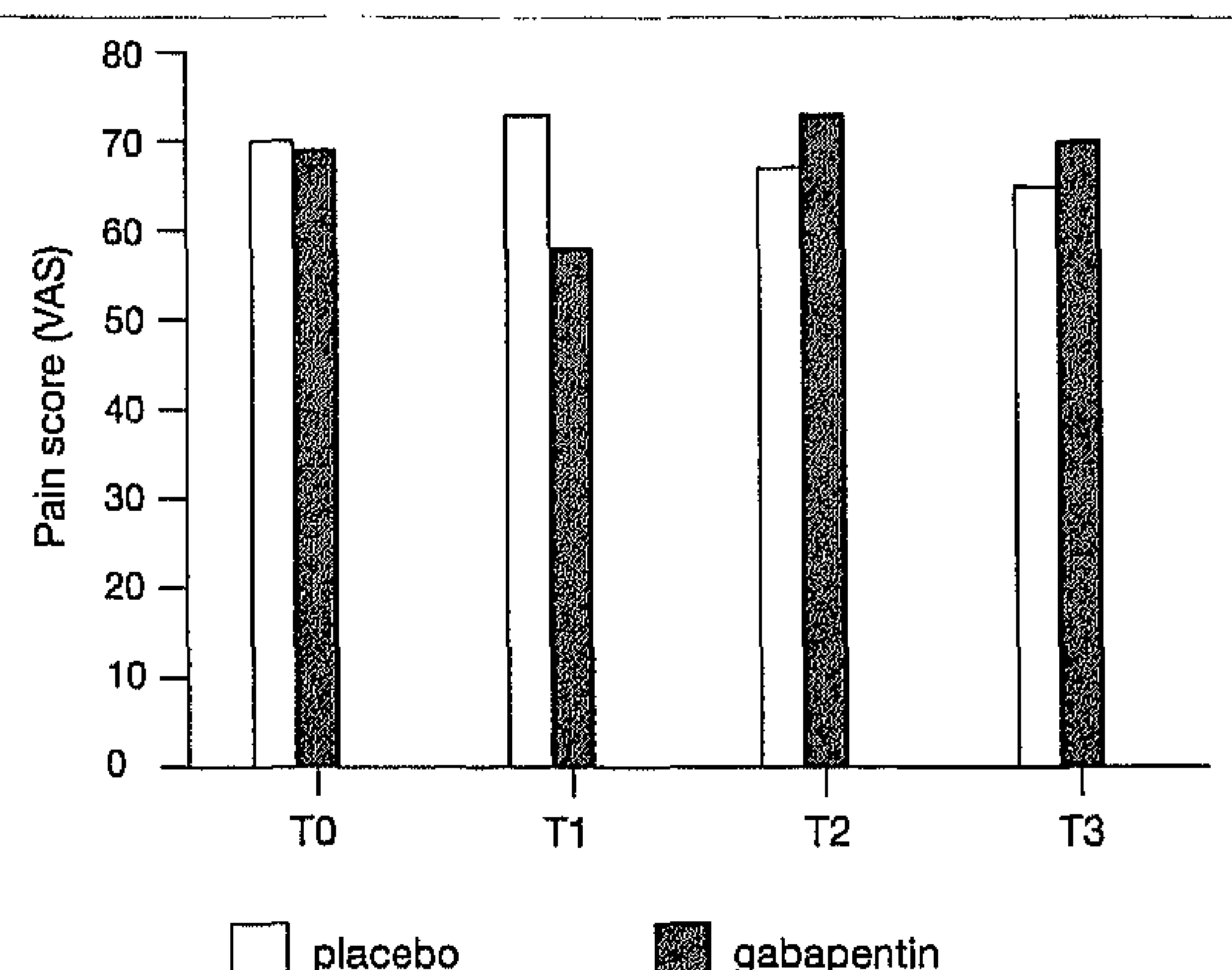

Figure 2 Global perceived pain relief (on a seven-point scale) as reported by patients. GBP-1 and -2 denote patients receiving GBP in the first and second period; placebo-1 and -2 are analogously denoted.

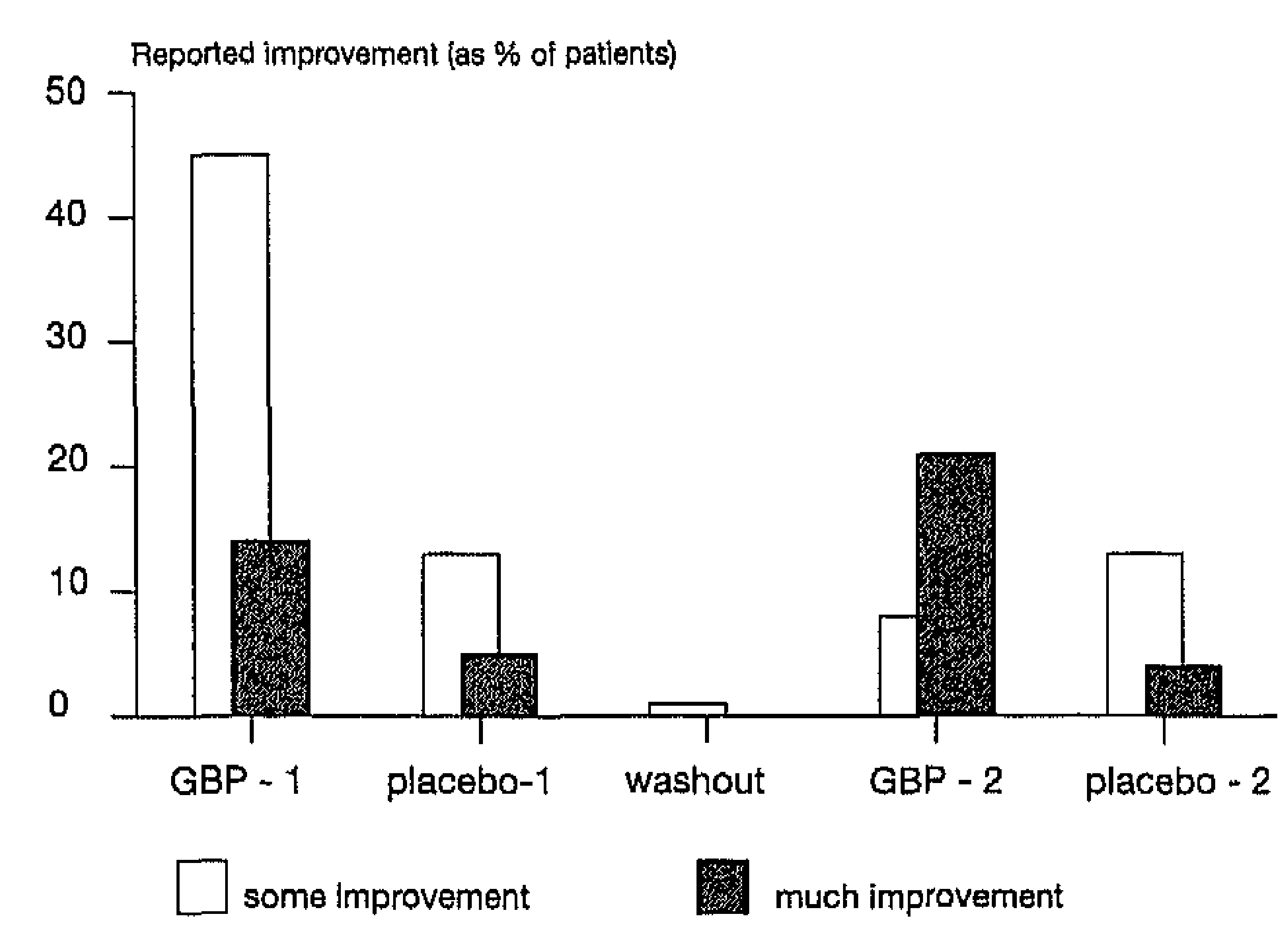




\section{References}

1. Forouzanfar T, Kemler M, Kessels AG, Köke AJ, van Kleef $M$, Weber WE. Comparison of multiple against single pain intensity measurements in complex regional pain syndrome type l: analysis of 54 patients. Clin J Pain 2002;18:234-7.

2. Marchettini P, Lacerenza M, leracitano D, Canal N. Sensitized nociceptors in reflex sympathetic dystrophies. Funct Neurol 1989;4(2):135-140.

3. Mackin G. Medical and pharmacologic management of upper extremity neuropathic pain syndromes. ] Hand Ther 1997;10(2):96-109.

4. Jänig W.The Puzzle of "Reflex Sympathetic Dystrophy": Mechanisms, Hypotheses, Open Questions. In: Jänig W, Stanton-Hicks M, eds. Reflex Sympathetic Dystrophy. A Reappraisal. Seattle: IASP Press, 1996: 1-24.

5. Sindrup $S_{1}$ Jensen $T$. Pharmacologic treatment of pain in polyneuropathy. Neurology 2000;55(7):915-920.

6. Tremont-Lukats IW, Megeff C, Backonja MM. Anticonvulsants for neuropathic pain syndromes: mechanisms of action and place in therapy. Drugs 2000;60(5):1029-1052

7. Pandey $C K$, Bose N, Garg G, Singh N, Baronia A, Agarwal $A$, et al. Gabapentin for the treatment of pain in Guillain-Barre syndrome: a double-blinded, placebo-controlled, crossover study. Anesth Analg 2002;95(6):1719-1723, table of contents.

8. Serpell MG. Gabapentin in neuropathic pain syndromes: a randomised, double-blind, placebo-controlled trial. Pain 2002;99(3):557-566.

9. Rowbotham M, Harden N, Stacey B, Bernstein P, Magnus Miller L. Gabapentin for the treatment of postherpetic neuralgia: a randomized controlled trial. JAMA 1998;280(21):1837-1842.

10. Tai $Q$, Kirshblum $S$, Chen B, Millis S, Johnston $M$, DeLisa JA. Gabapentin in the treatment of neuropathic pain after spinal cord injury: a prospective, randomized, double-blind, crossover trial. J Spinal Cord Med 2002;25(2):100-105.

11. Mellegers MA, Furlan AD, Mailis A. Gabapentin for neuropathic pain: systematic review of controlled and uncontrolled literature. Clin J Pain 2001;17(4):284-295

12. Morello CM, Leckband SG, Stoner CP, Moorhouse DF, Sahagian GA. Randomized double-blind study comparing the efficacy of gabapentin with amitriptyline on diabetic peripheral neuropathy pain. Arch Intern Med 1999;159(16):1931-1937.
13. Bone M, Critchley P, Buggy DJ. Gabapentin in postamputation phantom limb pain: a randomized, double-blind, placebo-controlled, cross-over study. Reg Anesth Pain Med 2002;27(5):481-486.

14. Garcia-Borreguero D, Larrosa $O$, de la Llave $Y$, Verger K, Masramon X, Hernandez G. Treatment of restless legs syndrome with gabapentin: a double-blind, cross-over study. Neurology 2002;59(10):1573-1579.

15. Backonja M, Beydoun A, Edwards KR, Schwartz SL, Fonseca $\bigvee$, Hes $M$, et al. Gabapentin for the symptomatic treatment of painful neuropathy in patients with diabetes mellitus: a randomized controlled trial. JAMA 1998;280(21):1831-1836.

16. Navani A, Rusy LM, Jacobson RD, Weisman S]. Treatment of tremors in complex regional pain syndrome. J Pain Symptom Manage 2003;25(4):386-390.

17. Stevens RA, Powar M, Stotz A, Barclay J, Kolbusz M. Gabapentin as an analgesic in CRPS, type I. Regional anesthesia and pain medicine 1999;24(3):32(31).

18. Mellick GA, Mellick LB, Reflex sympathetic dystrophy treated with gabapentin. Arch Phys Med Rehabil 1997;78(1):98-105.

19. Mellick GA, Mellicy LB, Mellick LB. Gabapentin in the management of reflex sympathetic dystrophy. $J$ Pain Symptom Manage 1995;10(4):265-266.

20. Mellick LB, Mellick GA. Successful treatment of reflex sympathetic dystrophy with gabapentin. Am J Emerg Med 1995;13(1):96.

21. Scheinfeld $N$. The role of gabapentin in treating diseases with cutaneous manifestations and pain. Int J Dermatol 2003;42(6):491-495.

22. Jagustyn P, Romaniak A. [GABApentin-new therapeutic possibilities]. Neurol Neurochir Pol 2002;36(5):971-980.

23. Block F. [Gabapentin for therapy of neuropathic pain]. Schmerz 2001;15(4):280-288.

24. Block F. [Gabapentin therapy for pain]. Nervenarzt 2001;72(2):69-77.

25. Tong HC, Nelson VS. Recurrent and migratory reflex sympathetic dystrophy in children. Pediatr Rehabil 2000;4(2):87-89.

26. Rovetta G, Baratto L, Monteforte P. Low dose gabapentin for shoulder-hand syndrome induced by phenobarbital: a three-month study. Drugs Exp Clin Res 1999;25(4):185-191.

27. Wheeler DS, Vaux KK, Tam DA. Use of gabapentin in the treatment of childhood reflex sympathetic dystrophy. Pediatr Neurol 2000;22(3):220-221. 
28. Forouzanfar T, van Kleef M, Weber W Radiofrequency lestons of the stellate ganglion in chronic pain syndromes: retrospective analysis of dirsical efficacy in 86 patients. Clin I Pain 2000:16(2):164-168.

29. Goris R. Treatment of Reflex Sympathetic Dystrophy with Hydroxyl Radical Scavengers. Unfalkchirurg 1985:88:330-332

30. Zyluk A. The reasons for poor response to treat. ment of posttraumatic reflex symptathetic dystro. phy. Acta-Orthop-Belg 1998:64(3):309-313

31. Kemler MA, Barendse GA, van Kleef M. de Vet $H C$. Rijks CP. Furnee CA. et al. Spinal cord stimulation in patients with chronic reflex sympathetic dystrophy. N Engl J Med 2000;343(9):618.624.

32. Merskey $\mathrm{H}$. Bogduk $N$. Classification of chronic pain. Descriptions of chronic pain syndromes and definitions of pain terms. 2 ed. Seattle: IASP Press, 1994.

33. Galer $B_{1}$ Jensen M. Development and preliminary validation of a pain measure specific to neuropathic pain: the Neuropathic Pain Scale. Neurology 1997:48(2):332-338.

34. Kemler M, Schouten $H$, Gracely R. Diagnosing sensory abnormalities with either normal values or values from contralateral skin: comparison of two approaches in complex regional pain syndrome l. Anesthesiology 2000;93(3):718-727.

35. Ochoa J. Yarnitzky D. Mechanical Imperalgesias in neuropathic pain patients: dynamic and static subtypes. Ann Neurol 1993:33:465-472

36. Oerlemans H, Oostendorp R, de Boo T, Perez R, Goris R. Signs and symptoms in complex regional pain syndrome type l/reflex sympathetic dystrophy: judgment of the physician versus objective measurement. Clin I Pain 1999;15(3):224-232.

37. Arrindell W, Attema I. SCL-90 handleiding bij een multidimensionele psychopathologie indicatie. Lisse: Swets \& Zeitlinger B.V. 1986

38. Galer B, Henderson J, Perander I, Jensen M. Course of symptoms and quality of life measurement in Complex Regional Pain Syndrome: a pilot survey.] Pain Symptom Manage 2000:20(4):286-292.

39. Schouten $H$.The mean difference between paired observations in crossover [Het gemiddelde verschil tussen gepaarde waarnemingen in een kruisproef]. In: Een praktische inleiding in methodologie en ana. lyse: Bohn, Stafleu, van Loghem, 1995: 79-83.
40. Kemier MA, de Vet HC. Does randomization intro. duce bias in unblinded trials? Epidemiology 2000:11(2):228

41. Moulin: DE, lezzi A, Amireh R. Sharpe WK. Boyd D, Merskey H. Randomised trial of oral morphine for chronic non-cancer pain Lancet. 1996:347(8995):143-147.

42. Fields H. Pain modulation: expectation, opioid analgesia and virtual pain. Prog Brain Res 2000:122:245. 253.

43. Chong M. Smith T. Hanna M. Case reports - reversal of sensory deficit associated with pain relief after treatment with gabapentin. Pain 2002:96(3):329-333.

44. Verdugo R, Ochoa J. Reversal of hypoaesthesia by nerve block, or placebo: a psychologically mediated sign in chronic pseudoneuropathic pain patients. ] Neurol Neurosurg Psychiatry 1998:65(2):196-203.

45. Filadora VA, 2nd, Sist TC, Lema MJ. Acute herpetic neuralgia and postherpetic neuralgia in the head and neck: response to gabapentin in five cases. Reg Anesth Pain Med 1999:24(2):170-174. 


\section{Summary and conclusions}

Complex Regional Pain Syndrome (CRPS) is being called Reflex Sympathetic Dystrophy. There are many synonyms for this syndrome, and even more definitions. In general, one can say that CRPS is a chronic pain syndrome with sensory, autonomic and motor dysfunction. Chapter 1 summarizes the contemporary view on its diagnosis, treatment and hypotheses on etiopathogenesis. The scientific relevance of chapter $2-7$ of this thesis is pointed out by comparing our studies with the literature.

Numerous signs and symptoms are being attributed to the CRPS syndrome. So far, there is no agreement which and in which way these need to be found in a patient to diagnose CRPS. CRPS, as a diagnosis, is not valid. Chapter 2 describes our study on this problem. We found that this is not only caused by different definitions for CRPS, but that also the assessment of signs and symptoms in patients is problematic. Important signs like edema, dystrophic changes and changed hair growth have a low interobserver agreement, even between CRPS experts (chapter 2).

There is also a discrepancy between signs and symptoms in CRPS patients. Many patients complain about swelling, discoloration and heat/cold sensations without these being confirmed by a physician during physical examination. The most objective signs like swelling or changed hair and nail growth are the least often confirmed in comparison with behaviour dependent signs like hypersensitive skin and limb dysfunction (chapter 4). This discrepancy between outcomes of patient interview and physical examination is also described in other diagnoses like irritable bowel syndrome, fibromyalgia, chronic fatigue syndrome and somatoform disorder.

Physicians are being taught implicitly to consider psychopathology as a differential diagnosis when a patient is presented with chronic, idiopathic pain with relatively few objective symptoms, changing signs in time and multiple diagnoses being addressed to in the past by other physicians. It therefore thinkable this diagnosis is sometimes being given to CRPS patients and vice versa. In our study with 6 CRPS specialists (surgeons, anaesthesiologists and a neurologist) somatoform disorder was an important differential diagnosis for chronic CRPS patients (chapter 3), especially for those physicians who also often treated other chronic pain patients. Of course, this is no proof for CRPS being a subtype somatoform disorder, but it is likely that patients with a somatoform disorder sometimes are misdiagnosed as having CRPS,

Clinical research in CRPS is not very useful as long as there are no generally accepted diagnostic criteria. For the time being, CRPS criteria in research need to be thorough, even though it may minimize the possible study population.

Chapter 5 describes a study on HLA antigen subtypes. We found an association of CRPS with MHC class 11 antigen HLA-DQ1. This antigen was prevalent in $42 \%$ of the controls in comparison to $69 \%$ in CRPS patients. This implies a possible genetic predisposition for (a subtype) of CRPS and this predisposition might involve the immune system. An association for HLA-DQ1 is also described for narcolepsy and multiple sclerosis.

Chapter 6 describes the study of antibodies to viruses and bacteria in CRPS. An association between CRPS and Parvovirus B19 infection was found. It is speculated that this virus might start an immune reactivity in predisposed patients, and thus result in a painful post infectious reaction after a trauma of a limb (read: after disposing antigen to the immune system). This would partially explain why only some people develop this syndrome after trauma. Of course, this model is incomplete as not every patient with HLA DQ1 and Parvovirus B19 infection develops CRPS and our results are not yet confirmed by 
other researchers. Now only symptomatic treatment is possible, with limited effect.

In this thesis' last chapter a patient study on gabapentin treatment is described. In a placebo controlled research we found that in chronic CRPS patients gabapentin can fulfil a small part in pain management, but can also reverse sensory deficit.

\section{Conclusions}

These study results show that CRPS is a syndrome with vague boundaries. The physical examination is not valid on most relevant aspects. An important differential diagnosis of CRPS is somatoform disorder. Nevertheless, it should not be forgotten that CRPS is an invalidating illness, which has huge impact on daily life. There are findings that points toward a genetic and/or inflammatory cause. A good therapy is not yet available. Gabapentin can be a possible aid in pain management and reversing of sensory deficits. 


\section{Samenvatting en conclusie}

Complex Regional Pain Syndrome (CRPS) is een chronisch pijnsyndroom dat gekenmerkt wordt door sensibele, autonome en motorische afwijkingen en wordt momenteel in Nederland vaak posttraumatische dystrofie genoemd. Behalve de veel gebruikte synoniemen Symparhische Reflex Dystrofie en posttraumatische dystrofie zijn er nog verschillende namen, en zelfs meer definities voor dit ziektebeeld. Hoofdstuk 1 geeft een overzicht over de huidige stand van zaken omtrent de diagnose, behandeling en hypothesen over de ethiopathologie.

Er zijn tientallen klachten en symptomen bij CRPS patiënten beschreven. Er is (nog) geen overeenstemming welke hiervan en in welke mate deze aanwezig moeten zijn om de diagnose te kunnen stellen.

Hoofdstuk 2 beschrijft onze studie naar dit probleem. We vonden dat dit niet alleen veroorzaakt wordt door verschillende gehanteerde definities, maar ook het medisch onderzoek naar klachten en symptomen bij een patient is problematisch.

Belangrijke klinische symptomen zoals oedeem, dystrofe veranderingen en veranderde haargroei, hebben een lage interobserver overeenstemming, zelfs bij CRPS experts (hoofdstuk 2).

Het blijkt dat deze gerapporteerde klachten relatief niet goed overeenkomen met de bevindingen bij lichamelijk onderzoek. Vaak klagen patienten over zwelling, verkleuring en warmte/koude sensaties zonder dat de arts deze afwijkingen kan vaststellen De meest objectiveerbare afwijkingen zoals toegenomen zwelling, haargroei of nagelgroei worden het minst vaak aangetroffen in vergelijking met relatief gemakkelijk na te bootsen afwijkingen als een overgevoelige huid of een functiebeperking van de aangedane ledemaat (hoofdstuk 4). Deze discrepantie tussen anamnese en lichamelijk onderzoek bij CRPS is in vergelijkbare mate aanwezig bij diagnoses zoals het prikkelbare darm syndroom, fibromyalgie, chronisch vermoeidheidssyndroom en somatoforme stoornis.

Omdat artsen impliciet geleerd wordt om psychopathologie in de differentiaal diagnose op te nemen als een patient zich presenteert met chronische onbegrepen pijnklachten met relatief weinig objectieve afwijkingen, is het denkbaar dat bij sommige CRPS patiënten deze diagnose gesteld wordt. In ons onderzoek met 6 CRPS specialisten (chirurgen, anesthesiologen en een neuroloog), bleek bij chronische CRPS patienten een somatoforme stoornis een belangrijke differentiaal diagnostische overweging (hoofdstuk 3), met name voor artsen die andere chronische pijn patiënten beroepsmatig zagen. Dit is geen bewijs om CRPS als een variant-somatoforme stoornis te beschouwen. Wel is het waarschijnlijk dat er binnen de populatie CRPS patiënten zich patiënten met een somatoforme stoornis bevinden. In hoofdstuk 5 wordt een onderzoek beschreven naar HLA antigeen subtypes. Wij vonden een associatie van CRPS met MHC klasse II antigeen HLA-DQ1. Dit antigeen was aanwezig in $42 \%$ van de controlegroep in vergelijking met $69 \%$ in de groep CRPS patiënten. Dit impliceert dat er mogelijk een genetische aanleg voor (een subtype van) CPRS bestaat en dat deze aanleg mogelijk betrokken is bij het immunologische afweersysteem van het lichaam. Een HLA-DQ1 associatie is binnen de neurologie eerder beschreven voor narcolepsie en multiple sclerose.

In hoofdstuk 6 wordt een verslag gegeven van onderzoek bij CRPS patienten naar antistoffen tegen virussen en bacteriën die neurologische verschijnselen kunnen geven. Er wordt een gevonden associatie beschreven tussen CRPS en Parvovirus B19 besmetting. De verklaring wordt geopperd dat een Parvovirus B 19 besmetting bij gepredisponeerde mensen een immuunreactie zou opwekken, waardoor een kwetsuur van een ledemaat een pijnlijke postinfectieuze auto-immuun reactie zou opwekken. De resultaten zijn niet alomvattend, want niet ieder persoon met HLA-DQ1 en Parvovirus B19 ontwikkelt 
CRPS en de resultaten zijn nog niet bevestigd door andere onderzoekers.

Momenteel is er geen adequate therapie voor CRPS omhanden. Er zijn alleen symptomatische therapiën mogelijk, alle met een beperkt effect.

In het laatste hoofdstuk wordt een placebo gecontroleerd gerandomiseerd onderzoek beschreven naar de behandeling van CRPS pijn met gabapentine.We vonden dat bij chronische CRPS patiënten gabapentine een aanvullende rol kan spelen in de pijnbestrijding, maar ook de verminderde tastzin bij CRPS patiënten significant kan verbeteren.

\section{Conclusie}

Deze studieresultaten laten zien dat CRPS een syndroom is met onscherpe grenzen. Het lichamelijk onderzoek is op de meeste relevante symptomen niet valide. Een belangrijke differentiaal diagnose is de somatoforme stoornis. Desondanks mag niet vergeten worden dat CRPS een invaliderende aandoening is met een grote impact op het dagelijks leven van de patient. Er zijn aanwijzingen voor een genetische en/of inflammatoire oorzaak van de klachten. Een goede therapie is vooralsnog niet voorhanden.

Gabapentine zou een mogelijke bijdrage aan de pijnvermindering en herstel van verminderde tastzin kunnen geven. 


\section{Curriculum Vitae}

Anton Cornelis van de Vusse werd op 20 augustus 1969 geboren te Poortugaal. Hij behaalde zijn VWO diploma in 1987 op het Christelijk Lyceum Veenendaal. Hierna ging hij studeren aan de Universiteit Maastricht, toen nog Rijksuniversiteit Limburg geheten. Hij behaalde in 1988 zijn propaedeuse Gezondheidswetenschappen en in 1989 zijn eerste jaar van Verplegingswetenschappen (FdGW) welke hij afbrak om in 1989 aan zijn doctoraalstudie Geestelijke Gezondheidkunde (FdGW) te beginnen. Hij behaalde zijn doctoraal examen in 1993 na een klinische stage neuropsychologie aan de CVA afdeling van Revalidatie Centrum Hoensbroeck en een wetenschappelijke studie naar cognitieve revalidatie bij patiënten met traumatisch hersenletsel. Ondertussen was hij in 1990 gestart met de studie Geneeskunde, wat resulteerde in 1994 in een Doctoraal Geneeskunde (Cum Laude). In 1995 volgde hij een stage aan Harvard University/ Beth Israel Hospital te Boston, USA op de afdeling Neurologie en in 1997 behaalde hij zijn artsexamen (Met Genoegen). Hierna heeft hij van 1997 tot 2000 als klinisch arts-pijnbestrijder/onderzoeker gewerkt aan het Academisch Pijncentrum Maastricht, afdeling Anesthesiologie, Academisch Ziekenhuis Maastricht (hoofd: dr.W. E. J.Weber). Na een jaar 'perifere' Neurologie in het Slotervaart Ziekenhuis (opleider; dr. J. van der Sande) te Amsterdam was hij van oktober 2001 tot mei 2003 als arts-assistent aangesteld bij de afdeling Neurologie van het Leids Universitair Medisch Centrum (opleider Prof. dr. R.A. C. Roos). Momenteel volgt hij de Huisartsopleiding aan de Vrije Universiteit te Amsterdam, welke hij medio 2006 hoopt te voltooien. 
Complex Regional Pain Syndrome, pathogenesis, diagnosis and treatment 


\section{Dankbetuiging}

Je begint met niets en eindigt met een boekje.

Zonder de steun van de volgende mensen was het niet gelukt; mijn handen, voeten en hoofd.

\section{Aalt Bast}

Gerard Barendse

Ella vd Berg-Loonen

Ruud van Buren

De medewerkers van het Centrale Proefdier Voorzieningen

Emilliënne Christophe

Marc Daemen

Gert-Jan Eggink

Chris Evelo

Tim Forouzanfar

Brad Galer

Marianne Groeneweg

Valère Goossens

Harm Hospers

Mark Jensen

Marius Kemler

Prof. Dr. Maarten van Kleef

Fons Kessels

Inge Lamé

Tjeerd Mondria

Nora Oosting en Leo Zander

Herman Schaalma

Prof. Dr. M. E. Sluiter

Suzanne Stomp-van den Berg

Hans van Suylekom

Prof. Harry Steinbusch en zijn medewerkers

Resy Vanderbroeck

Prof. Ir. Riekie de Vet

Prof. dr. J.S. H.Vles

Sandra Vroemen

Wim Weber

De firma Parke-Davis dien ik te bedanken dat ze bereid was om zowel gabapentine als placebo medicatie beschikbaar te stellen. Hierdoor kon ik de medicatie verstrekken aan de patienten en zelfs na afloop de patienten nog maanden vooruit helpen.

De tientallen 'dystrofie' patienten die meegedaan hebben aan alle screeningsprocedures en testbatterijen wil ik hierbij van harte bedanken. Ik hoop dat het onderzoek bijdraagt aan uw erkenning en beterschap. 